\title{
Reducción de estrés en pacientes con \\ Enfermedad Renal Crónica
}

Valeria Olvera Navas, Marisol Sánchez Beltrán, Diana Lucero Muñoz Arellano, Ana Leticia Becerra Gálvez y Leonardo Reynoso Erazo

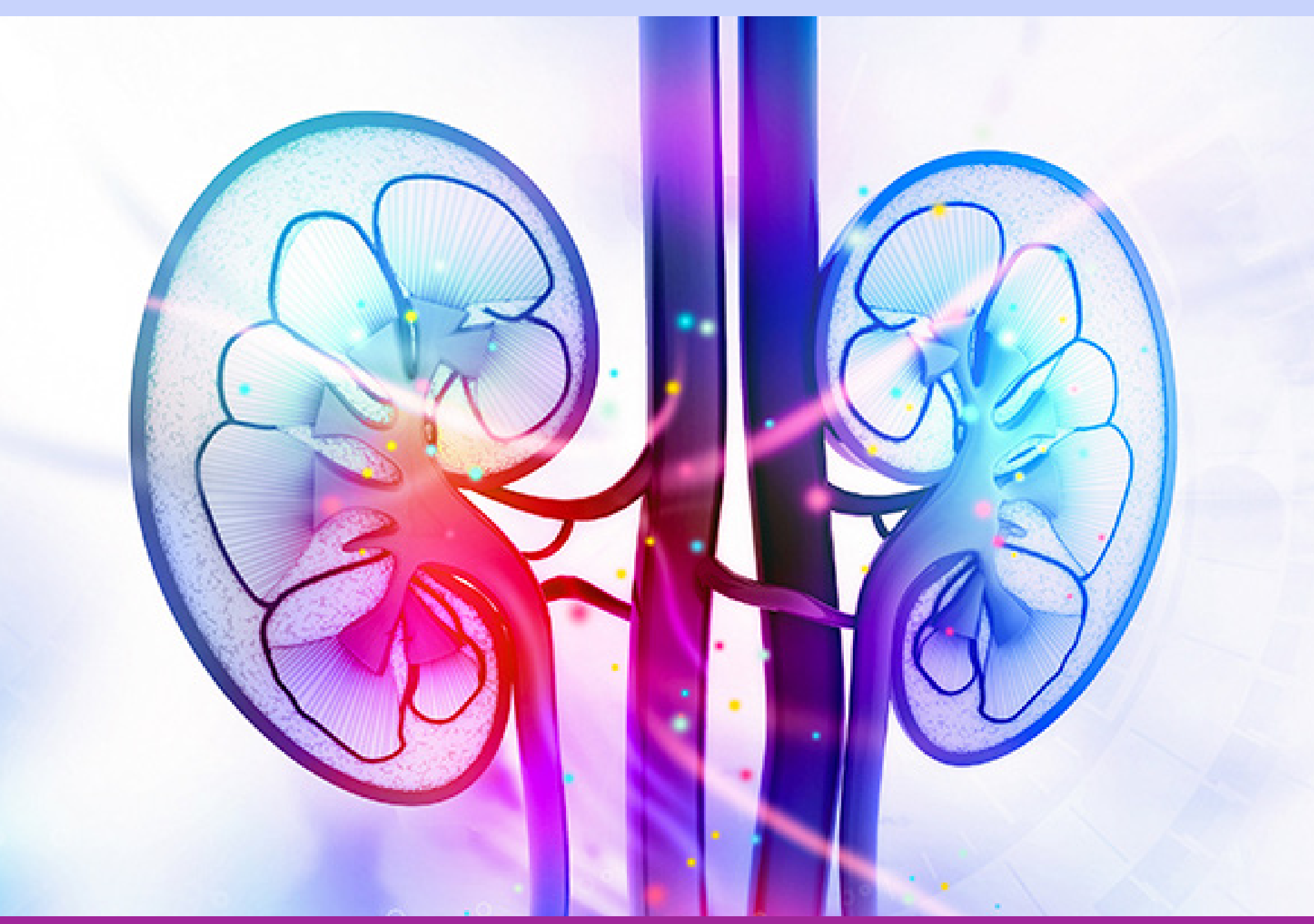

\section{Qartuppi}




\section{(c) (1) (3)(2)}

Esta obra se edita bajo una Licencia Creative Commons Atribución-NoComercial-Compartirlgual 4.0 Internacional. 


\section{Reducción de estrés en pacientes con Enfermedad Renal Crónica}

Valeria Olvera Navas, Marisol Sánchez Beltrán, Diana Lucero Muñoz Arellano, Ana Leticia Becerra Gálvez y Leonardo Reynoso Erazo 
Reducción de estrés en pacientes con Enfermedad Renal Crónica

1era. edición, abril 2021

ISBN 978-607-8694-08-2

DOI 10.29410/QTP.21.06

D.R. @ 2021. Qartuppi, S. de R.L. de C.V.

Villa Turca 17, Villas del Mediterráneo

Hermosillo, Son. 83220 México

http://www.qartuppi.com

Edición y Diseño: Qartuppi, S. de R.L. de C.V.

Imagen de portada: hywards para Adobe Stock 


\section{Tabla de Contenido}

8 Índice de tablas

9 Índice de figuras

10 Índice de anexos

11 Introducción

\section{PRIMERA PARTE}

1. La enfermedad renal crónica

1.1. Clasificación

1.2. Factores de riesgo

1.3. Sintomatología

2. Epidemiología

2.1. En el mundo

2.2. En México

3. La enfermedad renal crónica como un problema de comportamiento

3.1. Historia natural de la enfermedad

3.2. Complicaciones de la ERC

3.3. Tratamiento

3.3.2. No farmacológico

3.3.2.1. Modificaciones conductuales

3.3.2.1.1. Modificaciones en la alimentación

3.3.2.1.2. Modificaciones en la actividad física

3.3.3. Tratamiento sustitutivo

3.3.3.1. Diálisis peritoneal

3.3.3.2. Hemodiálisis

3.3.3.3. Trasplante renal

3.4. Estrés y Enfermedad Renal Crónica 
4. Modelo de estrés
4.1. El modelo de estrés y afrontamiento

5. Medicina Conductual

5.1. Qué es Medicina Conductual

5.2. Actividades del especialista en MC con pacientes que viven con enfermedad crónica

5.3. Evidencia de la efectividad de la TCC en el tratamiento del estrés en enfermos crónicos

6. Propuesta de guía

6.1. Justificación de modalidad en línea

6.2. Objetivos

6.2.1. Generales

6.2.2. Específicos

\section{SEGUNDA PARTE}

7. Un modelo de intervención supervisada en estrés (para terapeuta)

7.1. Generalidades

7.2. El modelo de supervisión

$$
\text { 7.2.1. Uso de las TIC's para la supervisión }
$$

7.3. Acciones del terapeuta

7.4. Evaluación conductual

7.4.1. Instrumentos

7.4.2. Evaluación inicial

7.4.3. Entrevista conductual

7.4.4. Análisis funcional del comportamiento (AFC)

7.4.5. Evaluación complementaria

7.5. Canalización

7.6. Planeación de la intervención

7.6.1. Identificación de áreas problema

7.6.2. Selección de estrategias

7.6.3. Selección de las TIC's

7.6.3.1. Normatividad

7.7. Elección y descripción de las técnicas

7.7.1. Psicoeducación

7.7.2. Estrategias de relajación

7.7.2.1. Relajación pasiva 
63

64

66

66

68

72

72

74

74

74

75

75

75

76

76

77

79

80

80

100

114

134
7.7.2.2. Respiración diafragmática

7.7.3. Autoinstrucciones

7.7.4. Terapia en solución de problemas

7.7.5. Uso de técnicas complementarias

8.1. Sistema de registros

8.1.1. Escalas visuales análogas

8.1.2. Registro de frecuencia cardiaca

8.1.3. Registro de eventos estresantes

8.1.4. Registro de autoinstrucciones

8.1.5. Identificación del problema

8.1.6. Generación de alternativas

8.1.7. Toma de decisiones

8.2. Mantenimiento

8.3. Seguimiento

8.3.1. Intervención en crisis

8.3.2. Monitoreo

8.4. Evaluación de satisfacción

8.5. Cartas descriptivas

00 Referencias

4 Anexos

34 Reseñas curriculares 


\section{Índice de tablas}

14 Tabla 1. Etapas de la ERC

15 Tabla 2. Factores de riesgo de la ERC

23 Tabla 3. Contraindicaciones de los tres procedimientos sobre el tratamiento sustitutivo de la ERC

27 Tabla 4. Actividades del especialista en Medicina Conductual

28 Tabla 5. Evidencia de la efectividad de la TCC en el tratamiento del estrés en enfermos crónicos

42 Tabla 6. Acciones del terapeuta en la intervención en línea

43 Tabla 7. Listas de verificación de la evaluación inicial

$44 \quad$ Tabla 8. Escalas de la evaluación inicial

$48 \quad$ Tabla 9. Elementos de la entrevista conductual

49 Tabla 10. Listas de verificación para la evaluación complementaria

49 Tabla 11. Escalas para la evaluación complementaria

61 Tabla 12. Objetivos de la psicoeducación

66 Tabla 13. Pasos de la técnica de autoinstrucciones

67 Tabla 14. Fases de la terapia en solución de problemas (TSP)

67 Tabla 15. Técnicas cognitivo conductuales complementarias

para el manejo del estrés

Tabla 16. Generalidades de las etapas de tratamiento

Tabla 17. Distribución de técnicas de acuerdo con las sesiones

Tabla 18. Características de la intervención en crisis

Tabla 19. Elementos sobre el modelo BASIC-ID

80 Tabla 20. Carta descriptiva de la sesión 1

81 Tabla 21. Carta descriptiva de la sesión 2

83 Tabla 22. Carta descriptiva de la sesión 3

86 Tabla 23. Carta descriptiva de la sesión 4

88 Tabla 24. Carta descriptiva de la sesión 5

90 Tabla 25. Carta descriptiva de la sesión 6

91 Tabla 26. Carta descriptiva de la sesión 7

93 Tabla 27. Carta descriptiva de la sesión 8

94 Tabla 28. Carta descriptiva de la sesión 9

96 Tabla 29. Carta descriptiva de la sesión 10

97 Tabla 30. Carta descriptiva de seguimiento 


\section{Índice de figuras}

17 Figura 1. Evolución de la enfermedad

18 Figura 2. Historia natural de la Enfermedad Renal Crónica

22 Figura 3. Protocolo para trasplante renal

25 Figura 4. Esquema de transacción de estrés

26 Figura 5. Ejemplo de caso: transacción del estrés en ERC

40 Figura 6. Flujograma de supervisión en el Programa de residencia en MC

$47 \quad$ Figura 7. Flujograma de evaluación

51 Figura 8. Flujograma de canalización

$54 \quad$ Figura 9. Flujograma de solicitud de intervención psicológica

55 Figura 10. Flujograma sobre inasistencia del paciente a la sesión

56 Figura 11. Flujograma de canalización con otros especialistas

57 Figura 12. Flujograma sobre procedimiento en caso de desconexión de internet

58 Figura 13. Flujograma sobre la toma de decisión para dar de baja al paciente

59 Figura 14. Flujograma sobre la toma de decisión para dar de alta al paciente

64 Figura 15. Instrucciones para la respiración diafragmática

69 Figura 16. Flujograma sobre la implementación de técnicas complementarias

73 Figura 17. Flujograma sobre la implementación de registros 


\section{Índice de anexos}

115 Anexo 1. Consentimiento informado

117 Anexo 2. Breve Checklist de Afrontamiento

118 Anexo 3. Checklist Síntomas de Estrés

120 Anexo 4. Escala de Ansiedad y Depresión Hospitalaria (HADS)

122 Anexo 5. Escala de Estrés Percibido (PSS-14)

123 Anexo 6. Checklist Ansiedad A

124 Anexo 7. Checklist Ansiedad B

125 Anexo 8. Inventario de Estrategias de Afrontamiento (CSI)

128 Anexo 9. Enfermedad Renal y Calidad de Vida (KDQOL-36)

131 Anexo 10. Versión Actualizada de la Escala de Adherencia Terapéutica

133 Anexo 11. Escala Reporte de Adherencia a la Medicación (MARS) 


\section{Introducción}

Debido a la pandemia por el virus SARS-COV-2 han surgido distintos cambios a nivel social, económico, laboral y académico; respuestas asociadas y derivadas del estrés figuran como principales problemáticas en el contexto de la pandemia, motivo por el cual esta guía pretende describir las pautas y sugerencias para el abordaje del estrés en pacientes con enfermedad renal crónica (ERC). El último punto será el eje rector del desarrollo de esta guía.

La residencia en Medicina Conductual (MC) de la Universidad Nacional Autónoma de México (UNAM) con sede en la Facultad de Estudios Superiores Iztacala (FES-I) se ha visto en la necesidad de adecuar su plan de trabajo referente a las prácticas clínicas que realizan los alumnos en centros hospitalarios. Grosso modo el quehacer del especialista en MC se caracteriza por identificar la dimensión psicológica en la relación salud-enfermedad, en otras palabras, identificar aquellos comportamientos de riesgo o saludables que dificulten ofaciliten el desarrollo de una enfermedad y, a su vez, esclarecer la relación de los diversos elementos psicológicos que participan en ella. En ese sentido, los especialistas en MC pueden trabajar a nivel preventivo con aquellas personas que aún no desarrollan alguna enfermedad y con aquellos que fueron diagnosticados con algún padecimiento. Es en esta última población en la que se centrará la atención psicológica.

Cabe resaltar que, ante la presencia de una enfermedad, en particular, crónicodegenerativa existen diversas situaciones que pueden someter al paciente en un estado de estrés, por ejemplo, diagnóstico, tratamiento, procedimientos quirúrgicos, etc. De igual manera, estos problemas psicológicos se incrementan o exacerban ante situaciones de restricción social, incertidumbre y con la disminución del contacto físico (Brooks et al., 2020). Por lo tanto, el psicólogo es aquel profesional encargado de entrenar al paciente en el desarrollo de habilidades o estrategias que le permitan afrontar aquellas situaciones evaluadas como estresantes.

La Terapia Cognitivo Conductual (TCC) ha resultado ser efectiva para atender el estrés en pacientes con enfermedades crónico-degenerativas. Una de las poblaciones que suelen responder a situaciones estresantes son los pacientes con Enfermedad Renal Crónica (ERC) debido a que por su condición de salud deben realizar distintos cambios en su vida cotidiana, por ejemplo, actividad física, alimentación, conductas de autocuidado e higiene, cambios 
a nivel personal y a nivel interpersonal. Motivo por el cual, la elaboración de esta guía está dirigida a terapeutas con el objetivo de ofrecer una intervención para la reducción de estrés en pacientes con ERC haciendo uso de las Tecnologías de la Información y Comunicación (TIC's).

Esta guía se divide en dos apartados. El primero proporciona una contextualización de la ERC a nivel mundial y nacional, características principales de la enfermedad: clasificación, sintomatología, factores de riesgo, complicaciones y diferentes tipos de tratamiento médico. Por otra parte, se describe la conceptualización del modelo de estrés de Lazarus y Folkman (1984) y su relación con la enfermedad. De igual manera, se muestra evidencia empírica sobre la efectividad de la TCC para el tratamiento de estrés con pacientes con enfermedades crónico-degenerativas y en particular con la ERC. Por último, se retoma el quehacer del especialista en MC ante dicha problemática.

El segundo apartado describe un protocolo de intervención basado en procedimientos de la terapia cognitivo-conductual. En primer lugar, se hace mención sobre la modalidad de terapia en línea como una opción para brindar atención psicológica, respetando las medidas sanitarias de distanciamiento social, preservando la salud de los pacientes y terapeutas. Después se describen las acciones del terapeuta en el proceso de intervención, así como cada una de las etapas del tratamiento: evaluación inicial (entrevista conductual, análisis funcional del comportamiento), implementación de técnicas, mantenimiento, seguimiento y monitoreo; el desarrollo de cartas descriptivas de cada sesión favorecerá la comprensión de este apartado. También se describen algunos instrumentos, escalas y checklists que podrían emplearse en caso de requerir evaluación complementaria. Aunado a lo anterior, se explica cómo evaluar e intervenir ante una situación de crisis; se diseñaron distintos flujogramas para facilitar la toma de decisiones por parte del terapeuta durante la intervención y, por último, en el apartado de anexos se incluyen algunos formatos que se utilizarán en el proceso terapéutico. 
Primera Parte 


\section{La Enfermedad Renal Crónica}

La ERC es la resultante de diversas enfermedades crónico-degenerativas, entre las que destacan la Diabetes Mellitus Tipo 2 (DM2) y la Hipertensión Arterial (HA), las cuales han ido en aumento a lo largo de los años a causa del desarrollo socioeconómico del país y de los nuevos estilos de vida que se han adquirido; en consecuencia, el aumento en el número de casos de ERC será evidente (Alcázar \& Otero, 2008; Tamayo y Orozco \& Lastiri-Quirós, 2016). Según la National Kidney Foundation (NKF, 2002), esta enfermedad se define como una disminución de la función renal, expresada por un filtrado glomerular (FG) y se diagnostica mediante marcadores, siendo la excreción urinaria de albúmina o las proteínas elevadas los principales indicadores.

\subsection{Clasificación}

La International Society of Nephrology (2013) realizó una clasificación conocida como KDIGO sobre las distintas etapas de la ERC, las cuales se observan en la tabla 1.

\section{Tabla 1}

Etapas de la ERC

\begin{tabular}{clc} 
Etapa & \multicolumn{1}{c}{ Descripción } & $\begin{array}{c}\text { Tasa de filtración glomerular (TFG) } \\
\mathrm{ml} / \mathrm{min} / 1.73 \mathrm{~m}^{2}\end{array}$ \\
\hline 1 & Daño renal (e. g., proteínas en la orina) con TFG normal & 90 o más \\
\hline 2 & Daño renal con leve disminución de la TFG & 60 a 89 \\
\hline 3 & Disminución moderada de la TFG & 30 a 59 \\
\hline 4 & Reducción severa de la TFG & 15 a 29 \\
\hline 5 & Insuficiencia renal & Menos de 15 \\
\hline
\end{tabular}

Nota: Elaboración propia a partir de "KDIGO 2012. Clinical Practice Guideline for the Evaluation and Management of Chronic Kidney Disease" por International Society of Neprhrology, 2013, Kidney International Supplements, 3(1), p. 5. 


\subsection{Factores de riesgo}

El Instituto Mexicano del Seguro Social (IMSS, 2019) menciona una serie de factores en torno a la ERC, por ejemplo, factores asociados al inicio del daño renal, factores que empeoran y aceleran el deterioro del riñón y factores relacionados con el estadio final, los cuales se muestran en la tabla 2.

\section{Tabla 2}

\section{Factores de riesgo de la ERC}

\begin{tabular}{|c|c|c|c|}
\hline $\begin{array}{l}\text { Factores que incrementan } \\
\text { la probabilidad } \\
\text { de daño renal }\end{array}$ & $\begin{array}{c}\text { Factores que inician } \\
\text { directamente el daño renal }\end{array}$ & $\begin{array}{l}\text { Factores de progresión } \\
\text { de la ERC }\end{array}$ & Factores de estadio final \\
\hline $\begin{array}{l}\text { - Edad avanzada } \\
\text { - Antecedentes } \\
\text { heredofamiliares de ERC } \\
\text { - Masa renal disminuida } \\
\text { - Bajo peso al nacer } \\
\text { - Hipertensión arterial } \\
\text { - Diabetes } \\
\text { - Obesidad }\end{array}$ & $\begin{array}{l}\text { - Enfermedades autoinmu- } \\
\text { nes } \\
\text { - Infecciones sistémicas } \\
\text { - Infecciones urinarias } \\
\text { - Litiasis renal } \\
\text { - Obstrucción de las vías } \\
\text { urinarias bajas } \\
\text { - Fármacos nefrotóxicos, } \\
\text { principalmente AINE } \\
\text { - Hipertensión arterial } \\
\text { - Diabetes }\end{array}$ & $\begin{array}{l}\text { - Proteinuria persistente } \\
\text { - Hipertensión arterial } \\
\text { mal controlada } \\
\text { - Diabetes mal controlada } \\
\text { - Tabaquismo } \\
\text { - Dislipidemia } \\
\text { - Anemia } \\
\text { - Enfermedad } \\
\text { cardiovascular asociada } \\
\text { - Obesidad }\end{array}$ & $\begin{array}{l}\text { - Dosis baja de diálisis } \\
\text { - Acceso vascular temporal } \\
\text { para diálisis } \\
\text { - Anemia } \\
\text { - Hipoalbuminemia } \\
\text { - Derivación tardía } \\
\text { a nefrología }\end{array}$ \\
\hline
\end{tabular}

Nota: Adaptado de Guía práctica Clínica de Prevención, Diagnóstico y Tratamiento de la Enfermedad Renal Crónica por Instituto Mexicano del Seguro Social, 2019, p. 38.

\subsection{Sintomatología}

De acuerdo con la Organización Panamericana de la Salud y la Organización Mundial de la Salud (OPS/OMS, 2018), la ERC temprana a menudo no presenta signos ni síntomas; incluso una persona puede perder hasta el $90 \%$ de su función renal sin haber mostrado algún signo; sin embargo, las pruebas de orina y sangre permiten detectar la presencia de proteínas y los niveles de creatinina elevados, indicadores que favorecen la temprana detección de esta enfermedad.

Por otro lado, en la ERC avanzada, mejor conocida como Enfermedad Renal Crónica en fase Terminal (ERCT), se presentan algunos signos y síntomas; por ejemplo, dolor abdominal, fatiga, diarrea, fiebre, ictericia, mareos, edema, dificultad para concentrarse, disminución de apetito y orina espumosa.

\section{Epidemiología}

\subsection{En el mundo}

En el 2017 se estimó que 697.5 millones de casos de ERC se registraron a nivel global, generando un impacto de salud mundial, dado que figura dentro de las primeras causas de 
muerte, ocasionando diferentes consecuencias negativas para la sociedad, en su mayoría a nivel socioeconómico derivado de los tratamientos (Bikbov et al., 2020). Si bien las cifras de la incidencia de la ERC no son exactas, en los últimos años se ha observado un aumento en el número de casos que son detectados, así como en el número de fallecimientos derivados de la enfermedad. Con relación a la mortalidad a nivel mundial, en el 2015 se estimó que 1.2 millones de personas fallecieron a causa de la enfermedad, y de acuerdo con los datos ha ido en aumento el porcentaje de fallecimientos desde el 2005. Existen muchas limitaciones acerca de los datos epidemiológicos sobre la enfermedad, no obstante, es notable tanto el aumento de nuevos casos como de las cifras de morbimortalidad (Luyckx, Tonelli, \& Stanifer, 2018).

Por su parte, Foreman et al. (2018) prevén que para el 2040 a nivel mundial el número de casos de la ERC aumenten, colocándola como la quinta causa de muerte. Se ha estimado un aumento acelerado de incidencia, prevalencia y mortalidad. De acuerdo con estas estimaciones se insiste en cubrir la necesidad de formular políticas públicas y grupos de salud pública con el compromiso de frenar el crecimiento de la incidencia (Jager et al., 2019).

\subsection{En México}

El Instituto Nacional de Salud Pública (INSP, 2020) reportó en el 2017 una prevalencia de la ERC del $12.2 \%$ y 51.4 muertes por cada 100 mil habitantes en México. Además, indica que la ERC ha tenido un gran impacto en las finanzas públicas y en la economía de las familias; "en 2014, el gasto en salud anual promedio por persona para esta patología se estimó en 8,966 dólares estadounidenses (USD) en la Secretaría de Salud, y de 9,091 USD en el Instituto Mexicano del Seguro Social" (párr. 3). De igual manera, el Instituto Nacional de Estadística y Geografía (INEGI, 2016) registró 13167 decesos por esta enfermedad, siendo la décima causa de muerte.

En México, como en muchos países, no existe un registro exacto de los pacientes con ERC que permita conocer la forma precisa de la epidemiología nacional, y así cubrir en medida de lo posible las necesidades de salud de esta población (Tamayo y Orozco \& Lastiri-Quirós, 2016).

\section{La enfermedad renal crónica como un problema de comportamiento}

\subsection{Historia natural de la enfermedad}

El estudio de las enfermedades infectocontagiosas permitió a Leavell y Clark (1958) desarrollar un modelo de estudio denominado Historia Natural de la Enfermedad (HNE), donde puede ubicarse el progreso y las intervenciones necesarias o convenientes para modificar la historia natural del padecimiento. Su propuesta se divide en dos periodos: prepatogénico y patogénico, como se puede observar en la figura 1. Estas etapas están divididas horizontalmente por la aparición de síntomas. En el primero, se incluye la tríada ecológica concebida como la relación entre el individuo, la enfermedad y el medio ambiente, mientras que, en el 
segundo se simboliza la línea de daño. De acuerdo con Herrera (2016), el daño puede presentarse en tres modalidades de evolución: (a) daño creciente, (b) curación, y (c) daño persistente o crónico.

Las intervenciones están diseñadas con base en el período en el que el paciente se encuentre. Por ello, la etapa prepatogénica se centra en la prevención primaria, promoviendo la salud y protegiendo a grupos específicos. En el caso del período patogénico, el trabajo radica en la prevención secundaria, que consiste en propiciar un diagnóstico oportuno para ofrecer un tratamiento eficaz y limitar el daño. Finalmente, la prevención terciaria está enfocada en la rehabilitación del paciente (Herrera, 2016).

Figura 1

Evolución de la enfermedad

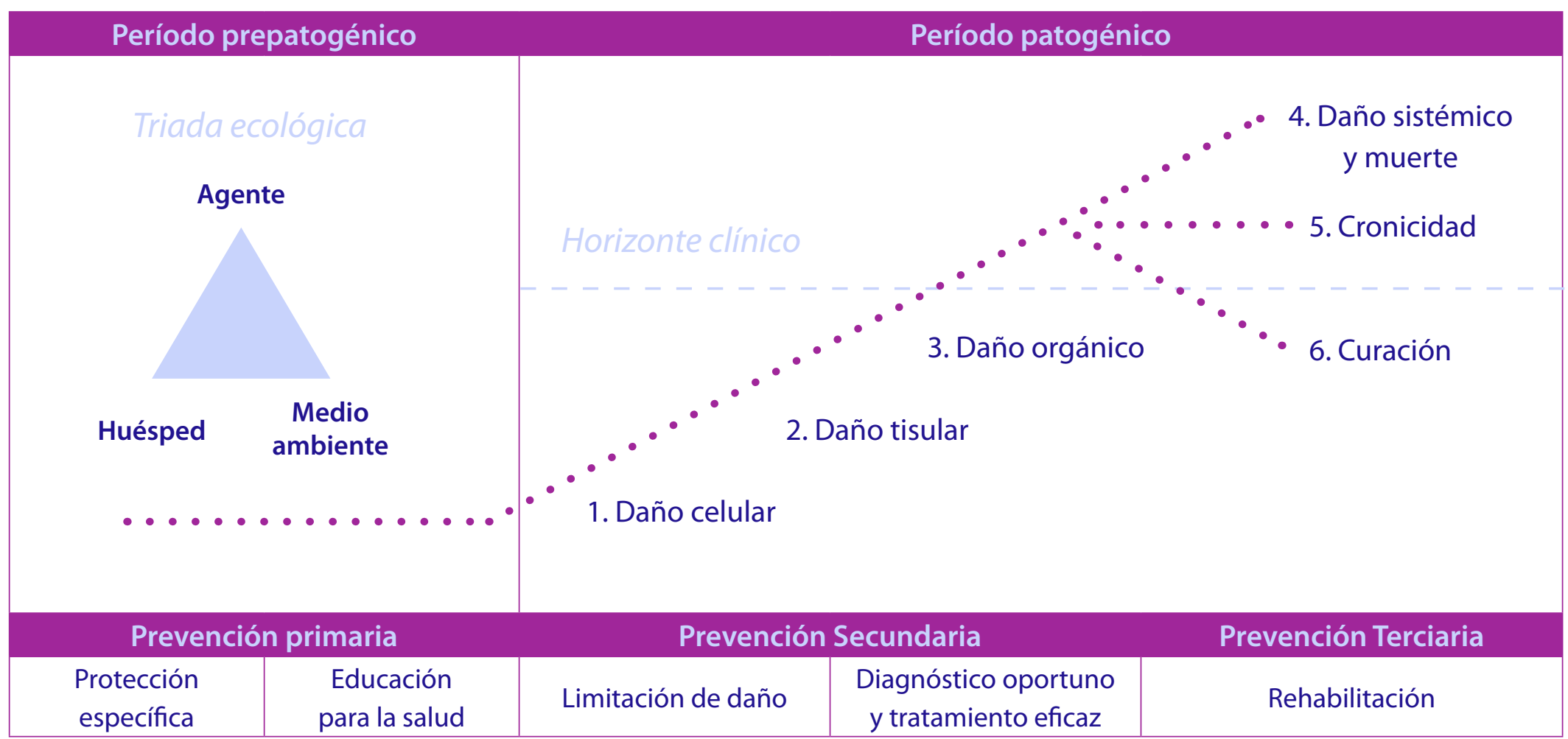

Nota: Evolución de la enfermedad. Adaptado de "Introducción" por F. Herrera (Coord.), Historia natural de 78 enfermedades: Manual gráfico. México: Manual Moderno.

Aunque el modelo de Leavell y Clark (1958) fue propuesto para enfermedades agudas posibilita la comprensión de la enfermedad crónica. La evolución de la enfermedad crónica se caracteriza por un deterioro en el organismo del paciente diagnosticado. En ese sentido, cuando un individuo es diagnosticado con una enfermedad crónica, los objetivos del tratamiento se dirigen a la implementación de estrategias encaminadas a modificar la evolución del padecimiento. Por ello, se puede ubicar que la intervención tiene como meta la prevención secundaria, específicamente la limitación del daño. En la figura 2 se describe la historia natural de la ERC, considerando el período prepatogénico y el período patogénico. 


\section{Figura 2}

\section{Historia Natural de la Enfermedad Renal Crónica}

Agente

Diabetes, congénitas,

hipertensión arterial

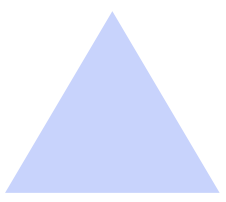

Huésped Medio ambiente

Hombres Factores socioculy Mujeres turales, obesidad, tabaquismo, inactividad física

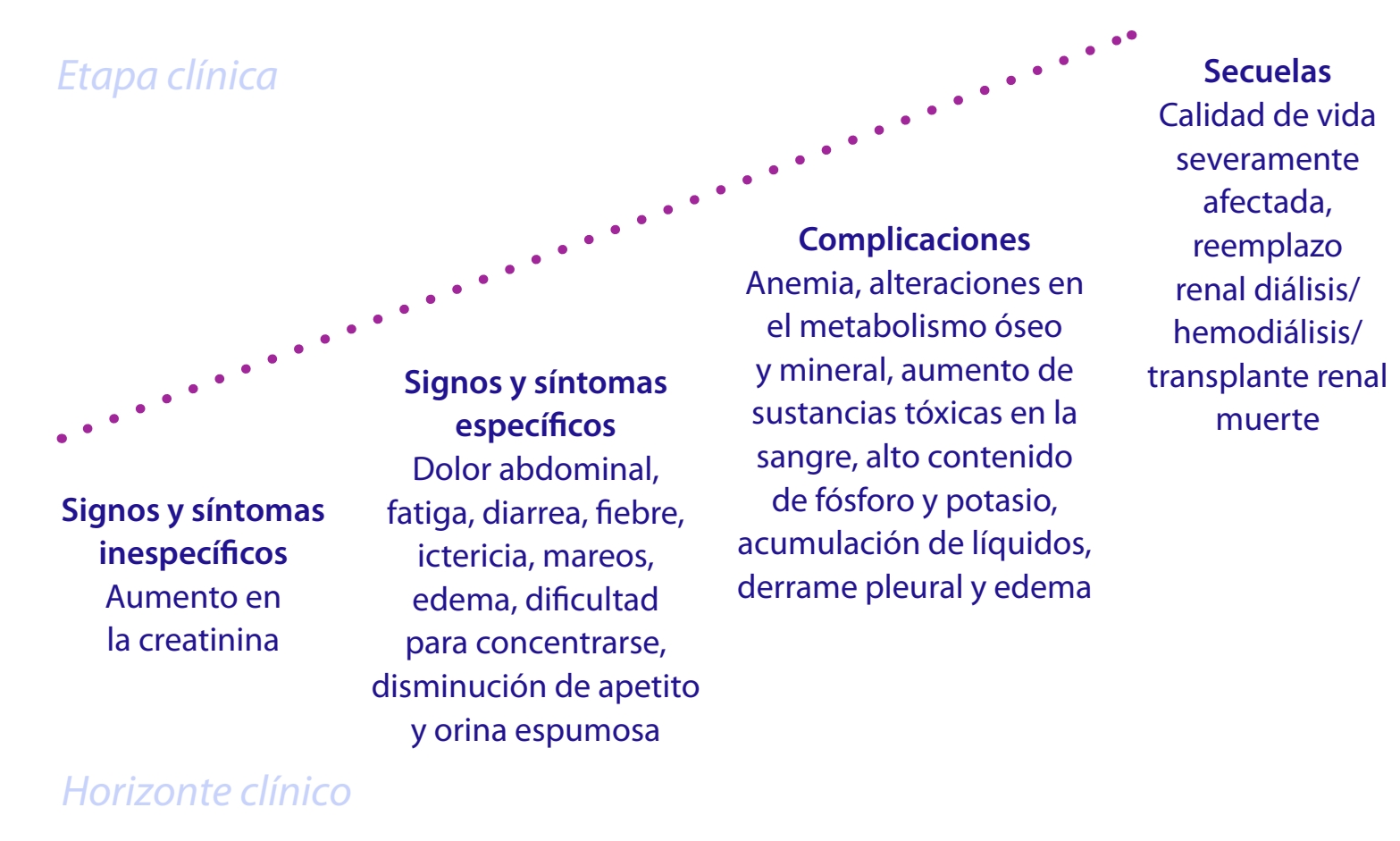

Fase silenciosa

Pérdida de $30 \%$ de masa renal
Fase subclínica

\section{Niveles de prevención}

\section{Prevención primaria}

- Control de la glucosa en sangre

- ControlT/A

- Alimentación saludable

- Control del peso corporal

- Incremento en la actividad física

- Evitar consumo de sustancias nocivas (alcohol, tabaco, drogas)

- Medir el nivel de creatinina

- Contol de diabetes e hipertensión

\section{Prevención secundaria}

Diagnóstico precoz

- Examen físico

- Exámenes de laboratorio: pruebas de función renal, electrolitos, ácido úrico, estudios de imagenología, química sanguínea

Tratamiento

- Inhibidores de enzima convertidora de angiotesina

- Diuréticos

- Manejo de la hipertensión

- Manejo del nivel de proteinuria

- Manejo del sobrepeso y la obesidad

- Manejo de la hiperglucemia

- Manejode la hiperlipidemia

- Manejo de la hiperuricemia

- El potasio sérico y creatinina debe ser monitoreada una vez por semana

- Restricción de fosfato de la dieta

- Terapia de reemplazo diálisis, hemodiálidis, trasplante

\section{Prevención terciaria}

Limitaciones del daño

- Seguir control de la hipertensión

- Dieta hipoproteica

- Seguir el tratamiento farmacológico

- Diálisis/hemodiálisis/trasplante renal

Rehabilitación

- Cambios de estilo de vida

- Ayuda psicológica

Nota: Elaboración propia. 


\subsection{Complicaciones de la ERC}

Las complicaciones de la ERC pueden ser prevenidas o retardadas por detección temprana y tratamiento. La enfermedad cardiovascular es la principal complicación de los pacientes con ERC. También pueden presentar anemia, alteraciones en el metabolismo óseo y mineral, aumento de sustancias tóxicas en la sangre, alto contenido de fósforo y potasio, acumulación de líquidos, derrame pleural y edema (Espinosa-Cuevas, 2016; Flores et al., 2009).

\subsection{Tratamiento}

Para el manejo adecuado del paciente con ERC se procurará disminuir la velocidad de la progresión del daño renal, a través del control en los niveles de presión arterial, niveles de proteinuria, el sobrepeso y la obesidad, la hiperglicemia, la hiperlipidemia y la hiperuricemia (Hurtado-Aréstegui, 2016). Las opciones de tratamiento de la ERC dependen de la etapa en la que se encuentre. Generalmente, durante las primeras cuatro etapas, el tratamiento es conservador (fármacos, dieta y medidas generales), mientras que en la etapa más avanzada (etapa 5) el tratamiento consiste en la terapia de reemplazo renal (diálisis peritoneal, hemodiálisis, o trasplante) (Rozman \& Cardellach, 2016).

\subsubsection{Farmacológico}

En la guía Prevención, Diagnóstico y Tratamiento de la Enfermedad Renal Crónica publicada por el IMSS (2019), se sugiere que el tratamiento farmacológico sea mediante la administración de inhibidores de la enzima convertidora de angiotensina o bloqueadores del receptor de angiotensina en pacientes con diabetes mellitus tipo 2 (DM2) y normoalbuminuria para reducir el riesgo de desarrollo de microalbuminuria. De igual manera, los especialistas recomiendan dar tratamiento con estatinas a dosis estándar a los pacientes con ERC de más de 50 años o mayores de 18 años con factores de riesgo cardiovascular (diabetes, hipertensión, etc.) para disminuir la presentación de eventos cardiovasculares.

\subsubsection{No farmacológico}

A causa del aumento tan acelerado de las enfermedades crónico-degenerativas, también conocidas como Enfermedades Crónicas No Trasmisibles (ECNT), se ha buscado frenar la incidencia y reducir la tasa de mortalidad tanto a nivel nacional como mundial, por lo que se ha centrado la atención en la promoción de la salud a través de tratamientos no farmacológicos con el objetivo de reducir o postergar los daños orgánicos (Alwan et al., 2010). De acuerdo con Allam y Arjona (2013), es necesario centrar la atención y los esfuerzos a la implementación de los tratamientos no farmacológicos para el manejo de las ECNT, pues se beneficiarán tanto el paciente como el sector salud (reducción de costos), el cual es uno de los mayores retos de cualquier gobierno. 
De acuerdo con la Organización Panamericana de la Salud, la Organización Mundial de la Salud (OPS/OMS, 2015), y la Sociedad Latinoamericana de Nefrología e Hipertensión (SLANH) para una atención integral del paciente con ERC se debe ofrecer un tratamiento multidisciplinario que incluya, además de medicamentos, otras medidas de atención que ayuden a postergar el avance de la enfermedad, es decir, realizar cambios del estilo de vida por medio de estrategias conductuales para disminuir la probabilidad de aparición de complicaciones del padecimiento.

Además, la OPS y la OMS (2017) refieren que las intervenciones de modificación de estilos de vida (alimentación, ejercicio, consumos de sustancias nocivas e higiene) permiten que el paciente se adhiera de mejor manera al tratamiento farmacológico, por lo cual debe implementarse como estrategia en el manejo de cualquier paciente con ECNT.

\subsubsection{Modificaciones conductuales}

El tratamiento de la ERC no solamente es médico, también hay un componente psicológico que puede favorecer tanto el curso de la enfermedad como la calidad de vida del paciente. Tamayo y Orozco y Lastiri-Quirós (2016) mencionan que, para hacerle frente a la ERC, se debe recurrir al apoyo de un equipo multidisciplinario para la atención del paciente, contemplando a médicos generales, familiares, internistas, nutriólogos, psicólogos y expertos en activación física, con el objetivo de mejorar el estado de salud del paciente. Las enfermedades no transmisibles como la ERC están relacionadas con el estilo de vida; por lo tanto, la modificación del comportamiento, relacionada con el éxito en la adherencia al tratamiento, es el elemento principal para prevenir la progresión de la disfunción renal y las complicaciones (Yamagata et al., 2016).

\subsection{Modificaciones en la alimentación}

Una de las piedras angulares del tratamiento no farmacológico de la ERC es la alimentación. Con una adecuada alimentación se puede disminuir la progresión del daño renal, particularmente cuando se comienza en una etapa temprana de la enfermedad. Los objetivos del manejo dietético en la ERC son: (a) retrasar la progresión de la insuficiencia renal, (b) mejorar o mantener el estado nutricio del paciente, (c) disminuir los síntomas urémicos y el hipercolesterolemia, (d) minimizar el catabolismo proteínico, (e) normalizar el desequilibrio hidroelectrolítico, (f) regular la tensión arterial, y (g) permitir una mejor calidad de vida al paciente.

En la etapa inicial de la enfermedad se requiere de una restricción proteínica moderada, mientras que la ingestión de nutrimentos energéticos no proteínicos (hidratos de carbono y lípidos) se mantiene o incrementa para cubrir los requerimientos de energía. Conforme avanza el daño y la función renal disminuye se necesita, además, una modificación en el consumo de fósforo, líquidos, potasio y sodio, e inclusive es factible la utilización de acetoanálogos de aminoácidos indispensables para su complementación en las etapas más avanzadas de 
la enfermedad. Cuando el paciente requiere de diálisis, en la etapa más avanzada, el aporte proteínico debe ser mayor a las etapas previas para compensar las pérdidas proteínicas propias del tratamiento dialítico (Alcázar \& Otero, 2008).

\subsection{Modificaciones en la actividad física}

El realizar actividad física tiene algunos beneficios en los pacientes con ERC, por ejemplo, aumenta la fuerza muscular, previene la pérdida de masa muscular, incrementa la función cardiovascular y optimiza la supervivencia al reducir el riesgo cardiovascular, mejorando así la calidad de vida de los pacientes. Sin embargo, se recomienda acudir con un profesional (médico), ya que el tipo de ejercicio a realizar dependerá de las condiciones particulares del paciente, por ejemplo, peso, edad, alimentación, o si se encuentra en algún tipo de tratamiento sustitutivo, ya que si el paciente está en procedimiento de diálisis peritoneal deben evitarse los ejercicios con mayor esfuerzo en el abdomen, debido al riesgo de hernias abdominales o un aumento en la presión del catéter. En general, la práctica de ejercicio sin supervisión puede tener como consecuencias lesiones musculares o efectos cardiovasculares (Pinillos, Herazo, Gil, \& Ramos, 2019).

\subsubsection{Tratamiento sustitutivo}

De acuerdo con el Centro Nacional de Excelencia Tecnológica en Salud (CENETEC, 2014), previo al inicio del tratamiento sustitutivo renal se debe tomar en cuenta la condición clínica del paciente, el tipo de enfermedad renal primaria, la edad, el estado nutricional y las comorbilidades.

Existen tres tipos de tratamiento sustitutivo renal: diálisis peritoneal, hemodiálisis y trasplante renal. A continuación, se describen las características principales de cada uno.

\subsubsection{Diálisis peritoneal}

Según el CENETEC (2009), la diálisis peritoneal es una alternativa a la hemodiálisis que aprovecha las características de transporte de líquidos y solutos del peritoneo, como una membrana de diálisis endógena. La diálisis peritoneal puede ser efectuada en forma continua ambulatoria (CAPD) o como continua ciclada (CCPD por sus siglas en inglés). El acceso a la cavidad peritoneal se logra mediante la colocación quirúrgica de un catéter de Silastic (catéter de Tenckhoff de diferentes diseños) a través de la pared abdominal. Una vez colocado dicho catéter, el paciente o un asistente recibe adiestramiento para poder llevar a cabo su propio procedimiento de diálisis.

La diálisis peritoneal se lleva a cabo introduciendo, por medio del catéter, el líquido de diálisis peritoneal, habitualmente entre 1500 a $3000 \mathrm{ml}$ (dependiendo del peso y la talla de la persona) dentro de la cavidad abdominal, permitiendo al líquido permanecer en el interior por un tiempo definido, para posteriormente ser drenado y eliminado de la misma forma. 
Durante cada periodo de estancia en cavidad se lleva a cabo la remoción de solutos y la ultrafiltración. La diálisis peritoneal al ser una terapia de autocuidado puede favorecer la independencia del paciente. La principal complicación de la diálisis peritoneal es la peritonitis bacteriana, su prevalencia varía considerablemente entre los pacientes y entre los centros de salud, pero se considera una frecuencia promedio de un episodio por paciente al año, siendo la presencia de episodios de peritonitis la principal causa de abandono de este tratamiento (CENETEC, 2009).

\subsubsection{Hemodiálisis}

El National Institute of Diabetes and Digestive and Kidney Disease (NIDDK, 2017) refiere que la hemodiálisis es la técnica predominante de tratamiento para la ERCT en todo el mundo. El procedimiento puede ser efectuado en unidades médicas especializadas. El tratamiento dura en promedio de tres a cinco horas y usualmente se efectúa tres veces por semana.

Para poder efectuar el tratamiento, se necesita un circuito extracorpóreo que permite obtener la sangre del paciente a través de un acceso vascular, hacer que esta pase por el dializador y retorne purificada. Todo el proceso es controlado por una máquina que es programada para que sea efectivo y seguro (NIDDK, 2017).

\subsubsection{Trasplante renal}

Asimismo, el NIDDK (2017) menciona que el trasplante renal es el tratamiento de elección en pacientes con ERCT, ya que en la mayoría de los casos ofrece una calidad de vida superior en comparación con la hemodiálisis y la diálisis peritoneal. En la figura 3, se observa el protocolo a seguir para un paciente en espera de trasplante renal. La baja disposición de órganos ha sido la principal limitante para la expansión de esta modalidad terapéutica. Las tasas de trasplante renal varían considerablemente de acuerdo con la edad de los pacientes, siendo menores en individuos de edad avanzada, quienes representan un grupo de riesgo relativamente mayor.

\section{Figura 3}

Protocolo para trasplante renal
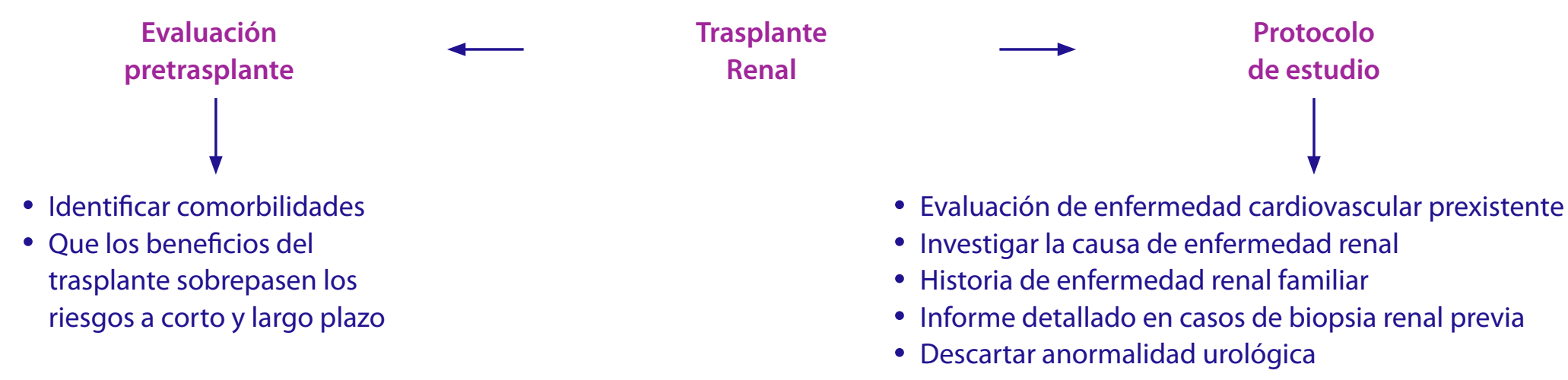

Nota: Elaboración propia a partir de Prevención, Diagnóstico y Tratamiento de la Enfermedad Renal Crónica por Instituto Mexicano del Seguro Social, 2019. 
Existen factores de riesgo para el desarrollo de complicaciones para cada procedimiento sustitutivo de la ERC (diálisis peritoneal, hemodiálisis y trasplante renal). En la tabla 3 se enlistan las principales contraindicaciones de cada procedimiento (CENETEC, 2014).

\section{Tabla 3}

Contraindicaciones de los tres procedimientos sobre el tratamiento sustitutivo de la ERC

\begin{tabular}{lll}
\multicolumn{1}{c}{ Diálisis peritoneal } & \multicolumn{1}{c}{ Hemodiálisis } & Trasplante renal \\
- Cavidad peritoneal no útil & - Pérdida o incapacidad de obtener & - Enfermedad maligna metastásica o \\
- Endometriosis peritoneal & un acceso vascular funcional & reciente \\
- Estomas abdominales & - Insuficiencia hepática grave & - Infección actual no tratada \\
- Fístula peritoneo-pleural & - Cardiopatías & - Enfermedad extra renal severa e \\
- Cirugía abdominal reciente & - Implante valvular & irreversible \\
- Válvula de derivación ventrículo-peritoneal & - Trastornos de coagulación & - Enfermedad psiquiátrica que altere la \\
- Tuberculosis peritoneal & - Enfermedad psiquiátrica no & adherencia al tratamiento \\
- Desnutrición grave o hipoalbuminemia & atribuible a síndrome urémico & - Abuso de drogas actual \\
$<2.5 g / d l$ & & - Potencial de rehabilitación limitado en \\
- Cirrosis hepática con insuficiencia hepática & & forma irreversible \\
avanzada & & - Oxalosis primaria \\
- Obesidad mórbida & & \\
- Enfermedad psiquiátrica no atribuible a & \\
síndrome urémico &
\end{tabular}

Nota: Elaboración propia a partir de Tratamiento sustitutivo de la función renal. Diálisis y hemodiálisis en la Insuficiencia Renal Crónica en el segundo y tercer nivel de atención por Centro Nacional de Excelencia Tecnológica en Salud (CENETEC), 2014, pp. 36-37.

\subsection{Estrés y Enfermedad Renal Crónica}

Las problemáticas derivadas de esta enfermedad son tanto a nivel macro como micro social, siendo el estrés una de las más frecuentes en los pacientes y, de no ser atendida, podría repercutir en distintos niveles de su vida (personal, familiar, escolar, laboral y social) (Vázquez, Vital, Bravo, Jurado, \& Reynoso, 2009).

Los factores psicosociales están asociados directamente con la ERC. El estrés representa en el paciente un factor de riesgo que dificulta la adaptación a la enfermedad, además de afectar fisiológicamente (presión arterial, frecuencia cardiaca, resistencia a la insulina, etc.) y podría estar asociado con daño y enfermedad tisular (Bruce et al., 2009). La relación entre el estrés y la salud es muy estrecha, mantener niveles altos de estrés por tiempos prolongados produce en el paciente diversos efectos negativos que originan comportamientos poco saludables, tales como consumo de tabaco, alcohol o drogas, trastornos en el sueño y alimentación, sedentarismo, entre otros, lo cual genera una progresión de la enfermedad o complicaciones, por lo que el manejo del estrés es crucial en las intervenciones del enfermo renal para la mejora de la calidad de vida (Bruce, Griffith, \& Thorpe, 2015). 


\section{Modelo de estrés}

\subsection{El modelo de estrés y afrontamiento}

Un aspecto inevitable de la vida es el estrés y la manera en como se afronta es lo que hace la diferencia en la vida cotidiana y la salud. El estrés es concebido como una relación entre la persona y el ambiente, en donde el individuo evalúa sus recursos y si estos se encuentran agotados o excedidos para poder hacerle frente a alguna situación percibida como amenazante (Lazarus \& Folkman, 1984). En esta evaluación se involucran procesos cognitivos y de distinción entre situaciones benignas y peligrosas, también se describe la situación evaluada como estresante valorando si es cambiante o no y cuáles son las estrategias de afrontamiento que el individuo emplea.

Por situaciones estresantes se entienden aquellos estímulos ambientales, sociales y físicos que desafían las capacidades de adaptación y los recursos de un organismo (Monroe \& Slavich, 2016), adicionalmente, aquellos que parecen ser molestos o perjudiciales para la persona (Cao, Masood, Lugman, \& Ali, 2018). Para Lazarus y Folkman (1984), existen diferentes tipos de amenazas o situaciones percibidas como estresantes, los cuales pueden identificarse como una tríada básica: pérdida o daño, amenaza, y desafío.

En ese sentido, los individuos afrontan las situaciones que perciben como estresantes mediante procesos, los cuales son definidos como esfuerzos cognitivos y conductuales constantemente cambiantes, que se desarrollan para manejar las demandas externas o internas que son evaluadas como excedentes o desbordantes de los recursos del individuo (Lazarus \& Folkman, 1984). A partir de las consideraciones anteriores, dicho autores proponen un modelo transaccional para el estudio del estrés. En este modelo se retoma el concepto de afrontamiento como un proceso, donde además del carácter interaccionista, es importante considerar la valoración que el individuo realiza ante ciertas situaciones. Esta valoración se divide en tres etapas: (a) evaluación primaria, (b) evaluación secundaria, y (c) afrontamiento. La primera se caracteriza por la percepción que el individuo hace sobre la situación que se le está presentando, la segunda se refiere a determinar qué es lo que puede hacerse al respecto y cuáles serían los resultados, y por último el afrontamiento se define como aquellos esfuerzos necesarios que permiten hacer frente a las demandas estresantes (Caballo \& Anguiano, 2002).

Estos procesos, llamados estrategias de afrontamiento, pueden ser centrados en: (a) emoción, con el objetivo de disminuir el grado de malestar emocional, como evitación, minimización, distracción, atención selectiva, entre otras; y (b) problema, estas estrategias están dirigidas a la definición del problema, buscan solución para este y consideran diferentes opciones en función del costo-beneficio (Lazarus \& Folkman, 1984).

En la figura 4 se puede observar el esquema de transacción de estrés que un individuo experimenta. 


\section{Figura 4}

Esquema de transacción de estrés

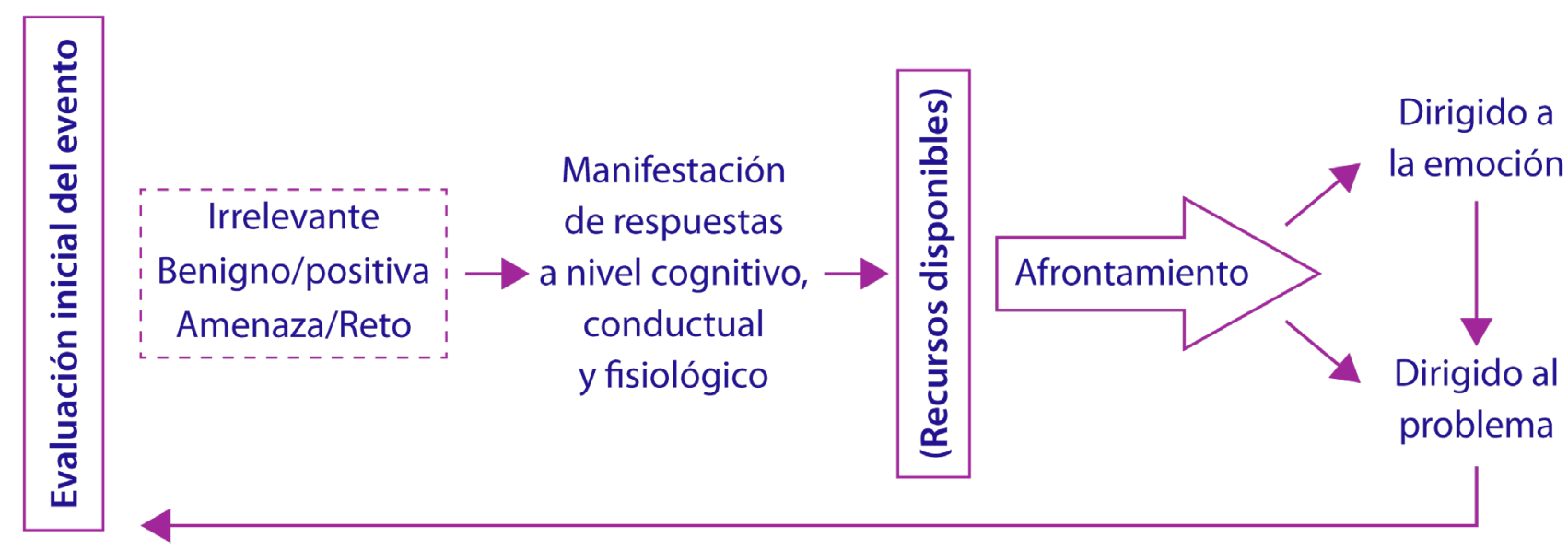

Nota: Recuperado de Trastorno de estrés postraumático en adultos. Intervención cognitivo-conductual para víctimas de sismos por L. Reynoso, A. L. Becerra, e I. Lugo, 2019, p. 19.

En la figura 5 se ilustra el caso de la paciente María, con recién diagnóstico de ERC KDIGO V debido a un mal control de DM2 y dentro de las recomendaciones terapéuticas deberá modificar su alimentación. María conceptualiza este evento como una situación estresante, ya que la evalúa como superior a sus capacidades (¿cómo voy a comer diferente a lo acostumbrado?). Por ello, la situación representa una amenaza para la paciente, ya que es un cambio en sus actividades diarias. Ante esta situación, María experimenta respuestas fisiológicas como sudoración y aceleración en el ritmo cardiaco, además refiere respuestas cognitivas caracterizadas por "será hacer dos comidas", "será mucho trabajo", finalmente, en las respuestas conductuales, la paciente mantiene las mismas conductas de alimentación previo al diagnóstico de ERCT.

Respecto a los recursos disponibles, María evalúa que cuenta con apoyo social y económico, habilidades sociales y, debido a la psicoeducación proporcionada por el psicólogo, adquirió conocimientos sobre el desarrollo de la ERC, entendiendo que fue a causa de un mal control de DM2. En cuanto a los estilos o estrategias de afrontamiento centradas en la emoción se encuentra la evitación, la creencia mágica (creer que inventarán una cura) y la normalización ("de algo nos tenemos que morir"), mientras que en las centradas en el problema destacan el reconocimiento del problema, la comunicación y la petición de apoyo social. La paciente identifica esta última como la estrategia más funcional.

De acuerdo con Ghosh y Verma (2018), la relación entre los factores estresantes psicosociales y la enfermedad se ve afectada por la naturaleza, el número, la vulnerabilidad biológica del individuo, los recursos psicosociales y los patrones de afrontamiento aprendidos. 


\section{Figura 5}

Ejemplo de caso: transacción del estrés en ERC

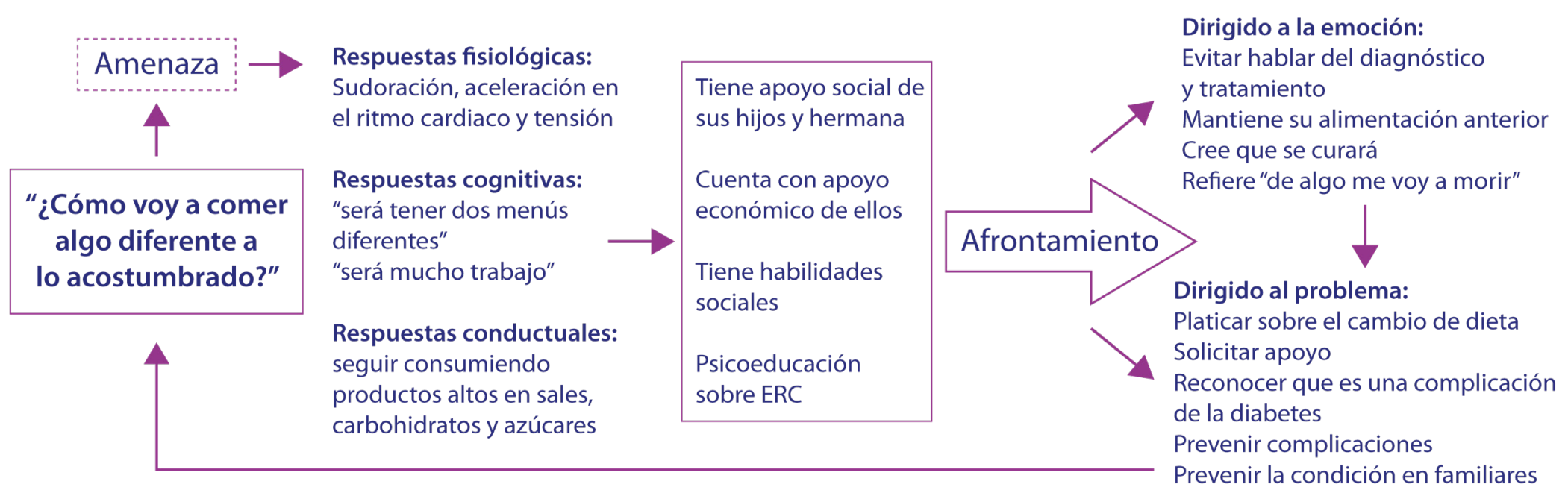

Nota: Adaptado de Trastorno de estrés postraumático en adultos. Intervención cognitivo-conductual para víctimas de sismos por L. Reynoso, A. L. Becerra, e I. Lugo, 2019, p. 22.

A manera de resumen, el estrés se define como una respuesta adaptativa tanto de la salud como de la enfermedad, así como generador de problemas de salud. Respecto al primero, se hace referencia a la manera de afrontar el estrés en situaciones cotidianas, ajustándose a las demandas de la situación. En cuanto al estrés como generador de problemas de salud, se hace hincapié en las respuestas fisiológicas en donde la cronicidad e intensidad del evento estresante pueden probabilizar o atenuar algunas complicaciones o sensaciones fisiológicas adversas.

\section{Medicina Conductual}

\subsection{Qué es Medicina Conductual}

La MC se define como "el campo interdisciplinario que se ocupa del desarrollo e integración del conocimiento y las técnicas de las ciencias del comportamiento, psicosociales y biomédicas con el objetivo de mejorar, comprender y tratar la salud y la enfermedad" (Smyth \& Zawadzki, 2016, p. 156). Dekker, Stauder y Penedo (2017) proponen ampliar la definición incluyendo la aplicación de estos conocimientos a la etiología, prevención, promoción de la salud, diagnóstico, tratamiento, rehabilitación y cuidado del paciente.

Por su parte, la Society of Behavioral Medicine (SBM, 2020) menciona que el papel del comportamiento en la salud tiene una fuerte evidencia en la efectividad para la prevención y el manejo de las enfermedades, lo cual tiene como beneficios la reducción de los costos sanitarios, así como aumentar la calidad de vida de los pacientes. De acuerdo con Reynoso (2014), el trabajo de la MC parte del abordaje integral del paciente con enfermedad, enfatizando que la conducta incide en la generación de enfermedades, por lo que identificar el comportamiento que se encuentra relacionado con la enfermedad es la principal labor. 


\subsection{Actividades del especialista en $\mathbf{M C}$ con pacientes que viven con enfermedad crónica} La medicina del comportamiento busca promover conductas saludables para mejorar la salud y, con ello, la calidad de vida del paciente sin importar el padecimiento, el sexo, la edad, la escolaridad o cualquier diferencia.

El especialista en MC está capacitado para trabajar de manera interdisciplinaria, centrando sus actividades en estudiar y modificar el comportamiento del paciente tanto en los contextos hospitalarios como fuera de ellos, con el fin de mejorar la calidad de vida del paciente, diseñando intervenciones bajo el marco teórico de la TCC. Además, el especialista en MC desarrolla sus habilidades y competencias profesionales con actitud y comportamiento ético (Reynoso, 2011). En la tabla 4 se muestran las principales actividades del especialista en MC. Cabe resaltar que el objetivo de identificar y solucionar los problemas psicológicos de los pacientes con enfermedad crónica como el estrés, la ansiedad, la depresión y diversas problemáticas que experimentan a lo largo del curso de la enfermedad, es disminuir la presencia de factores de riesgo que afecten el proceso de adaptación a esta.

\section{Tabla 4}

\section{Actividades del especialista en Medicina Conductual}

\begin{tabular}{|c|c|}
\hline Actividades & Descripción \\
\hline Evaluación & $\begin{array}{l}\text { Se realiza a través de la entrevista conductual en la que se obtienen datos relevantes con relación } \\
\text { a la problemática del paciente, recabando la información suficiente para la elaboración del análisis } \\
\text { funcional de la conducta. }\end{array}$ \\
\hline $\begin{array}{l}\text { Medición de variables } \\
\text { psicológicas y fisiológicas }\end{array}$ & $\begin{array}{l}\text { Para la medición de las variables psicológicas será necesario el uso de herramientas como } \\
\text { cuestionarios, escalas, checklist e inventarios validados y estandarizados con el fin de obtener } \\
\text { indicadores de las variables en estudio, mientras que para la medición de las variables fisiológicas el } \\
\text { especialista podrá hacer uso de herramientas como baumanómetro, oxímetro, termómetro, equipo de } \\
\text { biofeedback, entre otros, con el objetivo de cuantificar el estado fisiológico del paciente. }\end{array}$ \\
\hline $\begin{array}{l}\text { Elaboración de análisis } \\
\text { funcional de la conducta } \\
\text { (AFC) }\end{array}$ & $\begin{array}{l}\text { Es la principal herramienta para el especialista en MC para planear y dirigir la intervención, pues con } \\
\text { ella se identifica(n) la(s) conducta(s) problema(s) del paciente y busca explicar el mantenimiento del } \\
\text { comportamiento. El AFC ayuda a identificar las relaciones existentes entre las respuestas y las variables } \\
\text { del contexto. }\end{array}$ \\
\hline Planeación & $\begin{array}{l}\text { Realizar la adecuación de las técnicas, ajustándolas a las características y necesidades de cada paciente } \\
\text { posterior a la evaluación y a través de la elaboración de objetivos generales y específicos. }\end{array}$ \\
\hline Retroalimentación & $\begin{array}{l}\text { Explicar al paciente los resultados generales tanto de la evaluación, la medición y la intervención con } \\
\text { el objetivo de informar al paciente el proceso terapéutico y adecuarlo si es necesario. }\end{array}$ \\
\hline Intervención psicológica & $\begin{array}{l}\text { Implementar las técnicas de la TCC con el objetivo de modificar las conductas y cogniciones } \\
\text { disfuncionales a través del entrenamiento de estrategias y habilidades que le permitan al paciente } \\
\text { aprender nuevas formas de actuar, de expresar sentimientos, de evaluar pensamientos y formas de } \\
\text { afrontamiento. }\end{array}$ \\
\hline Monitoreo & $\begin{array}{l}\text { Proceso sistemático para la recolección y análisis de información sobre la efectividad del proceso } \\
\text { terapéutico. }\end{array}$ \\
\hline Seguimiento & $\begin{array}{l}\text { Posterior a la intervención psicológica se agendan sesiones de seguimiento con el objetivo de evaluar } \\
\text { el mantenimiento del cambio y, a partir de esa evaluación, trabajar la prevención en recaídas. }\end{array}$ \\
\hline
\end{tabular}


Actividades

Intervención en crisis
Descripción

Aplicar una serie de técnicas basadas en la TCC en cualquier momento del proceso terapéutico en el que se identifique una crisis, con el objetivo de reducir las respuestas exacerbadas de estrés, procurando salvaguardar el bienestar del paciente y fomentando la adaptación y el afrontamiento a corto, mediano y largo plazo.

Canalización a otro especialista

En el caso de que el paciente requiera apoyo de otros profesionales (especialistas en nutrición o bariatra, o psiquiatría) o que se identifique que el motivo de consulta no se relacione con los objetivos de la MC, el terapeuta deberá remitir con el instituto o especialista necesario.

Elaboración de expedientes clínicos

Realizar un reporte psicológico que incluye el historial clínico del paciente, el cual funge como guía para la toma de decisión del especialista en MC acerca del diagnóstico, pronóstico, además de contener información relevante sobre el proceso terapéutico, respetando el derecho de confidencialidad y con base en las normas oficiales.

Investigación Mostrar evidencia sobre la efectividad de las técnicas cognitivo-conductual en poblaciones con padecimientos crónicos en México.

Nota: Elaboración propia.

\subsection{Evidencia de la efectividad de la TCC en el tratamiento del estrés en enfermos crónicos}

Las intervenciones psicológicas sustentadas en la TCC han resultado ser efectivas en distintas enfermedades crónicas. A continuación, se describen diversos metaanálisis y estudios en pacientes con algunas enfermedades crónicas, y en particular con ERC. Estos artículos evidencian la efectividad: (a) para disminuir síntomas de depresión, ansiedad, fatiga y dolor en adultos con enfermedades crónicas, (b) terapia en línea bajo el modelo TCC sobre la disminución de ansiedad y depresión en personas con afecciones crónicas, (c) intervenciones psicológicas TCC para promover la adherencia al tratamiento en pacientes con ERC, y (d) reducción de síntomas de ansiedad y depresión en pacientes con ERC. En la tabla 5 se muestran algunos artículos sobre la evidencia de la TCC en pacientes con ERC.

\section{Tabla 5}

\section{Evidencia de la efectividad de la TCC en el tratamiento del estrés en enfermos crónicos}

$\begin{array}{llll}\text { Autores (año) } & \text { Objetivo } & \text { Estrategias } & \text { Resultados }\end{array}$

Bernard et al., (2018)
Determinar el efecto de

la TCC sobre depresión, ansiedad, fatiga y dolor en adultos con enfermedades crónicas.
Las bases de datos utilizadas fueron PubMed, PsyArticles, CINAHL, Sport Discus y el Registro Central Cochrane de Ensayos Controlados.
Se incluyeron 232 artículos. El tamaño muestral de los estudios incluidos varió entre 30 y 555 pacientes, con una edad media de 47.4 años. Los resultados destacaron que la TCC promovió una disminución significativa para la depresión, ansiedad y fatiga; no se observaron efectos significativos para el dolor. Los tamaños de efecto encontrados para la depresión, ansiedad y fatiga fueron de magnitud similar a los hallazgos de metaanálisis previos, los efectos de tamaño fueron 0.30 para la depresión, 0.29 para la ansiedad y 0.68 para la fatiga crónica. 
Autores (año)

Mehta, Peynenburg y Hadjistavropoulos (2019)
Objetivo

Evaluar la eficacia de la

TCC en línea sobre la ansiedad y la depresión en personas con afecciones crónicas.

\section{Estrategias}

Se realizó una búsqueda sistemática en la base de datos de MEDLINE, CINAHL, Psyclnfo, EMBASE y Cochrane para estudios relevantes publicados desde 1990 hasta septiembre de 2018.

Resultados

Los estudios incluidos consistieron en intervenciones de la TCC en la ansiedad y la depresión en pacientes con afecciones crónicas, como dolor $(n=950)$ mostró efectos moderados en la ansiedad ( $\mathrm{SDM}=0.64 \pm 0.249, \mathrm{p}=.01$ ), depresión (SDM $=0.64 \pm 0.16, p=.001)$, tinnitus $(n=493)$ reveló efectos pequeños en la ansiedad (SDM $=0.31 \pm 0.07, \mathrm{p}<.001)$ y depresión (SDM $=0.28 \pm 0.07, p<.001)$, fibromialgia $(n=238)$, se observaron efectos moderados en la ansiedad (SDM $=0.57 \pm 0.26, \mathrm{p}=.03$ ) y depresión (SDM $=0.42 \pm 0.13, p=.001)$, artritis $(n=484)$ mostró efectos moderados en la ansiedad (SDM $=0.53 \pm$ $0.11, p=.001$ ) y pequeños efectos en la depresión (SDM $=0.44 \pm 0.10, p=.001)$, enfermedades cardiovasculares, se encontraron solo dos estudios, en el primero mostró pequeños efectos en la ansiedad $(n=562)(S D M=0.22 \pm 0.08, p=.008)$ y la depresión (SDM $=0.20 \pm 0.08, p=.02)$, el segundo no encontró ningún efecto significativo del TCC presencial sobre la depresión (SDM $=0.31$ $\pm 0.29, p=.27$ ) en comparación con la terapia en línea. En cuanto a los pacientes con cáncer no se encontraron efectos significativos en la depresión (SDM $=0.19 \pm 0.17, p=.26)$, diabetes $(n=91)$ se observaron grandes efectos en la ansiedad (SDM $=0.86 \pm 0.22, p=.001)$ al igual que en la depresión (SDM $=1.11 \pm 0.23, p=.001)$, lesión medular no encontraron efectos significativos sobre la ansiedad ( $n=30)(S D M=0.52 \pm 0.29, p=.07) n i$ en la depresión (SDM $=0.17 \pm 0.29, p=.55$ ) y en las afecciones crónicas mixtas no se encontraron efectos significativos del ICBT en la depresión (SDM $=0.42 \pm 0.30, p=.15$ ).

$\begin{array}{ll}\text { Payne, Eaton, Mee y } & \text { Evaluar la eficacia } \\ \text { Blount (2012) } & \text { de una intervención } \\ & \text { cognitivo-conductual } \\ \text { para promover } & \text { la adherencia a } \\ & \text { la medicación en } \\ & \text { dos adolescentes } \\ & \text { afroamericanos con } \\ & \text { ERC en tratamiento de } \\ & \text { hemodiálisis. }\end{array}$

Duarte, Miyazaki, Blay y Sesso (2009)
La intervención se dividió en dos módulos utilizando técnicas de modificación cognitiva.
La adherencia a los medicamentos aumentó hasta un $90 \%$ en ambos jóvenes en relación con la línea base, demostrando así la efectividad de la TCC para esta problemática.

\section{Evaluar la efectividad} de la TCC en pacientes con ERC en tratamiento de hemodiálisis diagnosticados con depresión mayor.
El grupo de intervención estaba conformado por 41 pacientes, quienes recibieron 12 sesiones de terapia de grupo cognitivo-conductual, mientras que el grupo control estuvo conformado por 44 pacientes quienes no recibieron atención psicológica.
El grupo de intervención presentó mejoras significativas, en comparación con el grupo de control, en las puntuaciones medias de la escala general del Inventario de Depresión de Beck, puntuaciones MINI, y en las dimensiones de la calidad de vida que incluyeron la carga de enfermedad renal, sueño, calidad de la interacción social, salud general y resumen del componente mental. 
Autores (año)

Lerma, Pérez,

Bermúdez, Peralta,

Robles y Lerma

(2017)

\section{Objetivo}

Evaluar los efectos de

la TCC para reducir

la depresión leve y moderada, y los síntomas de ansiedad en pacientes con ERC en tratamiento de hemodiálisis.

\section{Estrategias}

Participantes 60 pacientes con puntuaciones leves o moderadas de depresión (Beck Depression Inventory) y ansiedad (Beck Anxiety Inventory) fueron asignados al azar al grupo de intervención y al grupo control. Las técnicas consistieron en reforzamiento positivo, respiración profunda, relajación muscular y reestructuración cognitiva.

\section{Nozaki, Oka y}

Chaboyer (2005)

\section{Evaluar la efectividad} de un programa basado en la TCC para el control en la ingesta de sal y el aumento de peso en pacientes con ERC en tratamiento de hemodiálisis.
La intervención se dividió en tres fases: evaluación inicial, intervención y seguimiento; el tamaño de la muestra fue de 22 pacientes, los cuales se dividieron en dos grupos, 11 de ellos fueron sometidos a la intervención desde la TCC y a los 11 restantes se proporcionó educación estándar de la enfermedad.

Sharp, Wild, Gumley Evaluar la efectividad y Deighan (2005)

La intervención grupal implicó una evaluación de una intervención grupal desde la terapia cognitiva conductual para mejorar la adherencia a la restricción de líquidos en pacientes con ERCT en tratamiento de hemodiálisis. inicial, cuatro semanas de tratamiento, la evaluación posterior al tratamiento y una evaluación de seguimiento posterior a 10 semanas de haber concluido. La intervención se diseñó para ser breve, incluyendo técnicas de psicoeducación, modificación de conductas, modificación cognitiva y entrenamiento en relajación muscular.

Chan, Dear, Titov, Chow y Suranyi (2016)

$\begin{array}{ll}\text { Determinar la eficacia } & \text { La intervención por } \\ \text { de una intervención a } & \text { internet dirigida a 22 } \\ \text { través de internet con el } & \text { pacientes, entrenados } \\ \text { objetivo de reducir los } & \text { para adquirir habilidades } \\ \text { síntomas de depresión } & \text { cognitivas y conductuales } \\ \text { y ansiedad en pacientes } & \text { a lo largo de ocho } \\ \text { con ERC desde la TCC. } & \text { semanas. }\end{array}$

Resultados

Los resultados mostraron diferencias significativas entre los dos grupos. El grupo de intervención mostró 33\% de utilidad clínica para los síntomas de depresión y $43 \%$ para los síntomas de ansiedad, mientras que en el grupo control no se observaron cambios.

Los autores encontraron diferencias significativas en el uso de la intervención cognitiva conductual en comparación con la educación estándar brindada al paciente, mostrando cambios en el control de la ingesta de sal y el control de peso en los pacientes que recibieron TCC, los cambios persistieron durante 12 semanas posterior a la intervención.

Los resultados indicaron cambios en la mejora de la adherencia terapéutica a largo plazo, mostrando cambios en indicadores cognitivos importantes para mediar el cambio de comportamiento.

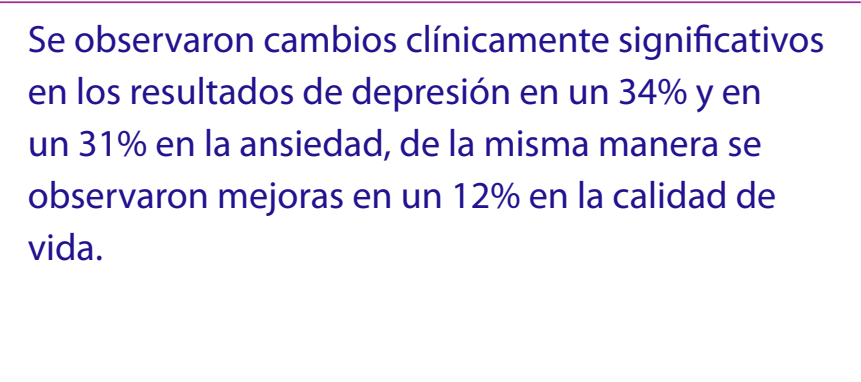


Autores (año)

Nadort, Schouten, Dekker, Honig, Van Oppen y Siegert (2019)

\section{Objetivo}

Evaluar la efectividad en costos de una intervención cognitiva conductual a través de internet para la reducción de síntomas de depresión en pacientes con ERC en tratamiento de diálisis.

Ng et al. (2019) Evaluar la eficacia de la TCC en pacientes en tratamiento de hemodiálisis con depresión, conjuntamente evaluar si se modifica la calidad de vida y los síntomas de ansiedad comórbidos.

\section{Estrategias}

Intervención dirigida a

206 pacientes durante 10

módulos de intervención

y seguimiento a los 6,12

y 18 meses posteriores al tratamiento, con grupo de comparación, el cual no fue sometido a ninguna intervención.

Revisión sistemática de la
literatura en las siguientes bases de datos: PubMed, EMBase, PsycINFO y CENTRA. Se seleccionaron ocho estudios para el metaanálisis, cinco de ellos utilizaron técnicas de relajación (entrenamiento en respiración, relajación muscular e imaginación guiada) como parte de la intervención. En cinco estudios se observa el uso de técnicas de modificación cognitiva, mientras que el uso de la psicoeducación como parte de la intervención se destaca en tres de los estudios, la inclusión de las técnicas de modificación conductual (autocontrol y reforzamiento) se presentan en cuatro de los estudios analizados, en dos estudios diferentes se complementaba la intervención con técnicas como solución de problemas y entrenamiento en habilidades sociales. Con respecto a la duración de la intervención, oscilaban entre cinco y doce sesiones, con duración de entre 20 y 120 minutos, con lapsos de una a tres semanas entre sesión y sesión.
Los resultados arrojados por los ocho estudios corroboraron la eficacia de la TCC sobre la disminución en síntomas de depresión y ansiedad y aumento en la calidad de vida.
Se demostró la efectividad en la reducción de los síntomas de depresión, además de ofrecer una opción rentable de intervención viable con respecto costo-beneficio. 


\section{Autores (año)}

Ahmad, Wan,

Zainuddin y

Mohamad (2020)

\section{Objetivo}

Evaluar la efectividad de la TCC mediante una intervención dirigida a la reducción de sintomatología de depresión en pacientes con ERC en tratamiento de hemodiálisis.

\section{Estrategias}

A través de una búsqueda sistemática en la base de datos Scopus, se analizaron 10 estudios entre 2009 y 2019. Con base en los resultados analizados se menciona el uso de técnicas de relajación, restructuración cognitiva, psicoeducación y modificación conductual para la intervención en la reducción de sintomatología de depresión. Se destaca el uso de intervenciones breves que van desde cuatro hasta 12 sesiones, con seguimientos de seis, nueve y 12 meses para el monitoreo de los cambios a largo plazo.

La intervención basada en la TCC de cuatro a seis semanas dirigida a 40 pacientes adultos. Las técnicas utilizadas fueron psicoeducación, autocontrol, entrenamiento en relajación (respiración diafragmática, respiración rítmica y relajación muscular), así como técnicas de modificación cognitiva. Con respecto a la modalidad de intervención fueron semipresenciales, ya que se combinaron las sesiones cara a cara con llamadas telefónicas, además de incluir una sesión de seguimiento a los tres meses posterior a la intervención.
Los resultados mostraron modificaciones a nivel cognitivo y comportamental, indicando reducción en la depresión y la ansiedad, y aumentando las estrategias de autocuidado, siendo estos indicadores de una reducción en la fatiga consecuente de la enfermedad.
Los estudios incluían nueve estudios con grupo control y uno sin grupo de contrastación, las intervenciones desde la TCC mostraron evidencia sobre su efectividad en la reducción de los síntomas de depresión contrastada con los pacientes que no fueron sometidos a ninguna intervención psicológica. de una intervención basada en la TCC.

Nota: Elaboración propia.

Los estudios revisados han documentado la efectividad de las TCC en la reducción de la sintomatología de estrés, ansiedad, depresión y dolor, así como han demostrado el aumento en la calidad de vida y la adherencia terapéutica de pacientes con diagnóstico de ERC. Los estudios también han sugerido el uso de intervenciones multicomponentes, destacando la implementación de técnicas de relajación tales como el entrenamiento en respiración (diagramática y rítmica) y la relajación muscular progresiva para la reducción de respuestas fisiológicas, además de enfatizar el uso de la psicoeducación, de técnicas de modificación 
conductual (reforzamiento positivo y autocontrol) y técnicas de modificación cognitiva (reestructuración cognitiva). Si bien, son las técnicas de mayor aplicación, también se han incluido técnicas de entrenamiento en habilidades sociales y en solución de problemas con resultados efectivos.

Pese a las diferencias entre las características de las muestras, los contextos y la estructura de la intervención, entre otros elementos, los resultados de los estudios empíricos convergen en mostrar los beneficios de las técnicas de la TCC para el tratamiento psicológico de población con problemas crónicos de salud. Estas intervenciones estuvieron conformadas entre cuatro y 12 sesiones con una duración entre 20 y 120 minutos por sesión. Asimismo, se subraya la invariabilidad de los beneficios con relación a la modalidad en que se apliquen (presencial o remota).

Por lo anterior, esta guía ha sido diseñada considerando el uso de psicoeducación, técnicas de relajación, entrenamiento en solución de problemas y autoinstrucciones. Cabe mencionar que el uso de las autoinstrucciones no se sugiere tal cual en los estudios analizados; sin embargo, forman parte de las técnicas de la TCC que muestran beneficios en la modificación de conducta a través del autodiálogo, es decir, permiten la redirección del comportamiento $y$, por ende, la modificación del pensamiento consecuente.

Finalmente, se optó por la elaboración de una intervención breve de aproximadamente 10 sesiones, las cuales oscilarán entre 60 y 120 minutos por sesión semanal, ajustadas de acuerdo con las necesidades de cada paciente. La intervención incluye sesiones de seguimiento al mes, tres y seis meses posteriores a la intervención para monitorear el mantenimiento de los cambios. La guía ha sido diseñada para la aplicación remota dada las condiciones actuales sanitarias a causa de la pandemia.

\section{Propuesta de guía}

El objetivo de este apartado consiste en la descripción de una guía para el especialista en $M C$, que le permita implementar un programa multicomponente cognitivo conductual para el manejo de estrés en pacientes con ERC, caracterizado por el entrenamiento de diferentes técnicas tales como psicoeducación, alternativas terapéuticas centradas en relajación, autoinstrucciones y solución de problemas.

Aunque es una guía que recurre al uso de estrategias de intervención nomotéticas, el paciente es abordado desde un enfoque ideográfico, puesto que es evaluado desde el análisis funcional del comportamiento, que permite atender a las necesidades específicas del individuo. Al ser un tratamiento con enfoque de TCC, la relación y el trabajo entre paciente y terapeuta será colaborativo. Se dejarán tareas (ya sean registros o ejercicios) que se espera que el paciente realice de manera individual durante el tiempo entre sesiones. Adicionalmente, el terapeuta procurará aclarar las dudas siempre que se presenten. 
Aunado a ello, se debe destacar la flexibilidad de la guía, ya que a pesar de que a lo largo de la propuesta se describen los objetivos y sesiones de la intervención, es el especialista en MC quien toma las decisiones terapéuticas en función de los objetivos y necesidades de cada paciente, teniendo la posibilidad de implementar técnicas complementarias afines al modelo de la TCC.

\subsection{Justificación de modalidad en línea}

Dadas las condiciones actuales por la pandemia de SARS-COV-2 (COVID-19) y atendiendo a la emergencia sanitaria, la atención psicológica se ofrece en línea, con el apoyo de Tecnologías de Información y Comunicación (TIC's) mediante el uso de las plataformas Zoom ${ }^{\circledR}$ y Google ${ }^{\circledR}$ (Gmail y Google Forms). Por lo tanto, se hace mayor hincapié en salvaguardar la confidencialidad, privacidad, datos y expediente clínico. Además, se establece un protocolo en caso de perder conexión con el paciente en plena sesión.

Al igual que en la terapia presencial, este protocolo cuenta con diferentes etapas: 1) encuadre, 2) evaluación, 3) intervención, 4) mantenimiento, 5) seguimiento, 6) encuestas de opinión del servicio brindado, y 7) un protocolo de intervención en crisis (PAPS), las cuales se describen posteriormente.

\subsection{Objetivos}

\subsubsection{Generales}

Proporcionar al especialista en MC las directrices de la intervención cognitivo-conductual enfocada en disminuir el nivel de estrés en personas con diagnóstico de ERC. Mientras que el objetivo general del programa es disminuir el nivel de estrés presente en personas con diagnóstico ERC, a partir de una intervención cognitivo-conductual centrada en la adquisición de estilos de afrontamiento funcionales en situaciones de estrés.

\subsubsection{Específicos}

- Describir la conceptualización y contextualización de la ERC a nivel mundial y en México.

- Describir las condiciones bajo las cuales se manifiesta el estrés en la interacción de un individuo que vive con ERC y su contexto, desde el modelo propuesto por Lazarus y Folkman (1984).

- Analizar la evidencia científica que da cuenta de la eficacia de la Terapia Cognitivo Conductual para el abordaje del estrés y otras emociones relacionadas en personas que viven con ERC.

- Describir a detalle las pautas de evaluación e intervención bajo la Terapia Cognitivo Conductual en el tratamiento del estrés y otras emociones relacionadas en pacientes que viven con $\mathrm{ERC}$. 
- Proporcionar una serie de flujogramas para la toma de decisiones en la implementación del tratamiento desde la TCC para el abordaje del estrés y otras emociones relacionadas en personas que viven con ERC.

- Describir los mecanismos de acción del tratamiento considerando la modalidad online, de supervisión y de intervención en caso de presentarse una crisis en pacientes que viven con $E R C$ que reciban el tratamiento que se plantea en esta guía. 


\section{Segunda Parte}




\section{Un modelo de intervención supervisada en estrés (para terapeuta)}

\subsection{Generalidades}

Debido a la situación sanitaria del 2020, en general, las personas se han visto en la necesidad de desarrollar cambios comportamentales en sus rutinas y estilos de vida, a causa del confinamiento mantenido desde el mes de marzo del mismo año. Estos cambios ambientales (e.g., permanencia en casa) y conductuales (e.g., limitación de salidas, pérdida de rutinas diarias y restricciones en convivencia para seguir las recomendaciones sanitarias) se deben apegar a las nuevas recomendaciones del sistema de salud nacional: mantener distanciamiento social y evitar lugares concurridos y de probable alto contagio como clínicas y hospitales. Todos estos cambios propician un reto para toda la población.

El programa de Residencia en Medicina Conductual con sede en la Facultad de Estudios Superiores Iztacala (FES Iztacala) perteneciente al programa de Posgrado de Maestría y Doctorado en Psicología de la Universidad Nacional Autónoma de México (UNAM) suspendió actividades presenciales (prácticas profesionales) en las instalaciones hospitalarias como medida institucional con el objetivo de prevenir contagios. Aunque eso no significó que las actividades se paralizaran totalmente, solo se adoptaron medidas para las nuevas condiciones sociales.

Por lo anterior, y aunado a los nuevos retos que afronta la sociedad por la pandemia - los cuales propician nuevas necesidades-, a la incidencia de enfermedades crónicas en la población mexicana y a los objetivos del programa de MC, se planteó el desarrollo de una guía para la atención psicológica, centrada en el quehacer de un especialista en MC, atendiendo las necesidades actuales y considerando la implementación de TIC's para cumplir con los nuevos lineamientos de salubridad. 


\subsection{El modelo de supervisión}

El plan de estudios de la Maestría en Psicología tiene como propósito la formación de profesionales capaces de detectar, evaluar e intervenir en el entorno mediante un plan coherente, articulado y flexible. Esto se logra mediante la incorporación de los alumnos a programas de residencia con práctica profesional supervisada, en los escenarios donde se realiza el ejercicio de la profesión, promoviendo así el desarrollo de competencias in situ (Ayala et al., 1998). En esa misma línea, el plan de estudios de la residencia en MC señala que los egresados deberán contar con los conocimientos y competencias necesarios para prevenir y solucionar problemas prioritarios mediante la aplicación de técnicas, métodos y procedimientos idóneos que sustentan el quehacer disciplinario, tanto a nivel individual como grupal, integrado de manera equilibrada en sus diferentes actividades (Reynoso \& Seligson, 1998). Al referirnos al desarrollo de competencias profesionales, se hace énfasis en lo que el alumno hace a partir de lo aprendido, reflejando que lo esencial no es la posesión de determinados conocimientos, sino el uso que se haga de ellos. Por ello, el plan de estudios no podría haber sido desarrollado sin un sistema de supervisión.

La supervisión, en el contexto del plan de estudios de MC de la Facultad de Estudios Superiores Iztacala, fue concebida como una interacción de aprendizaje centrada en las competencias del supervisado, donde el supervisor — que posee habilidades clínicas avanzadas - se relaciona con sus supervisados y, como equipo de trabajo, realizan tareas de planeación, dirección y evaluación de la práctica asistencial de estos últimos, a través del trabajo en actividades clínicas profesionales (detección, evaluación, prevención, intervención e investigación) que garantizan la adquisición y el dominio de competencias profesionales en contextos de salud.

El objetivo de la supervisión consiste en que los alumnos alcancen estándares máximos en términos de ofrecer una adecuada calidad de los servicios para los individuos y la comunidad. Dentro de la supervisión, los alumnos adquieren conocimientos, habilidades y examinan sus propias creencias, actitudes y sentimientos respecto a los sujetos como individuos, y de estos con su familia y comunidad. Se pretende que los alumnos desarrollen progresivamente una identidad profesional. Así, la supervisión se constituye como una actividad fundamental en las actividades de servicio/investigación de la residencia. El sistema de supervisión de los residentes está formado por dos tipos de supervisores:

- Supervisor in situ. Es un psicólogo contratado por la Institución hospitalaria, cuyo compromiso con los residentes en formación consiste en responsabilizarse de los mismos en el escenario clínico, siguiendo los horarios, las políticas y los reglamentos de la institución sede y de la UNAM. Al menos un psicólogo de cada una de las instituciones hospitalarias colabora con el programa de residencia con la categoría de supervisor in situ. 
- Supervisor académico. Es un psicólogo posgraduado, profesor de la UNAM que acude semanalmente al hospital para trabajar con los alumnos en la discusión de casos clínicos y realizando sesiones de revisión bibliográfica; debe garantizar dos horas semanales de supervisión de los casos atendidos por cada alumno de los cuales es responsable. Esta figura fue creada para coadyuvar al aprendizaje de los alumnos. En conjunto con el supervisor in situ supervisan y evalúan al residente; como es personal externo a la sede, no puede llevar a cabo actividades clínicas ni de servicio dentro de las instalaciones hospitalarias.

La supervisión académica tiene como propósito proporcionar al residente de MC estrategias y habilidades teórico-prácticas que favorezcan su desempeño. El supervisor tiene la responsabilidad, a través de los diferentes métodos y tareas asignadas, de encontrar, valorar y apoyar las habilidades inherentes del supervisado; buscando favorecer su autonomía en lo concerniente al trabajo clínico.

Para cumplir con las funciones señaladas anteriormente, se requiere que supervisor y supervisados desarrollen un programa de entrenamiento secuencial que inicia en las instalaciones universitarias, en donde se realizan las siguientes actividades: la revisión bibliográfica de distintas estrategias de recolección de información y aplicación de estrategias terapéuticas, acompañado de sesiones de discusión de las mismas; posteriormente, el modelado de algunas estrategias por parte del supervisor y la práctica entre los supervisados, donde el supervisor observa, señala y retroalimenta; además se llevan a cabo sesiones de práctica videograbada, donde se incluye juego de roles, con el propósito de retroalimentar a los supervisados, además de promover en ellos la autoobservación. Posteriormente, se acude a las instalaciones hospitalarias en donde se desarrolla un modelo de supervisión en cascada entre los dos grupos de alumnos, supervisora in situ y supervisor académico. Dentro de la sede hospitalaria se revisa y retroalimenta la elaboración de notas clínicas, se presentan y discuten los casos clínicos y se monitorea el trabajo clínico. La figura 6 ejemplifica este apartado.

\subsubsection{Uso de las TIC's para la supervisión}

A finales del siglo XX se empezó a realizar la práctica de la psicología a distancia; se utilizó el término telepsicología, derivado del término telesalud (del inglés telehealth) y en este incluían la supervisión de la práctica clínica. Nickelson (1998) definió la telesalud como el uso de las telecomunicaciones y la tecnología de la información para proveer acceso a la evaluación, el diagnóstico, la intervención, la consulta, la supervisión, la educación y la información a distancia. Y se agregó el término telesalud conductual entendiéndolo como la aplicación de esta misma tecnología para proveer servicios de salud conductual. A partir de este momento se acepta que los profesionales involucrados en la educación y la supervisión de estudiantes de posgrado deben adentrarse en este campo e integrarlo para el entrenamiento (Myers, Endres, Ruddy, \& Zelikovsky, 2012). 


\section{Figura 6}

Flujograma de supervisión en el Programa de residencia en MC

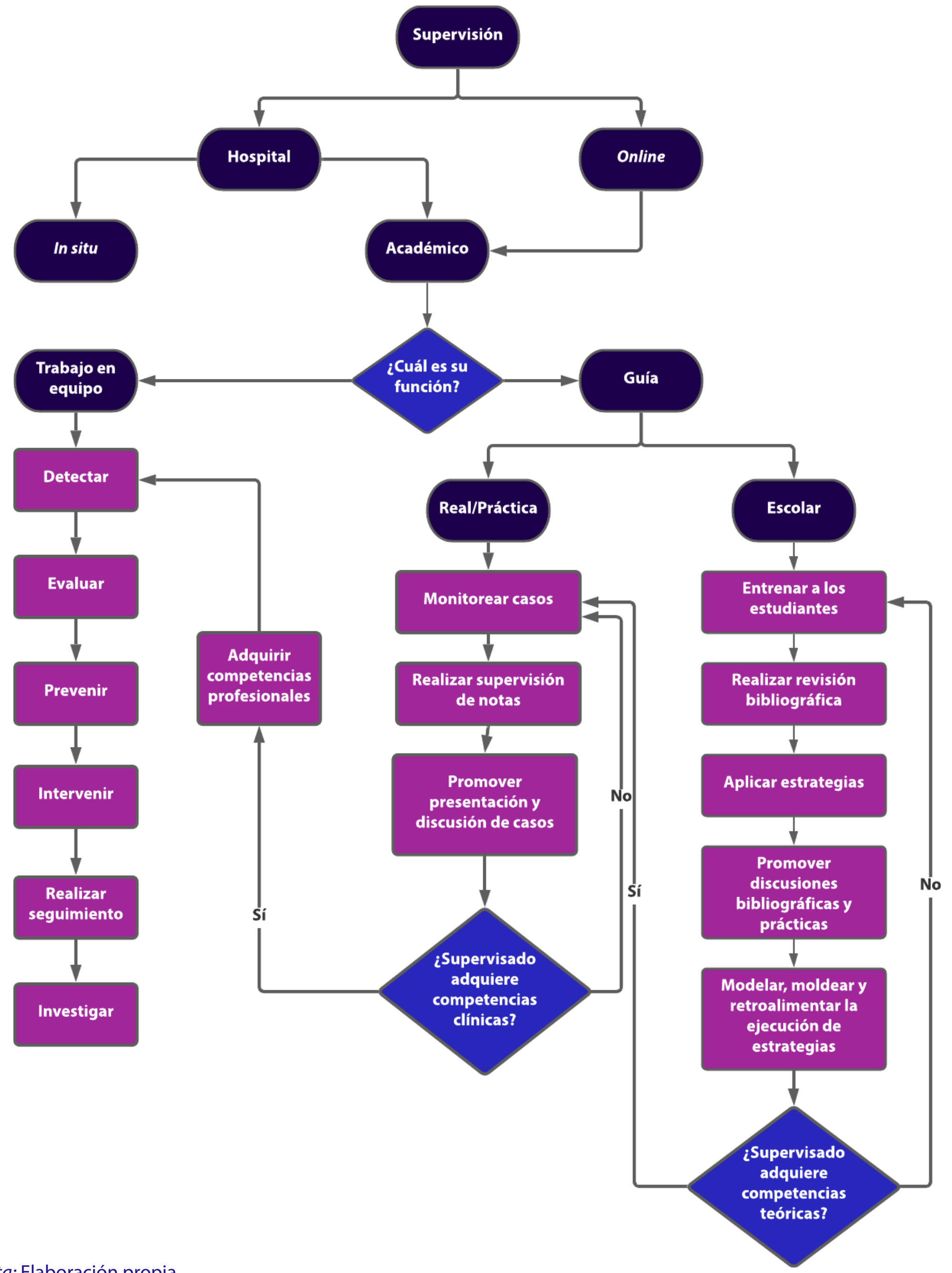

Nota: Elaboración propia. 
Los supervisores de MC han utilizado distintas TIC's, centrándose inicialmente en el correo electrónico; entre 2009 y 2011 se desarrolló un proyecto denominado Desarrollo de un sistema de tutoría y supervisión online para la residencia en Medicina Conductual, designado con las siglas PE301409 apoyado con recursos de la Dirección General de Asuntos del Personal Académico en el marco del Programa de Apoyo a Proyectos para Innovar y Mejorar la Educación (PAPIME), donde se proponía realizar tutoría y supervisión online para proveer a los estudiantes de apoyos para fomentar su autonomía y mejorar sus habilidades, destrezas y competencias profesionales. Tras esta experiencia trunca se trabajó en el uso y aprovechamiento de distintas TIC's entre las que se puede señalar: los bancos de recursos, la videograbación del desempeño de los alumnos en situaciones de evaluación de competencias profesionales, el uso de un portafolio inicialmente desarrollado con Moodle ${ }^{\circledR}$ y, posteriormente, las aulas virtuales de la UNAM, la página web de la residencia', los sitios como Facebook ${ }^{\circledast}$, Twitter $^{\oplus}$, YouTube ${ }^{\oplus 2}$, Dropbox ${ }^{\oplus}$, Google Drive ${ }^{\oplus}$ para almacenar información o ponerla a disposición de alumnos y docentes. Después, se utilizó el WhatsApp ${ }^{\circledR}$ como una forma de mensajería asincrónica y, en los últimos seis meses, las videoconferencias —utilizando ZOOM ${ }^{\circledR}$ preferentemente-.

La supervisión vía electrónica permite observar la práctica del supervisado independientemente de la distancia geográfica; para ello, supervisor y supervisados deben prepararse para utilizar adecuadamente este tipo de recursos, siempre dentro del marco ético que rige la profesión. La supervisión de actividades clínicas online no dista mucho de la realizada de manera presencial; de hecho, comparte las mismas normas éticas (American Psychological Association [APA], 2014; Association of State and Provincial Psychology Boards, 2015; Consejo General de la Psicología, 2017; De la Torre \& Pardo, 2018; Joint Task Force for the Development of Telepsychology Guidelines for Psychologists, 2013). Esta modalidad de trabajo solo puede ser utilizada si las competencias de los supervisados fueron entrenadas inicialmente de manera presencial.

Los supervisores deben contar con una formación académica sólida que les permita fundamentar sus acciones en un marco teórico conductual (en un sentido amplio) y ser capaces de retroalimentar a los supervisados de una manera respetuosa, objetiva, clara y oportuna para fortalecer la relación colaborativa en el marco ético y legal correspondiente, y así propiciar conductas relacionadas con la responsabilidad en el trabajo.

Antes de realizar el trabajo clínico online se deben incluir prácticas sobre el manejo del equipo tanto para supervisores como para supervisados, mediante casos simulados utilizando el modelo de solución de problemas y toma de decisiones, todo ello con el propósito de manejar adecuadamente el ambiente electrónico y tener alternativas para resolver problemas durante la sesión.

1 https://www.medicinaconductual-unam-fesi.org

2 https://www.youtube.com/channel/UCuGUYoeylmaTvtR4ePGbmEQ/videos 
En una segunda etapa del entrenamiento supervisado, previo al trabajo con pacientes reales, deberá realizarse práctica con casos simulados, utilizando juego de roles, ejemplificando dilemas éticos para el análisis y discusión con el grupo de trabajo. Aunado a lo anterior, en este tipo de práctica deberá resaltarse el hecho de que, dependiendo de la tecnología, algunos comportamientos durante la entrevista pueden no ser notados, por lo que en la supervisión se debe resaltar la necesidad de prestar atención tanto a la conducta verbal del paciente como al comportamiento no verbal. Las resultantes del trabajo a distancia permiten escuchar más atentamente (Marrow, Hollyoake, Hamer, \& Kenrick, 2002). La supervisión utilizando las TIC's impacta positivamente en la relación entre el supervisor y los supervisados, ya que permite una discusión más franca de aspectos relacionados con el diagnóstico y el tratamiento (Wood, Miller, \& Hargrove, 2005).

\subsection{Acciones del terapeuta}

En la tabla 6 se describen las distintas acciones que el especialista en MC debe realizar durante la intervención en línea.

\section{Tabla 6}

Acciones del terapeuta en la intervención en línea

\section{Actividades}

Ofrecer apoyo psicológico al paciente con el uso de la plataforma digital (Zoom $\left.{ }^{\oplus}\right)$.

Resolver dudas con respecto a la utilización de la plataforma digital (Zoom ${ }^{\circledR}$ ).

Abrir expediente clínico del paciente.

Establecer componentes de relación con el paciente.

Enviar, explicar y resolver dudas sobre consentimiento informado.

Aplicar los instrumentos y escalas destinadas a complementar la evaluación inicial.

Iniciar entrevista conductual.

Identificar la conducta problema.

Realizar análisis funcional del comportamiento.

Establecer hipótesis funcionales.

Diseñar un plan de intervención en función de la conducta problema.

Redactar notas clínicas en formato SOAP.

Enviar y explicar los registros que se lleguen a utilizar en la terapia.

Revisar y retroalimentar la ejecución del paciente con respecto al registro.

Enviar y explicar los materiales psicoeducativos que se utilicen durante la terapia.

Realizar evaluación complementaria en caso de requerirlo y enviar enlaces de los instrumentos, escalas y checklists indicados.

Canalizar al paciente con otro especialista si es necesario.

Realizar intervención en crisis en caso de que se presente un episodio.

Agendar próxima cita con el paciente.

Nota: Elaboración propia. 


\subsection{Evaluación conductual}

Caracterizado por ser un proceso continuo que ocurre antes, durante y después de la intervención, permite la toma de decisiones clínicas, emplea una metodología conductual que incluye la medición de los parámetros de la conducta, así como la recolección de datos e información por medio de métodos como la observación directa, las entrevistas, los registros, los instrumentos, etc. (Bravo \& Mora, 2014; Fernández-Ballesteros, 2013).

De acuerdo con Ruíz, Díaz y Villalobos (2012), la evaluación conductual:

- Tiene una metodología de evaluación coherente con los supuestos básicos.

- Asigna un seguimiento al proceso de intervención para su monitoreo continuo.

- Proporciona elementos teóricos-prácticos para la formulación clínica de casos mediante el proceso de análisis funcional de la conducta.

\subsubsection{Instrumentos}

La aplicación de instrumentos permite obtener información sobre el paciente. Algunos de los instrumentos que se utilizan son cuestionarios, listas de verificación y escalas psicométricas. Los primeros hacen referencia a una serie de preguntas relacionadas con los datos sociodemográficos, historia y experiencias del paciente; las listas de verificación son aquellas que miden la ocurrencia o frecuencia de una serie de conductas; y las escalas psicométricas son escalas estandarizadas, confiables, validadas y que evalúan un constructo en particular, por ejemplo, estrés o estilos de afrontamiento.

En la tabla 7 se enlistan las listas de verificación empleadas durante la evaluación inicial.

\section{Tabla 7}

Listas de verificación de la evaluación inicial

\begin{tabular}{clll} 
Nombre & Breve Checklist de Afrontamiento (Anexo 2) & Checklist Síntomas de estrés (Anexo 3) \\
Autores & Abaroa, González, Ortega, Reyes y Reynoso (2020) & Reynoso y Seligson (2005) \\
\cline { 2 - 3 } Ítems & 10 & 28 \\
\cline { 2 - 3 } & $\begin{array}{l}\text { Evalúa estilo de afrontamiento; cinco están dirigidos } \\
\text { a la emoción y cinco centrados en el problema. }\end{array}$ & $\begin{array}{l}\text { Evalúa síntomas del estrés en los tres niveles de respuesta: } \\
18 \text { evalúan respuestas fisiológicas, cinco respuestas } \\
\text { conductuales y cinco respuestas cognitivas. }\end{array}$
\end{tabular}

Nota: Elaboración propia.

Por su parte, en la tabla 8 se describen las propiedades psicométricas de los instrumentos a utilizar en la evaluación inicial. 


\section{Tabla 8}

\section{Escalas de la evaluación inicial}

\begin{tabular}{|c|c|c|c|}
\hline Nombre & $\begin{array}{l}\text { Escala de Ansiedad y Depresión } \\
\text { Hospitalaria (HADS) (Anexo 4) }\end{array}$ & $\begin{array}{l}\text { Escala de estrés percibido } \\
\text { (PSS-14) (Anexo 5) }\end{array}$ & $\begin{array}{l}\text { Inventario de Estrategias de Afrontamiento (CSI) } \\
\text { (Anexo 8) }\end{array}$ \\
\hline Autores & Zigmond y Snaith (1983) & $\begin{array}{l}\text { Cohen, Kamarck } \\
\text { y Mermelstein (1983) }\end{array}$ & Cano, Rodríguez y García (2007) \\
\hline Ítems & 14 & 14 & 40 \\
\hline $\begin{array}{l}\text { Factores } 0 \\
\text { subescalas }\end{array}$ & $\begin{array}{l}\text { Ítems pares (7) corresponden a } \\
\text { la subescala de Depresión. } \\
\text { Ítems impares (7) corresponden } \\
\text { a la subescala de Ansiedad. }\end{array}$ & $\begin{array}{l}\text { Grado en que las situa- } \\
\text { ciones en la vida de uno } \\
\text { se evalúan como estre- } \\
\text { santes. }\end{array}$ & $\begin{array}{l}\text { Cuenta con ocho subescalas: 1) Resolución de pro- } \\
\text { blemas (estrategias cognitivas y conductuales en- } \\
\text { caminadas a eliminar el estrés modificando la situa- } \\
\text { ción que lo produce), 2) Reestructuración cognitiva } \\
\text { (estrategias cognitivas que modifican el significado } \\
\text { de la situación estresante), 3) Apoyo social (estrate- } \\
\text { gias referidas a la búsqueda de apoyo emocional), } \\
\text { 4) Expresión emocional (estrategias encaminadas a } \\
\text { liberar las emociones que acontecen en el proceso } \\
\text { de estrés), 5) Evitación de problemas (estrategias } \\
\text { que incluyen la negación y evitación de pensamien- } \\
\text { tos o actos relacionados con el acontecimiento es- } \\
\text { tresante), 6) Pensamiento desiderativo (estrategias } \\
\text { cognitivas que reflejan el deseo de que la realidad } \\
\text { no fuera estresante), 7) Retirada social (estrategias } \\
\text { de retirada de amigos, familiares, compañeros y } \\
\text { personas significativas asociadas con la reacción } \\
\text { emocional en el proceso estresante), y 8) Autocrítica } \\
\text { (estrategias basadas en la autoinculpación y la auto- } \\
\text { crítica por la ocurrencia de la situación estresante o } \\
\text { su inadecuado manejo). }\end{array}$ \\
\hline $\begin{array}{c}\text { Forma } \\
\text { de calificar }\end{array}$ & $\begin{array}{l}\text { Cada ítem utiliza una escala } \\
\text { tipo Likert del } 0 \text { al } 3 \text {. Para ambas } \\
\text { subescalas, la puntuación obte- } \\
\text { nida se interpreta de la siguien- } \\
\text { te manera: } 0 \text { - } 7 \text { = rango de nor- } \\
\text { malidad; } 8-10=\text { caso probable; } \\
11-21=\text { caso de ansiedad o de } \\
\text { depresión clínico. }\end{array}$ & $\begin{array}{l}\text { Formato de respues- } \\
\text { ta tipo Likert de cinco } \\
\text { opciones de respuesta } \\
\text { que varían de } 0 \text { "nunca" a } \\
4 \text { "siempre". Para obtener } \\
\text { la puntuación total en la } \\
\text { escala PSS-14 se deben } \\
\text { invertir las puntuaciones } \\
\text { de los ítems positivos } \\
\text { (4, 5, 6, 7, 9, } 10 \text { y 13) } \\
\text { para, posteriormente, } \\
\text { sumar los } 14 \text { elementos. } \\
\text { El rango de puntuación } \\
\text { varía entre } 0 \text { (mínimo } \\
\text { estrés percibido) y 56 } \\
\text { (máximo estrés percibi- } \\
\text { do). Los puntajes } 0-14 \\
\text { indican que casi nunca } \\
\text { o nunca está estresado; } \\
15-28, \text { de vez en cuando } \\
\text { está estresado; } 29-42, \text { a } \\
\text { menudo está estresado, } \\
\text { y } 43-56, \text { muy a menudo } \\
\text { está estresado. }\end{array}$ & $\begin{array}{l}\text { Al inicio, la persona describe de manera detallada } \\
\text { una situación estresante; después, contesta cada } \\
\text { ítem según una escala tipo Likert de cinco puntos } \\
\text { que define la frecuencia de lo que hizo en la situa- } \\
\text { ción descrita. Al final de la escala, contesta un ítem } \\
\text { adicional acerca de la autoeficacia percibida del } \\
\text { afrontamiento. }\end{array}$ \\
\hline
\end{tabular}




\begin{tabular}{|c|c|c|c|}
\hline $\begin{array}{l}\text { Propiedades } \\
\text { psicométricas } \\
\text { originales }\end{array}$ & $\begin{array}{l}\text { Esta escala posee un alfa de } \\
\text { Cronbach de } 0.85\end{array}$ & $\begin{array}{l}\text { El coeficiente de confia- } \\
\text { bilidad alfa para el PSS } \\
\text { fue } .84 \text { (para estudiantes } \\
\text { varones universitarios), } \\
.85 \text { (para estudiantes mu- } \\
\text { jeres universitarias) y } .86 \\
\text { (en la muestra para dejar } \\
\text { de fumar) en cada una de } \\
\text { las tres muestras. }\end{array}$ & $\begin{array}{l}\text { Los coeficientes alfa de Cronbach fluctuaron entre } \\
.70 \text { y } .86 \text { en las subescalas, siendo } .81 \text { el promedio. }\end{array}$ \\
\hline $\begin{array}{l}\text { Propiedades } \\
\text { psicométricas } \\
\text { en México }\end{array}$ & $\begin{array}{l}\text { En pacientes con enfermedad } \\
\text { cardiovascular mostrando uni- } \\
\text { dimensionalidad } a=.94 \\
\text { (Herrera et al., 2017). En pacien- } \\
\text { tes con ERC en hemodiálisis, } \\
\text { escala total a = .80, ansiedad a } \\
=.80 \text { y depresión a = .71 (Lugo, } \\
\text { Pérez, \& Sánchez, 2018). En } \\
\text { pacientes con diversos padeci- } \\
\text { mientos crónicos, a = .90 (An- } \\
\text { guiano, Mora, Reynoso, \& Vega, } \\
\text { 2017). En población con obesi- } \\
\text { dad, a = .82 (Morales, Alfaro, } \\
\text { Sánchez, Guevara, \& Vázquez, } \\
\text { 2007). }\end{array}$ & $\begin{array}{l}\text { Para mujeres mexicanas } \\
\text { puérperas la consisten- } \\
\text { cia interna fue de } 0.718 \\
\text { (Torres, Vega, Vinalay, } \\
\text { Arenas, \& Rodríguez, } \\
\text { 2015). Por su parte, la } \\
\text { consistencia interna de } \\
\text { los } 14 \text { ítems fue alta } \\
\text { (a = .79) en colegiados de } \\
\text { Monterrey (Moral \& } \\
\text { Cazares, 2014). En cuanto } \\
\text { a la consistencia interna } \\
\text { para universitarios, el } \\
\text { coeficiente alfa fue de } \\
.83, \text { la correlación de los } \\
\text { ítems con la escala total } \\
\text { fue adecuada, con la co- } \\
\text { rrelación más baja en el } \\
\text { ítem } 12 \text { ( } r=.25 \text { ) (Gonzá- } \\
\text { lez \& Ladero, 2007). }\end{array}$ & $\begin{array}{l}\text { Se validó por Nava, Ollua, Vega y Soria ( } 2010 \text { ) en } \\
\text { una muestra de tipo incidental de } 219 \text { participan- } \\
\text { tes voluntarios, } 31 \% \text { fueron hombres y } 69 \% \text { muje- } \\
\text { res, con un rango de } 17 \text { a } 34 \text { años. } \\
\text { En población mexicana: Ofrece niveles de consis- } \\
\text { tencia interna satisfactorios -entre .63 y .80-, } \\
\text { en la línea de los resultados de Cano et al. (2007) y } \\
\text { Nava et al. (2010). }\end{array}$ \\
\hline
\end{tabular}

Nota: Elaboración propia.

\subsubsection{Evaluación inicial}

La evaluación inicial es el primer paso en el proceso terapéutico. En un primer momento, establecer rapport con el paciente favorece la libre expresión de emociones, motiva al paciente a asistir a sesiones posteriores y le brinda la sensación de ser comprendido. El rapport es un elemento central para TCC, ya que el trabajo del terapeuta con el paciente se caracteriza por ser colaborativo. A continuación, se enlistan algunas recomendaciones propuestas por Labrador (2011) para favorecer la interacción terapeuta-paciente:

- Escuchar atentamente al paciente.

- Observar al paciente a los ojos.

- Tratar inicialmente de usted, a menos que el paciente sugiera lo contrario.

- Llamar al paciente por su nombre.

- Evitar realizar notas todo el tiempo.

- Evitar el uso de tecnicismos, sin abusar del lenguaje coloquial.

- Utilizar un tono de voz adecuado.

- Remarcar lo dicho por el paciente, donde se enfatice lo que el paciente siente y expresa.

- Evitar hacer juicios de valor e inferencias. 
Un aspecto importante en este proceso es la presentación del terapeuta, por lo que enseguida se enlistan algunos elementos a considerar:

- Vestimenta formal (blusa, camisa, vestido con un largo no menor a la mitad de la rodilla; usar bata y evitar el uso de accesorios grandes y llamativos).

- Peinado adecuado (cabello recogido o suelto, pero que se vea el rostro).

- Mostrar un fondo neutral (librero, pared blanca, pared con el título profesional).

- Indicar nombre (Soy el o la psicólogo(a)

- Indicar grado académico (Cuento con el grado de licenciado(a) en Psicología).

- Mencionar que forma parte del Posgrado en Psicología de la UNAM (Actualmente me estoy formando como maestro(a) en Psicología por la UNAM).

Posterior a la presentación del terapeuta y paciente se explica la dinámica de la terapia en línea, se aclaran dudas al respecto y se procede al envío del consentimiento informado. La figura 7 muestra el proceso para iniciar la evaluación.

\subsubsection{Entrevista conductual}

Acorde a la definición de la APA (2020), la entrevista conductual (EC) es un enfoque de la entrevista clínica que se centra en recabar información relacionada con la conducta problema, los estímulos antecedentes y las consecuencias del refuerzo. De acuerdo con FernándezBallesteros (2013), en la EC se debe recoger la información de los datos sociodemográficos del paciente, posteriormente, el motivo de consulta y los datos potencialmente relacionados con la situación problema.

La EC forma parte de los elementos más relevantes del proceso terapéutico, puesto que además de obtener información del paciente permite la identificación de las relaciones funcionales de la conducta problema (Consejo General de la Psicología, 2017). Para Perpiña (2012), el terapeuta debe tener un estilo directivo en la ejecución de la EC, respetando los principios de privacidad y confidencialidad, y manteniendo una actitud ética y profesional.

Si bien existen diversos formatos para la aplicación de la EC, los elementos que son necesario abordar son los descritos en la tabla 9.

Al finalizar la EC es necesario realizar un cierre, que implica hacer un resumen de la sesión, mencionar la utilidad de la información obtenida, aclarar dudas, retroalimentar, reforzar al paciente y agendar la próxima sesión, culminando con agradecer y despedir al paciente. 


\section{Figura 7}

\section{Flujograma de evaluación}

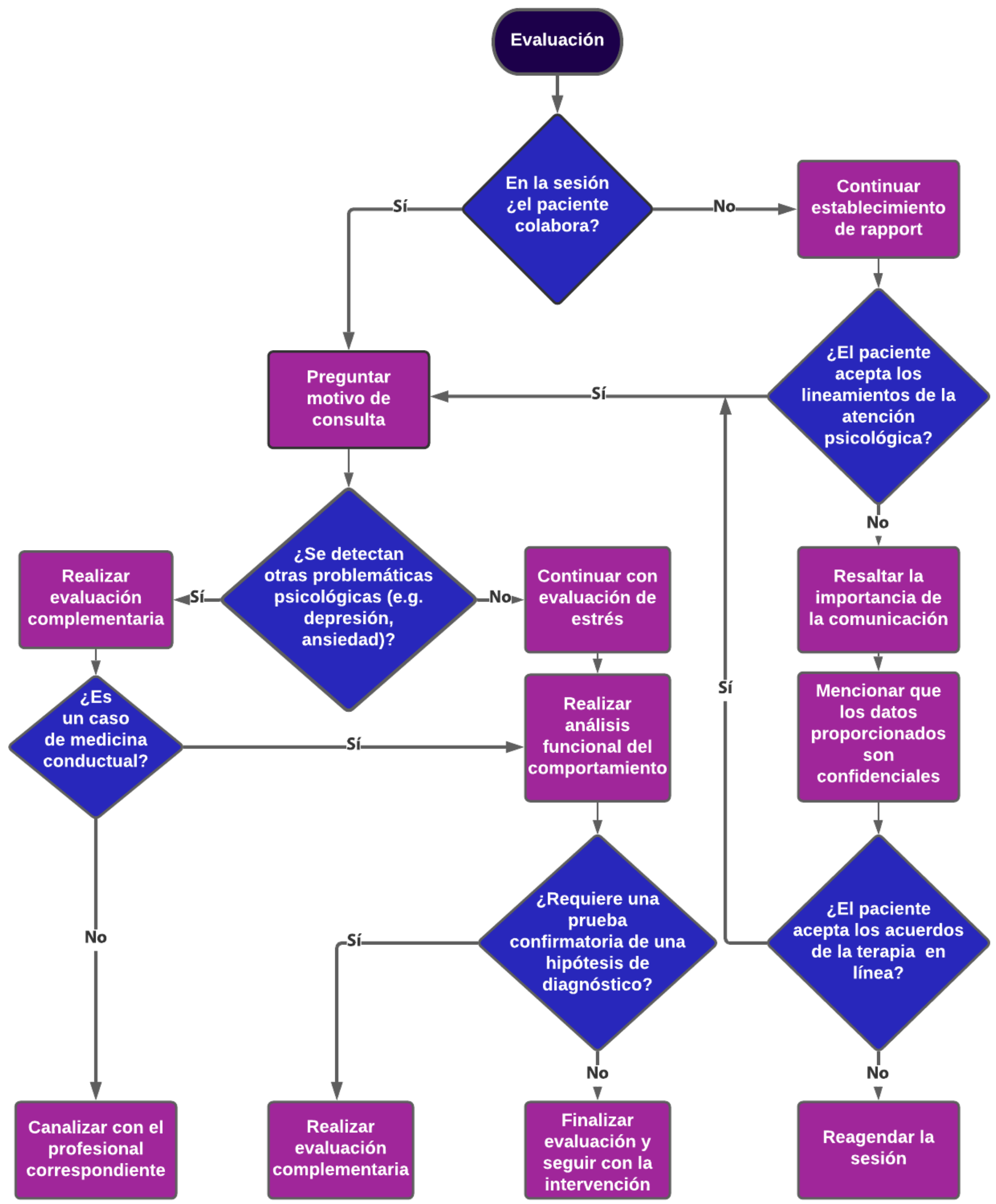

Nota: Elaboración propia. 


\section{Tabla 9}

Elementos de la entrevista conductual

\begin{tabular}{ll} 
Datos sociodemográficos & \multicolumn{1}{c}{$\begin{array}{c}\text { Elementos } \\
\text { Nombre del paciente, edad, lugar de origen y residencia, religión, ocupación, estado civil, } \\
\text { hijos, escolaridad y padecimientos médicos. }\end{array}$} \\
\hline Análisis del problema actual & $\begin{array}{l}\text { Identificación y descripción detallada de la conducta problema, se deberán incluir } \\
\text { datos en los tres niveles de respuesta; motor, cognitivo y fisiológico, así como detallar } \\
\text { los estímulos antecedentes y consecuentes. Cuantificar la conducta a través del uso de } \\
\text { parámetros como: frecuencia, duración, intensidad, geografía, entre otras. }\end{array}$ \\
\hline Historia de la enfermedad & $\begin{array}{l}\text { Antecedentes heredofamiliares, comorbilidades, tiempo del diagnóstico, tratamientos } \\
\text { invasivos previos y tratamientos farmacológicos. }\end{array}$ \\
\hline Tratamientos previos y actuales & $\begin{array}{l}\text { Será necesario contemplar todos los tratamientos tanto farmacológicos como } \\
\text { (médicos/psiquiátricos/ psicológicos) }\end{array}$ \\
$\begin{array}{l}\text { no farmacológicos y sustitutivos: medicamentos, alimentación, actividad física, } \\
\text { procedimiento de diálisis, hemodiálisis o trasplante renal. En caso de haber recibido } \\
\text { tratamiento psicológico o psiquiátrico indagar motivo. }\end{array}$ \\
\hline Consumo de sustancias & $\begin{array}{l}\text { Evaluar si existen hábitos nocivos para la salud como el consumo de alcohol, drogas y } \\
\text { tabaco, contemplando parámetros de la conducta. }\end{array}$ \\
\hline Objetivos y expectativas del paciente & $\begin{array}{l}\text { Indagar sobre los objetivos y expectativas de la intervención psicológica con la finalidad } \\
\text { de evaluar si son realistas y plausibles (metas a corto, mediano y largo plazo). }\end{array}$ \\
\hline Recursos y limitaciones & $\begin{array}{l}\text { Ambos aspectos son elementos que permiten que el proceso terapéutico se logre o se } \\
\text { dificulte, por lo que se deberá evaluar los recursos como las estrategias de afrontamiento } \\
\text { y el apoyo social y las limitaciones como el tipo de abstracción de la información. }\end{array}$ \\
\hline
\end{tabular}

Nota: Elaboración propia.

\subsubsection{Análisis funcional del comportamiento (AFC)}

El análisis funcional del comportamiento (AFC) es aquel que permite identificar las relaciones funcionales entre la conducta y el contexto. A su vez, facilita la organización de la información recabada, la redacción de los objetivos terapéuticos en función de la problemática, el desarrollo de hipótesis funcionales y la selección de las técnicas a implementar en la intervención. De acuerdo con Kaholokula, Bello, Nacapoy y Haynes (2009), estas son algunas características del AFC: identifica las variables relevantes, controlables y causales que están funcionalmente relacionadas con la conducta problema, es flexible $y$, por ende, susceptible de modificación con el paso del tiempo, considera la posible existencia de otras relaciones funcionales, incluye amplios sistemas sociales, es decir, considera todos los contextos en los que el paciente se encuentra inmerso y es compatible con un enfoque constructivo, ya que a partir de las habilidades y déficits identificados en la evaluación se plantean los objetivos de intervención.

\subsubsection{Evaluación complementaria}

En ocasiones, a pesar de realizar el proceso de evaluación comprendido como aplicación de instrumentos, entrevista y AFC, el terapeuta puede necesitar información adicional o 
comprobar una hipótesis de diagnóstico psicológico para propiciar su tratamiento con alternativas terapéuticas o canalizarlo. Esto podría realizarse en caso de trastornos de ansiedad, depresión o problemáticas referentes a habilidades sociales.

Respecto a la necesidad de profundizar sobre algunos datos del paciente y de la conducta problema, se deben identificar aquellos vacíos de información en el AFC y retomar la entrevista conductual con el fin de abordarlos. En el caso de requerir una prueba confirmatoria de una hipótesis de diagnóstico, se emplearán escalas adicionales para propiciar la toma de decisiones terapéuticas acorde a la problemática y necesidades del paciente. Las listas de verificación propuestas para esta evaluación se presentan en la tabla 10.

\section{Tabla 10}

\section{Listas de verificación para la evaluación complementaria}

\begin{tabular}{|c|c|c|}
\hline Nombre & Ansiedad A (Anexo 6) & Ansiedad B (Anexo 7) \\
\hline Autores & Adaptado de Reynoso y Becerra (2013) & Reynoso (2002) \\
\hline Ítems & 19 & 23 \\
\hline Factores & Evalúan respuestas fisiológicas, conductuales y cognitivas. & Evalúan respuestas fisiológicas. \\
\hline
\end{tabular}

Nota: Elaboración propia.

En la tabla 11 se presentan las escalas seleccionadas para esta evaluación junto con sus propiedades psicométricas.

\section{Tabla 11}

\section{Escalas para la evaluación complementaria}

\begin{tabular}{|c|c|c|c|}
\hline Nombre & $\begin{array}{l}\text { Kidney Disease Quality of Life Short } \\
\text { Form } 36 \text { (Anexo 9) }\end{array}$ & $\begin{array}{l}\text { Versión Actualizada de la Escala de } \\
\text { Adherencia Terapéutica (Anexo 10) }\end{array}$ & $\begin{array}{l}\text { Medication Adherence Report Scale } \\
\text { (MARS) (Anexo 11) }\end{array}$ \\
\hline Autores & $\begin{array}{l}\text { Hays, Kallich, Mapes, Coons } \\
\text { y Carter (1994) }\end{array}$ & Pedraza-Banderas y Valero (2018) & Horne y Hankins (2002) \\
\hline Ítems & $\begin{array}{l}43 \text { ítems específicos para enferme- } \\
\text { dades renales y una encuesta de } \\
\text { salud de } 36 \text { ítems que proporciona } \\
\text { un núcleo genérico y un ítem de } \\
\text { calificación de salud general. }\end{array}$ & 30 & $\begin{array}{l}\text { Original } 10 \\
\text { México } 7\end{array}$ \\
\hline $\begin{array}{l}\text { Factores o } \\
\text { subescalas }\end{array}$ & $\begin{array}{l}\text { SF36 presenta ocho subescalas: } \\
\text { 1) Funcionamiento físico, 2) Papel } \\
\text { físico, 3) Dolor, 4) Salud general, } \\
\text { 5) Bienestar emocional, 6) rol } \\
\text { emocional, 7) Funcionamiento } \\
\text { social, y 8) Energía/cansancio. }\end{array}$ & $\begin{array}{l}16 \text { evalúan atención médica y } \\
\text { cumplimiento de recomendaciones } \\
\text { efectuadas por el personal sanitario; } \\
\text { seis cambios en estilo de vida; ocho } \\
\text { situaciones de barrera o aspectos } \\
\text { que interfieren ante la adherencia. }\end{array}$ & $\begin{array}{l}\text { Evalúa el patrón de conductas de } \\
\text { falta de adherencia al tratamiento. } \\
\text { La versión original cuenta con } \\
\text { nueve ítems de falta de adherencia } \\
\text { intencional y uno no intencional. En } \\
\text { la versión de México solo son siete } \\
\text { de tipo intencional. En el mundo se } \\
\text { ocupan versiones de cinco ítems. }\end{array}$ \\
\hline
\end{tabular}




\begin{tabular}{|c|c|c|c|}
\hline $\begin{array}{c}\text { Forma } \\
\text { de calificar }\end{array}$ & $\begin{array}{l}\text { El componente genérico del KD- } \\
\text { QOL-36 (ítems 1-12) es el SF-12, el } \\
\text { cual permite obtener dos puntajes } \\
\text { generales: el Resumen del Compo- } \\
\text { nente Físico (PCS) y el Resumen del } \\
\text { Componente Mental (MCS). } \\
\text { El componente específico del } \\
\text { KDQOL-36 (ítems 13-36) permite } \\
\text { obtener los puntajes de las subesca- } \\
\text { las específicas carga; síntomas/pro- } \\
\text { blemas, y efectos de la enfermedad } \\
\text { renal (Zúñiga et al., 2009). }\end{array}$ & $\begin{array}{l}\text { Se responde con una escala tipo Li- } \\
\text { kert de cinco opciones de respuesta } \\
\text { para frecuencia. }\end{array}$ & $\begin{array}{l}\text { Cuenta con un formato de respuesta } \\
\text { tipo Likert de cinco puntos, que va } \\
\text { de: "siempre" a "nunca". El puntaje } \\
\text { total de la escala se obtiene } \\
\text { sumando cada ítem, lo que implica } \\
\text { que a mayor puntuación-mayor } \\
\text { adherencia. En la versión de México } \\
\text { son solo cuatro opciones de } \\
\text { respuesta y va de "siempre lo hago } \\
\text { así" a "nunca lo hago así". }\end{array}$ \\
\hline $\begin{array}{l}\text { Propiedades } \\
\text { psicométricas } \\
\text { originales }\end{array}$ & $\begin{array}{l}\text { La consistencia interna del instru- } \\
\text { mento fue aceptable, con valores } \\
\text { de coeficiente alfa de } 0.7 \text { en } 12 \text { de } \\
\text { las } 18 \text { subescalas (rango 0.4-0.9). La } \\
\text { validez de constructo fue aceptable, } \\
\text { especialmente en el componente } \\
\text { genérico SF36, con coeficientes de } \\
\text { correlación de } 0.5 \text { para la mayoría } \\
\text { dimensiones. El instrumento com- } \\
\text { pleto presentó un coeficiente alfa } \\
\text { de Cronbach de } 0.925\end{array}$ & $\begin{array}{l}\text { Los factores explican } 44 \% \text { de la } \\
\text { varianza, con una alta confiabilidad } \\
\text { ( } a=0.890)\end{array}$ & La versión original tiene un $a=.85$ \\
\hline $\begin{array}{l}\text { Propiedades } \\
\text { psicométricas } \\
\text { en México }\end{array}$ & $\begin{array}{l}\text { Se validó en México por Dehesa, } \\
\text { Correa, Olvera, González, Baizabal } \\
\text { y Orozco (2016), en una muestra } \\
\text { de } 194 \text { pacientes mayores de edad, } \\
\text { con diagnóstico de ERC que se } \\
\text { encontraban en tratamiento de } \\
\text { hemodiálisis, de diferentes regiones } \\
\text { geográficas del país, clínicamente } \\
\text { estables y con al menos un mes en } \\
\text { tratamiento. }\end{array}$ & Se realizó en México. & $\begin{array}{l}\text { Se realizó en México en pacientes } \\
\text { asmáticos, su único factor explica } \\
\text { el } 47 \% \text { de la VTE y cuenta con un } \\
\mathrm{a}=.85 . \text { La estructura muestra una } \\
\text { buena bondad de ajuste }(\mathrm{X} 2= \\
20356, \mathrm{p}=.061, \mathrm{X} 2 / \mathrm{gl}=1.69, \\
\mathrm{RMSEA}=.062, \mathrm{GFI}=.971, \mathrm{AGFI}= \\
.933, \mathrm{TLI}=.963, \mathrm{NFI}=.951 \text { y CFI }= \\
.97)(\text { Lugo \& Vega, 2020). }\end{array}$ \\
\hline
\end{tabular}

Nota: Elaboración propia.

\subsection{Canalización}

Es necesario que durante la entrevista inicial se recaben los datos que confirmen el diagnóstico médico de enfermedad crónica descrita en la primera parte, así como la presencia de sintomatología de estrés derivada o no del padecimiento médico. Si durante la evaluación inicial el MC identifica problemáticas de otra índole deberá canalizar con el especialista de la salud correspondiente, como son en los casos de:

- Presencia de otros problemas clínicos como violencia, trastorno de abuso de sustancias, trastornos de ansiedad, etc., o que requieran atención psiquiátrica.

- Presencia de problemas clínicos como depresión mayor, ideación o intento suicida, trastornos alimenticios u otros trastornos psiquiátricos que requieren el apoyo de un especialista en psiquiatría.

- Presencia de comorbilidad con trastornos cromosómicos o que afecten el desarrollo cognitivo del paciente. 
- Apoyo complementario de algún especialista en nutrición como nutriólogo o bariatra.

- Al respecto, se presenta la figura 8 , donde se puede observar el flujograma que facilita la toma de decisiones respecto a la canalización.

\section{Figura 8}

Flujograma de canalización

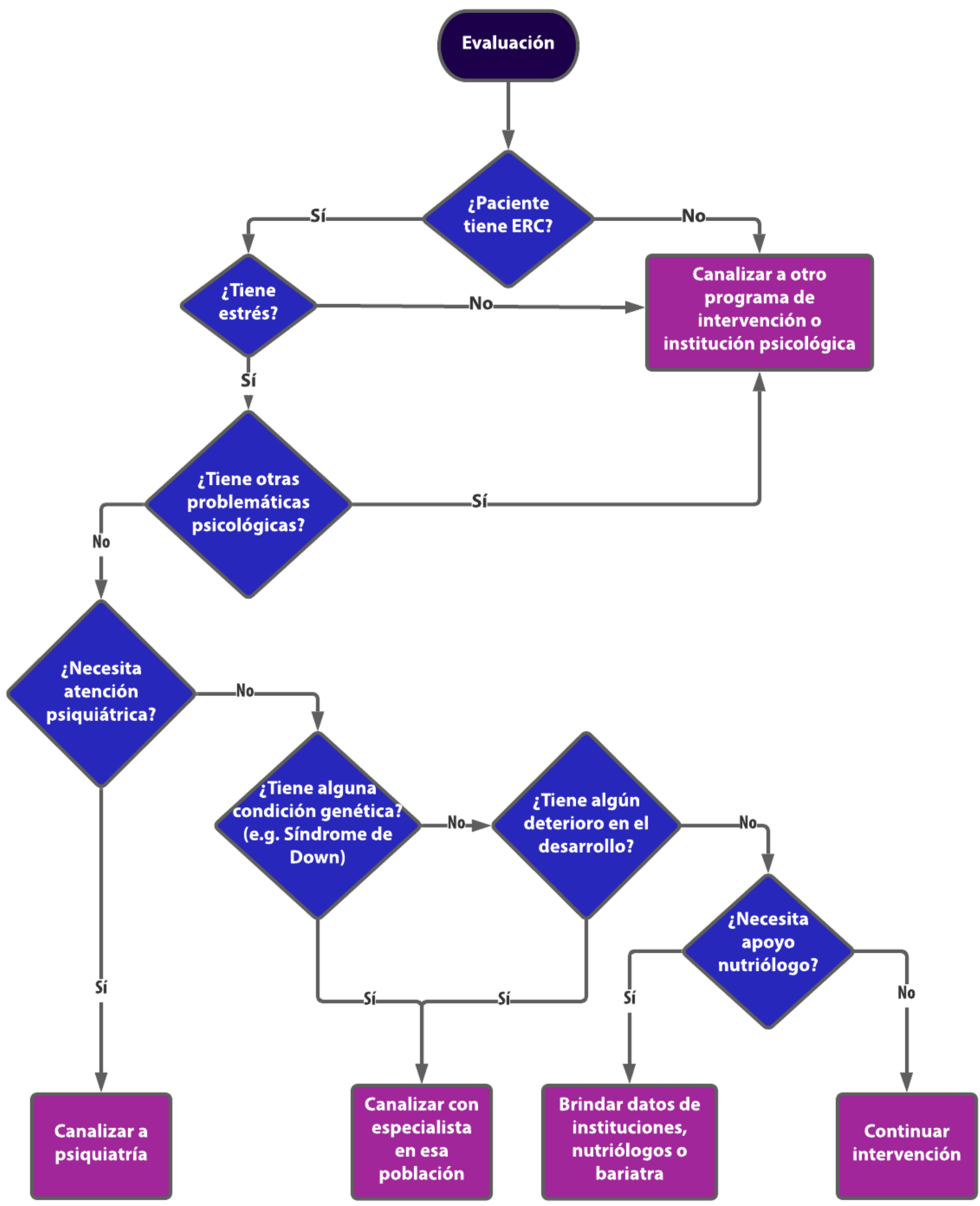

Nota: Elaboración propia. 


\subsection{Planeación de la intervención}

Sin restar importancia a los demás elementos descritos en esta guía, la intervención resulta ser el punto medular de este documento, ya que en este apartado se definen las acciones a seguir en el proceso terapéutico. Los programas de intervención multicomponente bajo la TCC han resultado ser efectivos para atender pacientes con enfermedades crónico-degenerativas y con diversas problemáticas psicológicas, por ejemplo, brindar atención a pacientes con ERC y estrés. En el caso particular de esta intervención, se implementarán técnicas como psicoeducación, relajación, autoinstrucciones y solución de problemas. El objetivo principal es que el paciente haga uso de sus recursos personales para afrontar las situaciones evaluadas como estresantes y así tener el control de estas y de su propia enfermedad.

Por último, es imperante resaltar que la intervención estará ajustada en función de las características del paciente con la finalidad de brindar una atención individualizada.

\subsubsection{Identificación de áreas problema}

Una de las posibilidades que pueden ocurrir en el contacto inicial con el paciente es que presente problemáticas simultáneas al estrés; por lo que a través de las pruebas psicométricas validadas y estandarizadas, pero principalmente por el AFC, el terapeuta identificará la conducta problema analizándola en términos de excesos y déficits conductuales, y con el respaldo de los instrumentos de evaluación. Con base en el AFC, se implementan distintas estrategias de intervención a partir del conjunto de técnicas conductuales para alcanzar las metas terapéuticas de información, control y apoyo (Kaholokula, Godoy, O’Brien, Haynes, \& Gavino, 2013).

\subsubsection{Selección de estrategias}

Dada la flexibilidad de la guía, la selección de estrategias debe respetar la idiosincrasia del paciente, eligiendo aquellas estrategias que cubran las necesidades específicas para cada individuo y que permitan conseguir los objetivos generales y específicos de la intervención. Al realizar intervenciones individualizadas, la meta final es solucionar la problemática evaluada. Uno de los aspectos que posibilita el éxito de la intervención es la evaluación y el monitoreo continuo, ya que esto permite que, de ser necesario, el terapeuta realice ajustes y, con ello, prevenga las recaídas o el abandono de la intervención (Marín \& Mosteiro, 2012).

Para fines prácticos, en esta guía se seleccionaron técnicas para el manejo del estrés que incluyen estrategias para: (a) brindar información que favorezca el cambio conductual, (b) el manejo de las respuestas fisiológicas, y (c) el afrontamiento. Es relevante mencionar que todas las estrategias fueron seleccionadas con base en la evidencia sobre su efectividad en población con ERC, si bien la guía recomienda un programa de intervención que integra técnicas tales como la psicoeducación, el entrenamiento en relajación, las autoinstrucciones y la técnica de solución de problemas; también contempla, si es necesario, el uso de técnicas 
complementarias. Con fines de evaluar la efectividad de las técnicas se recomienda diseñar un plan de seguimiento y estrategias de automonitoreo.

\subsubsection{Selección de las TIC's}

En la actualidad, el uso de las TIC'S en el proceso de enseñanza y aprendizaje ha sido de gran ayuda, ya que ha posibilitado el acceso remoto (temporal o atemporal) a múltiples usuarios; su utilización racional debe tener en cuenta algunos criterios al seleccionar dichos recursos para mantener la calidad en el desarrollo profesional (Cárdenas, 2013). Hoy en día y ante las innovaciones tecnológicas, los profesionales en psicología clínica y de la salud han incursionado en el uso de aplicaciones para ofrecer tratamientos a las personas que lo necesiten y que por diversas situaciones no puedan acceder a estos tratamiento de manera presencial. El uso de las intervenciones vía remota ha sido una alternativa de gran utilidad, así como otras tecnologías de telecomunicaciones, pues además de ser de fácil acceso, la portabilidad y la personalización tienen gran beneficio y ventajas en el paciente, ya que se percibe seguridad, control y confiabilidad; es una tendencia que cubre las necesidades de la sociedad en el siglo XXI, por lo tanto, el rápido avance tecnológico obliga a los profesionales de la salud a la implementación de estas herramientas como apoyo terapéutico o como vía (De Barcelona et al., 2009).

Esta guía está elaborada para implementarse por vía remota, por lo cual se seleccionó

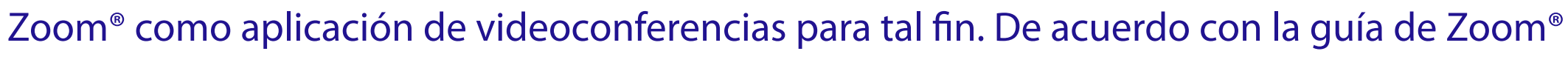
(2020), esta es una plataforma online de videoconferencia en alta definición, que cuenta con diversas funciones como el compartir escritorio, pizarra, chat, grabación, sistema telefónico y compartir documentos, es de fácil acceso y está disponible para dispositivos móviles, tabletas y equipos de cómputo, que cuentan con acceso a internet, solo es necesario instalar la aplicación, además que en su versión gratuita permite reuniones de hasta 60 minutos, encuentros seguros y privados, agendados, lo cual lo convierte en una herramienta de fácil acceso para la utilización en la aplicación de intervenciones terapéuticas.

Igualmente, para la evaluación de las variables psicológicas se utilizará una aplicación para la elaboración y aplicación de formularios, a través de Google Forms ${ }^{\oplus}$ —aplicación para crear encuestas y cuestionarios online, que permite enviarlos-, que es compatible con todos los sistemas operativos disponibles y no tiene ningún costo ni limitaciones en su uso.

Finalmente, con el objetivo de aprovechar la accesibilidad de las TIC's en la intervención, se seleccionó una aplicación móvil para favorecer el entrenamiento en relajación, la cual está disponible para el sistema operativo de iOS y Android, BreatheSync ${ }^{\circledast}$ y Breathe ${ }^{\oplus}$, respectivamente. Adicionalmente, se utilizará una aplicación para la medición de pulso cardiaco, la cual puede ser Heart Rate Free ${ }^{\circledast}$ (para sistema operativo iOS) o Ritmo cardíacoMonitor $^{\circledast}$ (para sistema operativo Android). A pesar de tener un nombre diferente, el manejo y contenido de la aplicación es similar, motivo por el cual se seleccionaron. La utilización de 
la aplicación se hace basada en el biofeedback, que permitirá a los usuarios complementar el entrenamiento en relajación, específicamente en respiración, y obtener datos instantáneos de su desempeño. En otras palabras, el usuario obtendrá retroalimentación sobre su ejecución y los resultados en su organismo.

\subsubsection{Normatividad}

La intervención psicológica al ser online deben considerarse elementos relacionados con: (a) cómo será la comunicación con el paciente ante la solicitud del servicio psicológico, como se puede observar en la figura 9; (b) ausencias por parte del paciente en la sesión, como se puede ver en la figura 10; (c) canalizar al paciente con algún especialista, como se observa en la figura $11 ;(d)$ qué pasaría si hubiesen fallas en la conexión a internet y la sesión se viese interrumpida, como se describe en la figura 12; y (e) ante qué situaciones se daría de baja o de alta al paciente, cuántas inasistencias estarían permitidas, como se puede observar en las figuras 13 y 14.

\section{Figura 9}

Flujograma de solicitud de intervención psicológica

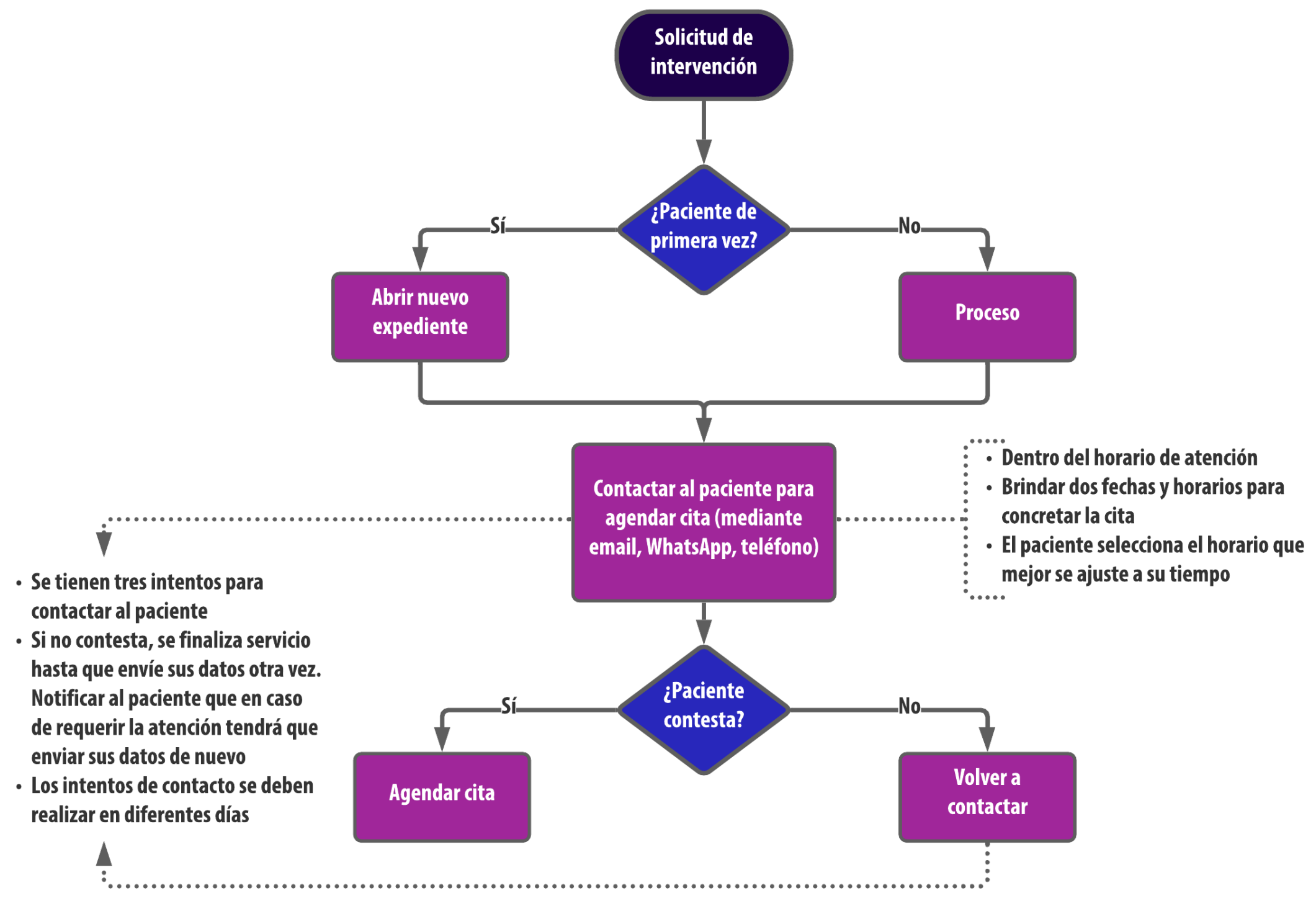

Nota: Elaboración propia. 
Figura 10

Flujograma sobre inasistencia del paciente a la sesión

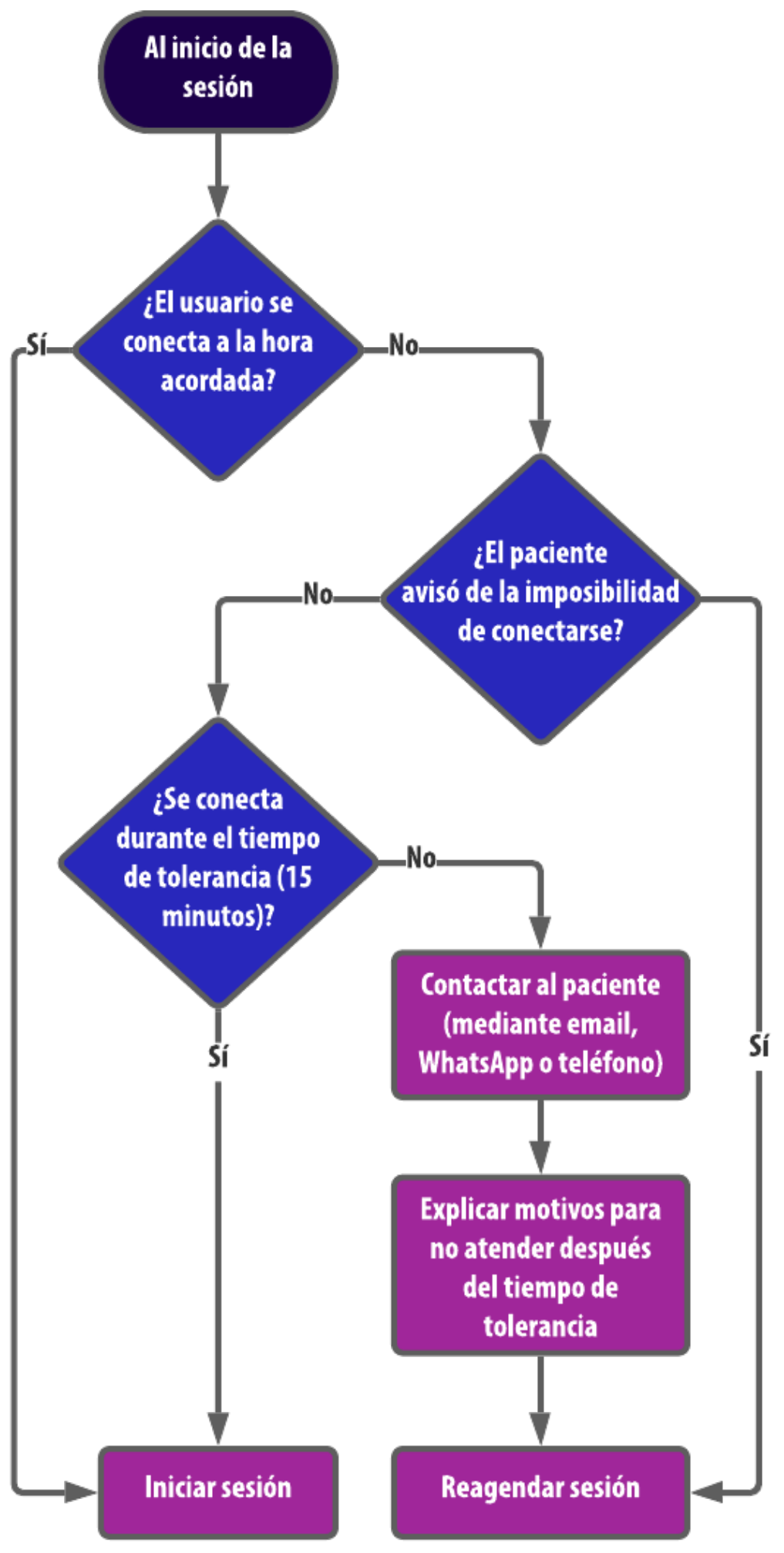

Nota: Elaboración propia. 
Figura 11

Flujograma de canalización con otros especialistas

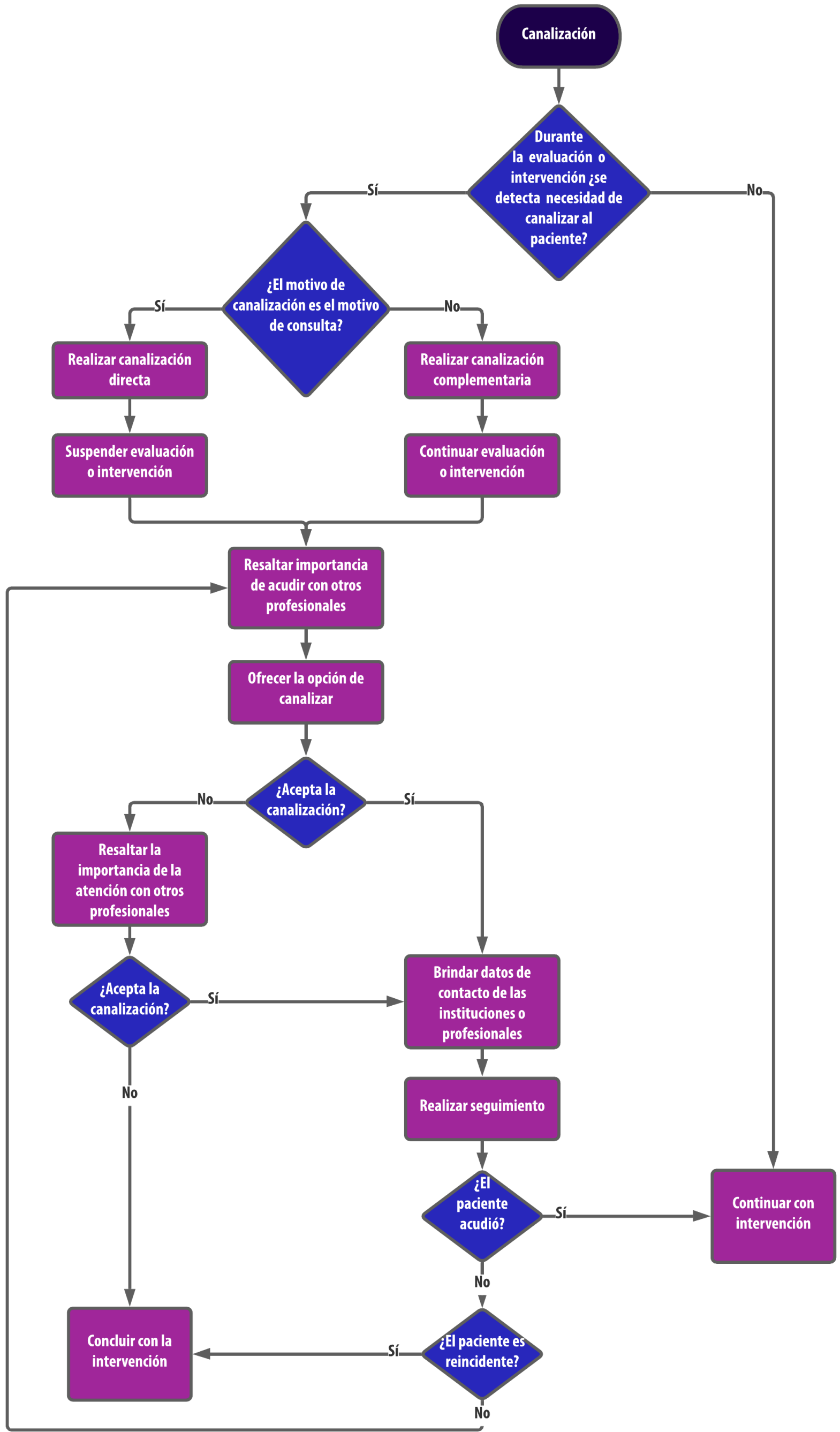

Nota: Elaboración propia. 
Figura 12

Flujograma sobre procedimiento en caso de desconexión de internet

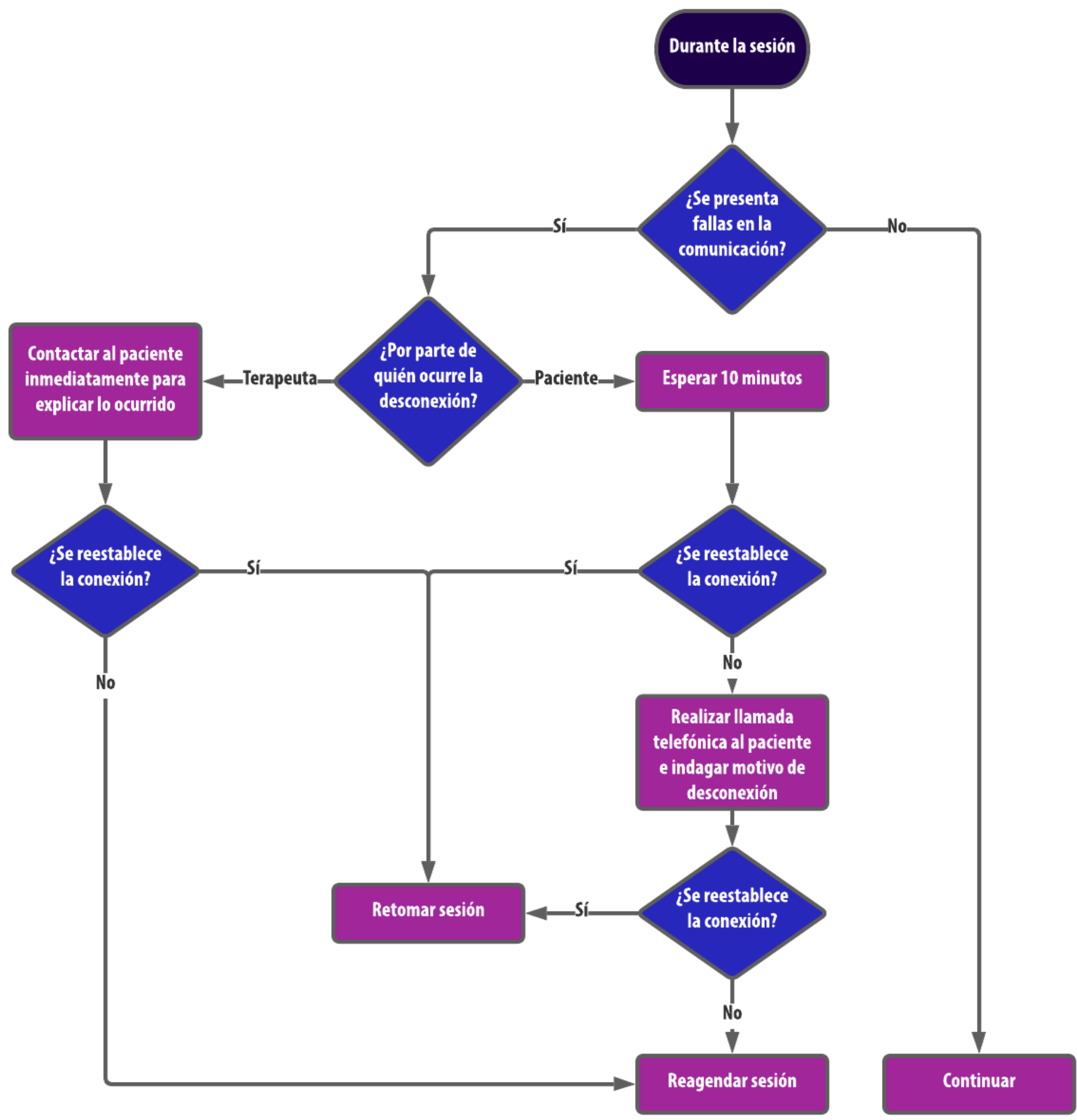

Nota: Elaboración propia. 
Figura 13

Flujograma sobre la toma de decisión para dar de baja al paciente

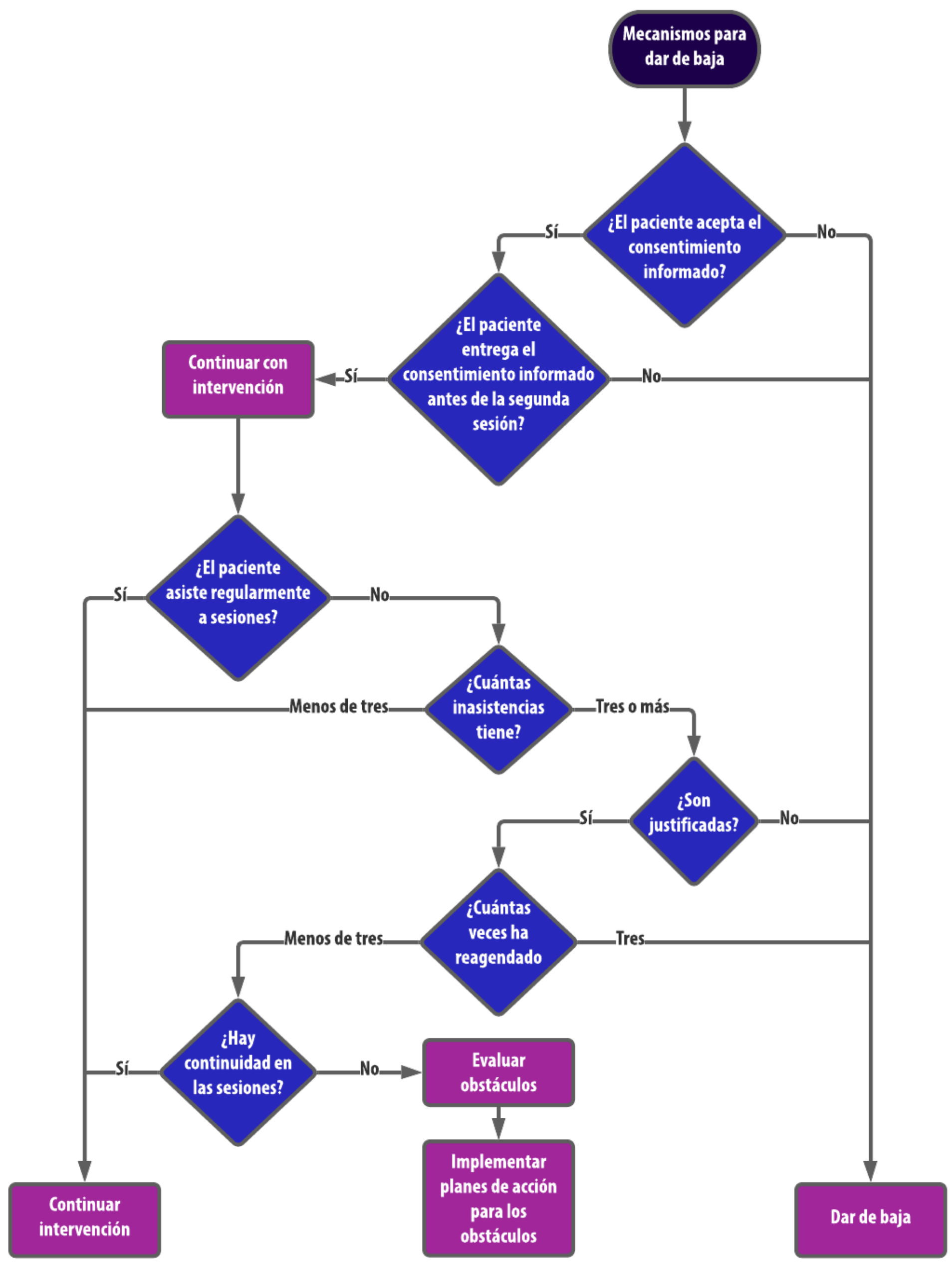

Nota: Elaboración propia. 
Figura 14

Flujograma sobre la toma de decisión para dar de alta al paciente

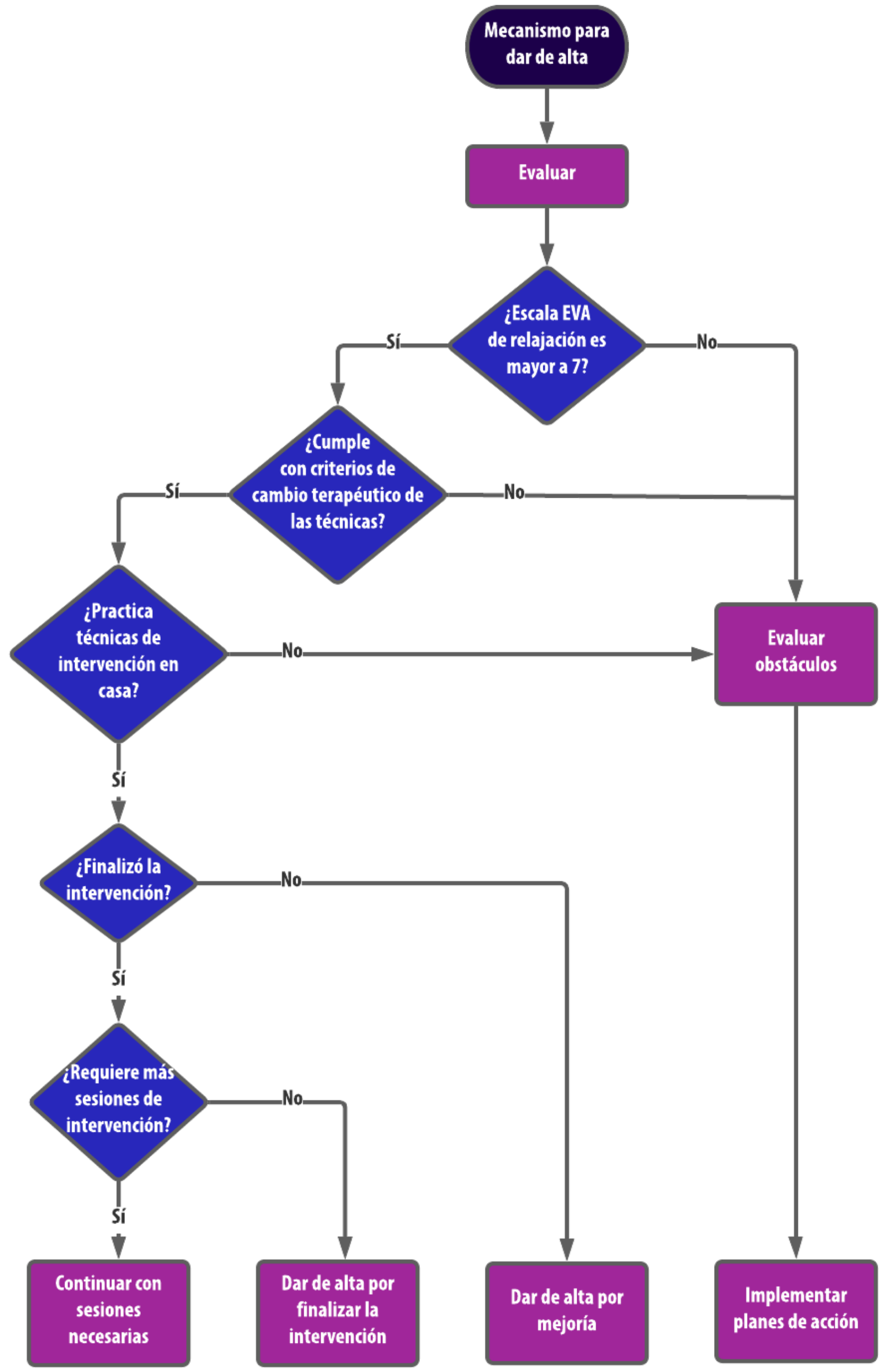

Nota: Elaboración propia. 


\subsection{Elección y descripción de las técnicas}

Se llevará a cabo un programa de intervención basado en diferentes técnicas bajo el modelo cognitivo conductual siguiendo las fases del tratamiento que se describe en el desarrollo de la intervención.

\subsubsection{Psicoeducación}

La técnica de psicoeducación permite educar a un individuo sobre algún aspecto de su enfermedad con el fin de mejorar la adaptación y aceptación de esta, además de promover la cooperación activa en relación con el tratamiento y la rehabilitación, lo cual fortalece las habilidades de afrontamiento (Goldman, 1988). Atri y Sharma (2007) definen a la psicoeducación como la educación especializada que comprende los esfuerzos educativos dirigidos a los pacientes y sus familias con el objetivo de ayudar a prevenir la recaída de las enfermedades y restaurar la salud.

El uso de la psicoeducación es un elemento primordial para cualquier intervención, ha demostrado efectividad tanto en pacientes como en familiares y se torna esencial para promover el papel activo del paciente, ya que proporciona información suficiente sobre alguna condición específica y permite que el individuo identifique las condiciones que influyen en su situación actual (salud-enfermedad) (Atri \& Sharma, 2007).

De acuerdo con Gavino (2006), proporcionar información al paciente sobre algún tema particular le permite actuar adecuadamente ante determinadas situaciones. Para brindar la psicoeducación es necesario, en un primer momento, evaluar la información que tiene el paciente sobre el tema y aquella que desea conocer. La información brindada deber ser clara, concisa y sin tecnicismos que limiten el entendimiento; implementar retroalimentación es una clave para la evaluación de la adquisición de datos, los cuales pueden complementarse con material escrito o audiovisual para reforzar la información.

Bauml (2006) refiere que la psicoeducación debe ser proporcionada por una persona debidamente capacitada y calificada. Además, menciona el beneficio de una adecuada implementación de la técnica, ya que mejora las estrategias de afrontamiento a través de la percepción de control en la enfermedad, pues se logra identificar los factores causales y modificables de esta. El objetivo final es que tanto el paciente como sus familiares adquieran competencias básicas para que puedan tomar decisiones informadas en el proceso de la enfermedad.

La tabla 12 describe los objetivos de la psicoeducación. 
Tabla 12

Objetivos de la psicoeducación

\section{Objetivos}

Facilitar un manejo informado y responsable de la enfermedad para el paciente y sus familiares.

Promover el papel del paciente como "experto".

Promover el papel de los familiares como "expertos".

Profundizar el conocimiento de la enfermedad.

Mejorar el cumplimiento del tratamiento.

Promover la prevención de recaídas.

Promover la prevención de crisis.

Promover la prevención del suicidio.

Nota: Adaptado de "Psychoeducation: A Basic Psychotherapeutic Intervention for Patients with Schizophrenia and Their Families" por Bauml, 2006, Schizophrenia Bulletin, 32, p. S4.

La psicoeducación es el elemento primordial de las intervenciones psicológicas, pues se espera que la implementación se aborde desde la primera entrevista con el paciente, es fundamental brindar la información segmentada a lo largo de las sesiones, los contenidos deben estar planeados e individualizados para cada paciente tanto con enfermedad aguda como crónica, los elementos a incluir en el contenido son el diagnóstico y sus implicaciones, la necesidad de realizar un tratamiento integral, la importancia del tratamiento farmacológico y no farmacológico, y la relevancia del tratamiento psicológico (Bulacio, Vieyra, \& Mongiello, 2010).

Las tres fases que componen a la técnica de psicoeducación son: (a) educación, la cual tiene como objetivo desarrollar conocimientos para una correcta interpretación de los fenómenos; (b) jerarquización del problema, identificación de los déficits y necesidades; y (c) práctica de las habilidades aprendidas, se espera que el paciente practique lo aprendido logrando modificar actitudes y conductas (Cuevas \& Moreno, 2017).

Si bien la meta de la psicoeducación es crear un puente entre la comunicación proporcionada por el especialista de la salud y el paciente, incorporando conocimiento asequible; será labor del terapeuta que el paciente obtenga una perspectiva de control al tratamiento, todo con base en el conocimiento previo y las posibles dudas que tenga del tema, por lo que se sugiere el uso de esta como precursora a cualquier estrategia complementaria en una intervención psicoterapéutica y psicosocial (Albarrán \& Macías, 2007). La guía sugiere la implementación de sesiones de psicoeducación relacionadas al estrés y las consecuencias a nivel cognitivo, conductual y fisiológico; además de la información sobre el diagnóstico de ERC (etiología, síntomas y consecuencias) y la relación entre la ERC y el estrés. 


\subsubsection{Estrategias de relajación}

El uso de las estrategias de relajación en pacientes que presentan estrés tiene como objetivo regular la activación fisiológica y, con ello, mejorar su calidad de vida. Las técnicas con mayor apoyo empírico en su eficacia son: las técnicas de relajación muscular progresiva, las técnicas de relajación autógena, las técnicas de control de la respiración, y las visualizaciones (Blanco et al., 2014). El éxito de la relajación se debe a que se logra por medio de técnicas que inducen respuestas parasimpáticas (sistema vegetativo) antagonistas al sistema simpático. En el estrés aparecen respuestas simpáticas, el procedimiento para reducirlas consiste en la activación de respuestas parasimpáticas que disminuye el ritmo del corazón (Zou et al., 2017).

Las estrategias de relajación abarcan una variedad de técnicas, procedimientos o actividades que ayudan a reducir las respuestas fisiológicas producidas por el estrés, tales como la frecuencia cardiaca, la tensión arterial, la tensión muscular; así como disminuir la experiencia emocional subjetiva negativa de la que se acompaña. Cabe mencionar que no sirven para anular el problema orgánico ya presente sino para aminorar los efectos fisiológicos. El entrenamiento en relajación, como intervención terapéutica para pacientes que sufren estrés, permite al individuo contar con una herramienta para afrontar la situación estresante con lo cual reducirá los efectos fisiológicos (Norelli, Long, \& Krepp, 2020; Rentería \& Valladares, 2018). Para la aplicación de las técnicas de relajación será necesario que el terapeuta precise las instrucciones de los ejercicios a través de la verbalización de los pasos con un tono, volumen y ritmo de voz apropiado; las instrucciones serán genéricas, contemplando y adecuando siempre las necesidades de cada paciente. A continuación, se describirán de manera más detallada las técnicas para la intervención planteada.

El control voluntario de la respiración tiene efectos directos en la regulación de los niveles de estrés, ya que un adecuado entrenamiento induce a la activación del sistema parasimpático (Cea- Ugarte, González-Pinto, \& Cabo-González, 2015). Este tipo de entrenamiento es una opción terapéutica con resultados a corto plazo, ofrece importantes beneficios debido a que puede ser un método sencillo y de breve tiempo en su aplicación (Labrador, De Arce, \& Florit, 1996). Los ejercicios de respiración tienen como objetivo enseñar al paciente a restaurar el patrón respiratorio para proporcionar la oxigenación necesaria y comprometer una menor cantidad de esfuerzo muscular. Las técnicas de respiración suponen una alternativa preventiva y terapéutica, pues permiten a los individuos controlar sus propios niveles de activación generando una respuesta incompatible con el estrés, caracterizada por un patrón reducido de actividad somática y autónoma, y cambios cognitivos que implican sensaciones de tranquilidad, confort y sosiego (Vázquez, 2001).

\subsubsection{Relajación pasiva}

La relajación pasiva se refiere al hecho de concentrar la atención en el patrón de la respiración. De esta manera, el individuo se pone en contacto con el proceso respiratorio, lo que le 
ayuda a sentir que tiene un cierto control sobre él. El control voluntario de la respiración puede ser terapéutico desde una perspectiva cognitiva, ya que la concentración en la respiración puede servir de ayuda como estrategia distractora de las preocupaciones y los pensamientos que generan tensión (Vázquez, 2001). Los efectos fisiológicos basados en una respiración controlada permiten la disminución de la frecuencia respiratoria y el aumento en la amplitud de esta, reduciendo la frecuencia cardiaca (Zou et al., 2017).

Previo al entrenamiento de cualquier ejercicio de respiración es necesario evaluar los tiempos de inspiración y espiración del paciente, ya que la respiración varía continuamente. La finalidad del entrenamiento en relajación pasiva es que se consiga un patrón respiratorio apropiado fisiológicamente, por lo tanto, el paciente deberá realizar inspiraciones vía nasal y espiraciones bucales, los ejercicios pueden realizarse en diferentes posturas como de pie, sentado o acostado; dependerá del objetivo terapéutico y de las condiciones del paciente. La secuencia del ejercicio es la siguiente: inspiración, pausa y espiración; los tiempos y duración de las pausas y la profundidad dependen de cada paciente, en ningún momento debe ser forzada sino constante y fluida (Barrio, García, López, \& Bedia, 2006; Cea-Ugarte et al., 2015; Labrador et al., 1996).

\subsubsection{Respiración diafragmática}

La respiración diafragmática es un entrenamiento que implica la profundización de la inhalación por contracción del diafragma y expansión del abdomen, y una posterior exhalación, así como pausas entre estas, que como consecuencia llevan a una disminución en la frecuencia respiratoria y a la maximización de la cantidad de oxígeno en sangre (Ma et al., 2017). Los movimientos del diafragma permiten una mayor expansión pulmonar y, por ende, mayor oxigenación. Al ser una respiración más profunda requiere menor esfuerzo muscular.

La evidencia de los beneficios fisiológicos ha indicado que se produce una disminución en el ritmo cardiaco y en la presión arterial; es utilizado para la disminución de estrés, ansiedad, dolor crónico, insomnio, depresión, náuseas y dolor muscular. Su objetivo primordial es la activación del sistema parasimpático para producir estados de relajación en el paciente (Russell, Scott, Boggero, \& Carlson, 2016).

De este modo, la respiración diafragmática es una herramienta complementaria para el control del estrés, pues es un entrenamiento psicofisiológico no invasivo que favorece los estados de relajación sin necesidad de requerir ningún equipo especial ni consumo de fármacos, además de ser de fácil aplicación y ejecución. Es una habilidad que requiere de práctica diaria que implica de 15 a 20 minutos para obtener los resultados (Larios et al., 2019). En la figura 15 se pueden observar los cuatro pasos básicos para la aplicación del entrenamiento. 


\section{Figura 15}

Instrucciones para la respiración diafragmática

\section{Paso 1}

Siéntese cómodamente en una silla, cuidando de apoyar la espalda en el respaldo. También se puede realizar de pie o acostado.
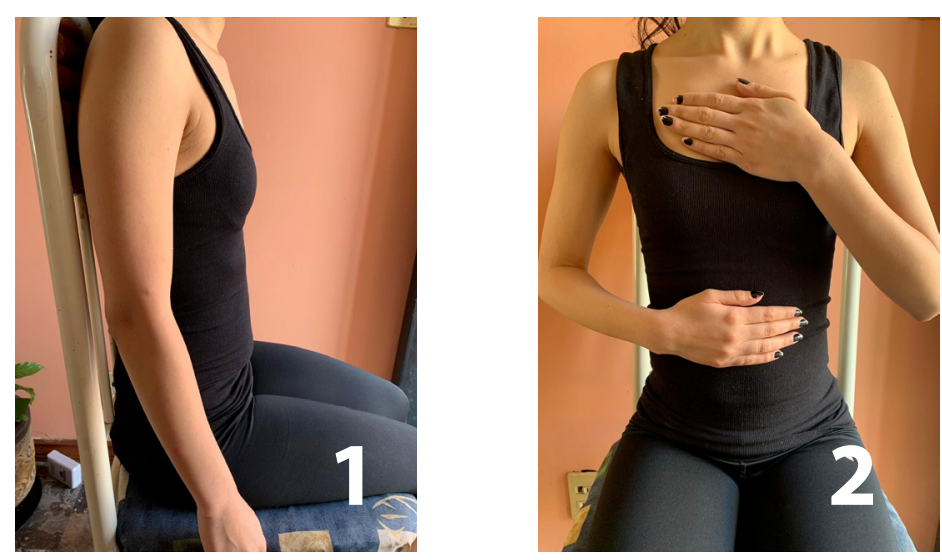

Paso 3

Inhalar por la nariz y llevar el aire a la parte inferior de los pulmones, permitiendo que el abdomen se levante o infle conforme entre el aire. Es importante mantener la respiración unos cuantos segundos

\section{Paso 2}

Coloque una mano sobre el pecho y la otra en el abdomen. La primera no deberá moverse, mientras que la mano en el abdomen se moverá al inhalar y exhalar.
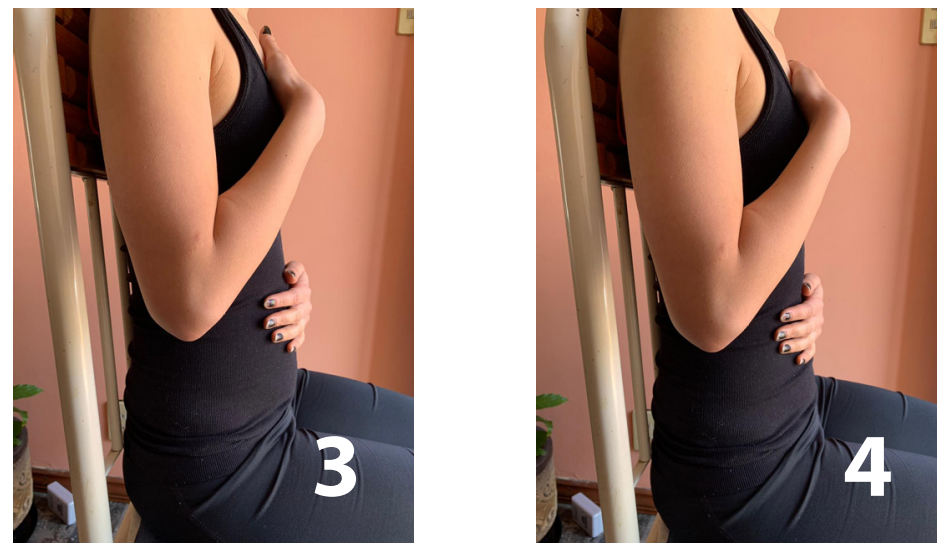

\section{Paso 4}

Exhalar por la boca lentamente, de tal forma que se contraiga o desinfle el abdomen.

\section{Paso 5}

Descanse unos segundos y repita los pasos.

Nota: Elaboración propia. Fotografía: Diana Lucero Muñoz Arellano.

Es indispensable que el terapeuta y el paciente en conjunto ajusten los segundos de cada paso para evitar malestar, esto se puede acompañar de aplicaciones que complementen el entrenamiento en la técnica de relajación, se utilizará Breathe ${ }^{\circledast}$ (para dispositivos Android) y BreatheSync ${ }^{\oplus}$ (para dispositivos iOS). Además de utilizar otra para medir la frecuencia cardiaca como Ritmo cardíaco-Monitor ${ }^{\circledast}$ (para sistema operativo Android) y Heart Rate Free ${ }^{\circledast}$ (para sistema operativo iOS). Su utilización podrá mejorar y retroalimentar el entrenamiento y la práctica del paciente.

\subsubsection{Autoinstrucciones}

La técnica de autoinstrucciones tiene como objetivo modificar las creencias y cogniciones desadaptativas, así como implementar o desarrollar nuevas habilidades en el individuo. Para el entrenamiento, el terapeuta debe identificar aquellos pensamientos desadaptativos y modelar el comportamiento deseado a través de las autoinstrucciones (APA, 2020). La técnica sugiere que el cambio del comportamiento se puede guiar a través de autoverbalizaciones del paciente; estas verbalizaciones o diálogos internos deberán adecuarse para cada momento o situación estresante (Meichenbaum, 2002). 
El entrenamiento en autoinstrucciones es una técnica empleada para sustituir autoverbalizaciones internas (pensamientos) negativas por otras positivas que el sujeto utiliza antes, durante y después de una situación evaluada como estresante (Meichenbaum, 1977). Es común que la utilización de la técnica esté acompañada de otras técnicas como visualizaciones, paro al pensamiento, ejercicios de respiración, entre otras, con el fin de facilitar su comprensión (Del Arco, Tornero, \& García, 2014).

De acuerdo con Meichenbaum (2002), la técnica está diseñada para la resolución de problemas, ya que durante el entrenamiento se incorporan estrategias cognitivas que pueden emplearse ante diversas respuestas de estrés, debido a que proporciona autoafirmaciones para el afrontamiento, pues como consecuencia de experimentar estrés se presentan pensamientos automáticos negativos, por lo que se buscará modificar estos por otros más funcionales acorde al momento; durante la preparación pueden implementarse verbalizaciones como "puedo hacer esto", durante la situación pueden implementarse verbalizaciones como "lo estoy haciendo bien", para el afrontamiento de la activación emocional se pueden implementar verbalizaciones como "voy a relajarme" y para reforzar se pueden implementar verbalizaciones como "no lo hice tan mal". Para Caballo (1998), se trata de una técnica que permite la modificación del comportamiento mediante el uso de instrucciones $u$ órdenes que el paciente se da a sí mismo.

La adecuada implementación de la técnica demanda la identificación de las verbalizaciones del paciente, las imágenes y los sentimientos habituales durante cada fase de la experiencia estresante; posteriormente, terapeuta y paciente en conjunto identificarán cómo estas autoverbalizaciones afectan a la respuesta de estrés y dificultan el afrontamiento, para después elaborar alternativas de frases autodirigidas en miras de producir respuestas más adaptativas para afrontar, recordando que estas alternativas se ajustarán a las necesidades del paciente (Meichenbaum, 2002).

Ruiz, Díaz y Villalobos (2012) señalan que para aplicar la técnica se debe considerar: (a) la definición de la tarea, (b) la aproximación al problema, (c) la focalización de la atención, (d) el autorrefuerzo, (e) las autoverbalizaciones para afrontar los errores, (f) la autoevaluación, y (g) el autorrefuerzo. Esta herramienta es útil para el manejo del estrés complementada con técnicas de relajación, pues el paciente adquiere una estrategia para afrontar de manera más adaptativa (Casado \& Laguna-Bonilla, 2017).

En la tabla 13 se describen las cinco fases a seguir para la implementación de las autoinstrucciones. 


\section{Tabla 13}

Pasos de la técnica de autoinstrucciones

\begin{tabular}{lll}
\multicolumn{2}{c}{ Fases } & \multicolumn{1}{c}{ Descripción } \\
\hline 1 & Modelamiento de la conducta & El terapeuta modela la conducta o tarea y la realiza dándose las autoinstrucciones en voz alta. \\
\hline 2 & Guía externa en voz alta & El terapeuta da las instrucciones en voz alta y el paciente realiza la conducta. \\
\hline 3 & Autoinstrucciones en voz alta & El paciente realiza la conducta dándose las autoinstrucciones en voz alta. \\
\hline 4 & Autoinstrucciones en voz baja & El paciente realiza la conducta dándose las autoinstrucciones en voz baja. \\
\hline 5 & Autoinstrucciones encubiertas & El paciente realiza la tarea con autoinstrucciones encubiertas. \\
\hline
\end{tabular}

Nota: Adaptado de Manual de técnicas de intervención cognitivo conductuales por M. A. Ruiz, M. A. Díaz \& A. Villalobos, 2012, España: Desclée de Brouwer.

\subsubsection{Terapia en solución de problemas}

La terapia en solución de problemas (TSP) implica el desarrollo de una serie de habilidades orientadas a mejorar la capacidad del individuo para hacer frente con eficacia a una variedad de situaciones estresantes de la vida cotidiana. El objetivo general de esta terapia es fomentar la adopción y la implementación efectiva de actitudes adaptativas de resolución de problemas y comportamientos para mejorar el bienestar general (Nezu, Nezu, \& Salber, 2013).

De acuerdo con D'Zurilla y Nezu (2001), los tres principales componentes de la TSP son: solución de problemas, problema y solución. La clara comprensión de estos elementos es crucial para obtener un resultado exitoso. Estos autores definen un problema como cualquier situación que requiere una respuesta adaptativa y que debido a la existencia de algunas barreras la persona no encuentra una respuesta efectiva, inmediata y evidente. Una solución es una respuesta de afrontamiento en la que el objetivo principal es maximizar las consecuencias positivas y minimizar las negativas. La tabla 14 describe las fases de la TSP.

LaTSP ha resultado ser efectiva para el control y prevención del estrés al demostrar que, si se desarrollan habilidades de solución de problemas, el paciente estará en condiciones de afrontar diversas situaciones estresantes.

\subsubsection{Uso de técnicas complementarias}

Con base en el AFC elaborado en la etapa de evaluación, el experto en MC podrá identificar la presencia de estrés y otras áreas de injerencia en las cuales sea necesario intervenir. Las técnicas deben dirigirse a las necesidades de cada paciente y ser acordes al modelo de intervención. El especialista en MC deberá determinar cuáles son estas. El entrenamiento en técnicas cognitivo-conductuales se ha aplicado en intervenciones con pacientes con enfermedades crónicas y ha sido efectivo (Melchy, 2015). Particularmente en los pacientes con ERC se producen cambios en la alimentación e ingesta de líquidos, que se mantienen a lo largo de los seguimientos (Torres, 2010); de igual manera se observan cambios significativos en la calidad de vida, disminución de sintomatología de estrés, depresión y ansiedad, y una 
Tabla 14

Fases de la terapia en solución de problemas (TSP)

\begin{tabular}{ll} 
Orientación al problema & \multicolumn{1}{c}{ Objetivos } \\
\hline $\begin{array}{l}\text { Definición y formulación } \\
\text { del problema }\end{array}$ & $\begin{array}{l}\text { Identificar que los problemas forman parte de la vida diaria, pero que es posible } \\
\text { solucionarlos. }\end{array}$ \\
\hline $\begin{array}{l}\text { Generación de alternativa } \\
\text { de solución }\end{array}$ & Describir la naturaleza del problema y establecer metas específicas y alcanzables. \\
& $\begin{array}{l}\text { Formular la mayor cantidad de alternativas con la finalidad de aumentar la } \\
\text { probabilidad de elegir la más adecuada. Para favorecer el desarrollo de alternativas } \\
\text { se deben considerar los siguientes principios: cantidad, entre más opciones mejor; } \\
\text { aplazamiento de juicio, no evaluar la viabilidad de la solución; y variedad, ampliar las } \\
\text { opciones de solución. }\end{array}$ \\
\hline Toma de decisiones & $\begin{array}{l}\text { Realizar un balance decisional en el que se analicen los costos y beneficios de cada una } \\
\text { de las alternativas planteadas, considerando viabilidad, riesgos, consecuencias a corto } \\
\text { y largo plazo, así como bienestar personal e interpersonal. }\end{array}$ \\
\hline $\begin{array}{l}\text { Ejecución y verificación } \\
\text { de la solución }\end{array}$ & $\begin{array}{l}\text { Llevar a cabo la solución seleccionada; el terapeuta evaluará los resultados y verificará } \\
\text { anteriores para elegir otra alternativa o identificar si los obstáculos presentados se } \\
\text { debieron a algún déficit de habilidades o aspectos emocionales. }\end{array}$ \\
\hline
\end{tabular}

Nota: Elaboración propia.

mejor adherencia al tratamiento médico (Cukor et al., 2013; Sohn et al., 2018). De acuerdo con la revisión sistemática de $\mathrm{Ng}$ et al. (2019) sobre el efecto de la TCC en pacientes con ERC, se demostró que es una intervención eficaz en la reducción de síntomas de depresión y ansiedad, además de mejorar la calidad de vida.

La tabla 15 muestra algunas técnicas cognitivas conductuales complementarias, lo que demuestra la flexibilidad de esta guía. Por su parte, en la figura 16 se presenta el flujograma para la selección de técnicas complementarias.

\section{Tabla 15}

\section{Técnicas cognitivo conductuales complementarias para el manejo del estrés}

\section{Técnicas Descripción}

Relajación muscular Procedimiento dirigido a conseguir la reducción de los niveles de activación fisiológica mediante la progresiva disminución progresiva y voluntaria de la contracción muscular, por lo cual, el paciente deberá aprender a identificar las sensaciones de tensión generadas en el músculo para posteriormente eliminar la tensión, permitiendo el alargamiento de las fibras musculares (Vázquez, 2001).

A través del entrenamiento de la tensión y distensión de los distintos grupos musculares, el paciente aprenderá a identificar la relajación de algunas partes del cuerpo. La versión de la técnica a utilizar (16, 8 y 4 grupos musculares) se ajustará a cada paciente de acuerdo con sus necesidades.

Relajación autógena Entrenamiento en el que se le enseña al paciente a relajar el cuerpo a través de cuatro elementos: 1) La reducción de la estimulación externa (luz, ruido, estímulos invasivos, etc.); 2) Una actitud de concentración pasiva; 3 ) La repetición de las frases inductoras de la relajación que van dirigidas a: sensaciones de pesadez y calidez en los brazos, piernas abdomen y frente; y 4) La percepción de la parte del cuerpo a la que se hace referencia (Vázquez, 2001). 

función de la gratificación a largo plazo (Rachlin, 2000). El objetivo de los procedimientos de autocontrol es reforzar a las personas para que sean capaces de poner en marcha estrategias que les permitan regular su comportamiento de acuerdo con sus objetivos. Las técnicas se pueden diferenciar según se centren en los antecedentes, la conducta o los consecuentes van centrados en la alteración del contexto para favorecer o inhibir la aparición de las conductas (Labrador, 2008).

Asertividad

El entrenamiento en asertividad implica enseñar al paciente un conjunto de conductas, emitidas en un contexto interpersonal, que expresa los sentimientos, actitudes, deseos, opiniones o derechos de esa persona de un modo directo, firme y honesto, respetando al mismo tiempo los sentimientos, actitudes, deseos, opiniones y derechos de las otras personas. Esta conducta puede incluir la expresión de emociones (Flores \& Díaz-Loving, 2002).

Manejo de contingencias

Técnicas fundamentadas en el condicionamiento operante que tienen como objetivo la reducción de conductas no deseadas mediante el uso de técnicas como: reforzamiento diferencial de tasas bajas, reforzamiento diferencial de otras conductas, reforzamiento diferencial de conducta incompatible, castigo positivo, castigo negativo, sobrecorrección, costo de respuesta, tiempo fuera, extinción y saciedad del estímulo, y el aumento y mantenimiento de conductas deseadas a través de técnicas como: reforzamiento positivo, reforzamiento negativo, instigación, instrucciones, modelamiento, guía física, inducción situacional, moldeamiento o aproximaciones sucesivas, encadenamiento y desvanecimiento.

Técnicas de Técnicas dirigidas a que el paciente identifique tanto los sesgos o patrones negativos del pensamiento, el modificación funcionamiento de las cogniciones como los procesos cognitivos y la forma en que afectan directamente cognitiva las emociones y conductas, aunado al entrenamiento en la autoobservación, el análisis y la modificación de sus pensamientos (Dongil-Collado, 2008).

Nota: Elaboración propia.

\section{Tratamiento}

La intervención se diseñó para implementarse de manera online en población con ERC. Se realizó para ejecución remota por la situación sanitaria actual y para cubrir las necesidades de atención psicológica de los pacientes; sin embargo, no es uso exclusivo de esta modalidad de intervención, ni necesariamente de esta población blanco.

El papel de las TIC's como instrumento de aprendizaje ofrece la oportunidad de brindar información por medio de vías de telecomunicación y ha sido un elemento fundamental durante la pandemia ocasionada por el SARS-COV-2 (COVID-19) (Organización de las Naciones Unidas para la Educación [UNESCO], 2020). De acuerdo con Wang et al. (2020), debido a las condiciones sanitarias las personas han presentado síntomas de estrés entre moderados a graves. Además, el hecho de padecer una enfermedad crónica per se genera situaciones evaluadas como estresantes, por lo que brindar atención psicológica para la reducción del estrés es una necesidad.

Se espera que, debido a la pandemia, las intervenciones psicológicas se ofrezcan por medios remotos, que sean dinámicas y flexibles a fin de atender los aspectos psicológicos de la población que lo requiera (Duan \& Zhu, 2020). Un reto para los especialistas en MC será abordar la atención psicológica online haciendo uso de herramientas de comunicación tales como aplicaciones de mensajería, videollamadas, páginas web, redes sociales, entre otras, y así brindar atención a distancia (Martínez, 2020). 


\section{Figura 16}

Flujograma sobre la implementación de técnicas complementarias

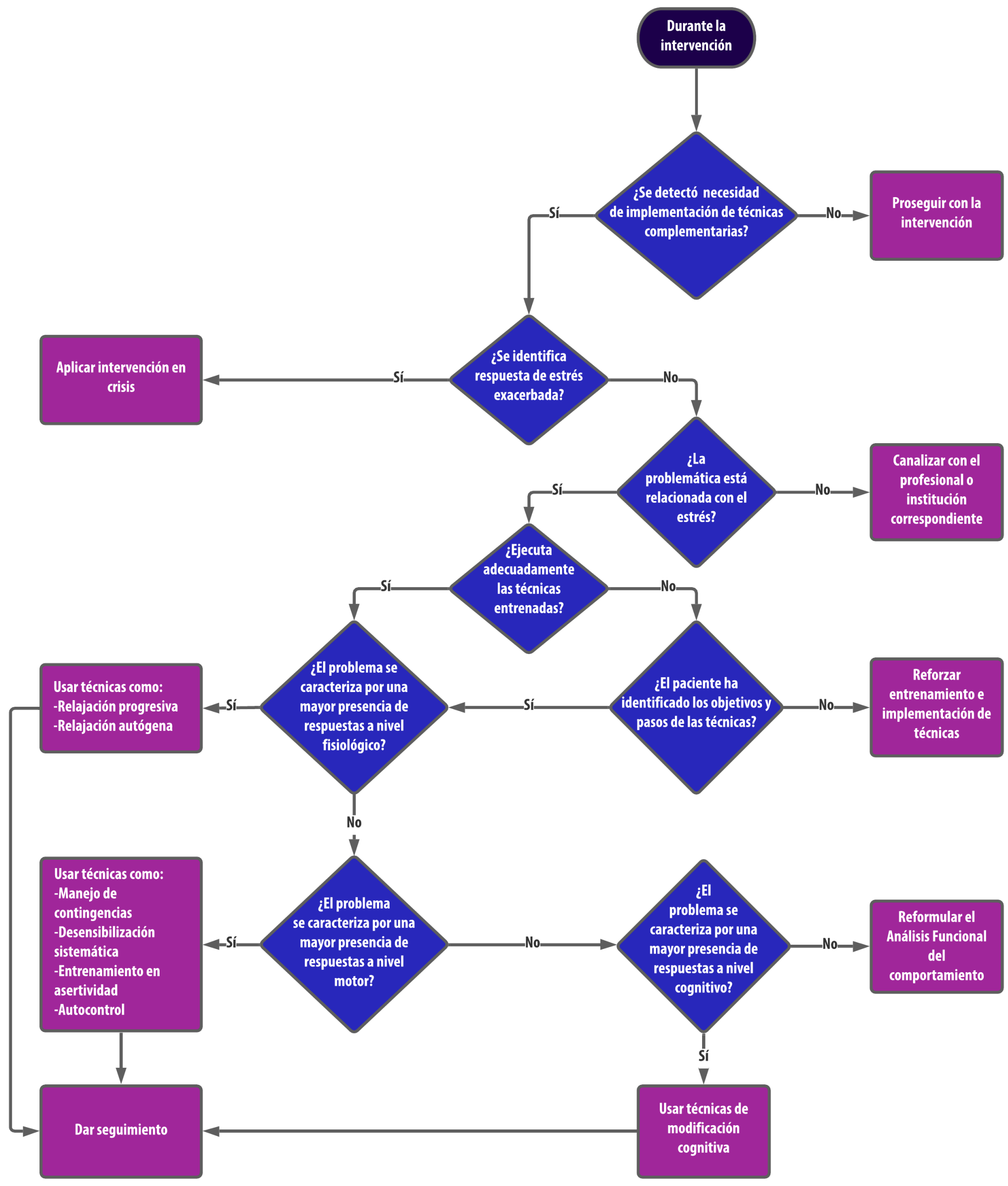

Nota: Elaboración propia. 
El modelo de trabajo integra los elementos fundamentales del proceso terapéutico, desde la evaluación, la intervención y el seguimiento, cuidando las individualidades del paciente para realizar los ajustes necesarios y cumpliendo con los criterios de ética, legalidad y profesionalismo (Inchausti, García-Poveda, Prado-Abril, \& Sánchez-Reales, 2020). De igual manera, esta modalidad de intervención es una alternativa a la atención psicológica presencial que dota de los mismos beneficios al paciente (Macías \& Valero, 2018).

Para la propuesta se hará uso de comunicación bilateral, ya que en un primer momento el paciente es el que a través de la página web (https://www.mciztacala.org) o por correo electrónico contactará y enviará sus datos para que se comuniquen con él, y en un segundo momento el terapeuta es quien deberá contactar al paciente a través de llamada telefónica, videollamada o mensajería. El programa de intervención se implementará a lo largo de ocho etapas que se muestran en la tabla 16.

\section{Tabla 16}

Generalidades de las etapas de tratamiento

Etapa

\begin{tabular}{ll} 
Difusión & Mediante la divulgación por medio de redes sociales se realizará la captación de pacientes. \\
\hline Envío de datos & $\begin{array}{l}\text { El paciente deberá completar la información de la ficha de identificación y contestar la batería de } \\
\text { instrumentos para su evaluación inicial. }\end{array}$ \\
\hline Contacto al paciente & El terapeuta establecerá comunicación con el solicitante para agendar la sesión. \\
\hline Evaluación & $\begin{array}{l}\text { El terapeuta analizará la información obtenida de la entrevista conductual y de los resultados de la batería } \\
\text { inicial o, en su caso, los resultados de los instrumentos complementarios. }\end{array}$ \\
\hline Intervención & $\begin{array}{l}\text { El terapeuta implementará el proceso de intervención que incluye desde la psicoeducación de las } \\
\text { variables de interés (enfermedad y estrés), así como el entrenamiento y ejercicio de las técnicas sugeridas. }\end{array}$ \\
\hline Mantenimiento & $\begin{array}{l}\text { El terapeuta evaluará la generalización de las habilidades en el manejo del estrés ante diferentes } \\
\text { condiciones. }\end{array}$ \\
\hline $\begin{array}{l}\text { Evaluación } \\
\text { postintervención }\end{array}$ & El paciente deberá contestar nuevamente la batería de instrumentos para la evaluación posterior. \\
\hline Seguimiento & El terapeuta evaluará de los cambios conductuales a través del tiempo.
\end{tabular}

Nota: Elaboración propia.

A continuación, se describen las ocho etapas del programa. La primera etapa es la difusión. Para cubrir las necesidades psicológicas de los pacientes con ERC y estrés, se difundirá la información del programa por medio de redes sociales oficiales de la residencia en MC sede Atizapán (Instagram ${ }^{\circledast}$, Twitter $^{\circledR}$, Facebook ${ }^{\circledR}$ ) donde se compartirán carteles con el fin de que los pacientes interesados puedan acercarse y contactar al equipo de MC, la divulgación de la información contará con datos del programa, instituciones de adscripción, nombre de la intervención y sus beneficios, datos de contacto y página (https://www.mciztacala.org) de la residencia MC sede Atizapán para obtener más información o solicitar la atención. 
La segunda etapa será el envío de datos. Cuando el paciente interesado acceda a la página web (https://www.mciztacala.org) y solicite la atención psicológica, se redirigirá a un enlace de Google Forms ${ }^{\circledR}$ con el fin de que proporcione los datos de identificación y contacto personal, así como responder la batería de instrumentos, una vez completado esos apartados se enviará la información, los especialistas en MC evaluarán los resultados obtenidos y realizarán el primer contacto con el paciente, para concretar una cita para la primera sesión, esto se realizará a través de correo electrónico o llamada.

La cuarta etapa denominada evaluación, implica el encuadre (presentación, rapport, modalidad en línea, enfoque de trabajo, consentimiento informado), la evaluación (entrevista conductual) y la aplicación de instrumentos complementarios de ser necesario para confirmar o descartar algún diagnóstico diferencial. Una vez concluida la evaluación, el terapeuta hará la devolución sobre las generalidades del AFC y de los resultados de la batería de instrumentos.

En la quinta etapa se iniciará el proceso de intervención, donde se aplicarán las técnicas seleccionadas, con el fin de lograr los objetivos generales y específicos, además de entrenar en el uso del sistema de registro. Cabe resaltar que el especialista en MC podrá modificar en cualquier momento la ruta de la intervención con el fin de lograr los objetivos y cubrir las necesidades del paciente, por lo que la guía sugiere técnicas complementarias de ser necesario.

Para el mantenimiento se espera evaluar los cambios conductuales y entrenar al paciente en la elaboración de planes de acción para modificar los obstáculos que impidan o limiten la puesta en marcha de las estrategias y habilidades entrenadas. Al finalizar la sesión de mantenimiento será necesario efectuar la séptima etapa, la postevaluación, en la cual se le pedirá al paciente que conteste nuevamente la batería de instrumentos con el fin de evaluar los resultados de la intervención.

Finalmente, en la octava etapa se realizará el seguimiento para evaluar los cambios conductuales a través del tiempo, las sesiones se agendarán primero al mes y después a los tres y seis meses posteriores a la intervención. Si durante el tratamiento el paciente presenta alguna crisis (síntomas exacerbados de estrés), se suspenderá la etapa en la que se encuentre y se iniciará el protocolo de intervención en crisis.

A lo largo de 10 sesiones se llevará a cabo el tratamiento y tres sesiones de seguimiento. Existe evidencia empírica acerca de la efectividad de las intervenciones cortas de hasta ocho semanas sobre las intervenciones más prolongadas (Heber et al., 2017). En la tabla 17 se observan el número de sesiones, la etapa del proceso terapéutico y las técnicas a ejecutar. 
Tabla 17

Distribución de técnicas de acuerdo con las sesiones

\begin{tabular}{|c|c|c|}
\hline Sesión & Etapa & Técnica \\
\hline 1 & Evaluación & Entrevista conductual \\
\hline \multirow[t]{2}{*}{2} & Evaluación & $\begin{array}{l}\text { Entrevista conductual } \\
\text { Evaluación complementaria* }\end{array}$ \\
\hline & Intervención & Entrenamiento en respiración diafragmática o pasiva \\
\hline \multirow[t]{2}{*}{3} & Evaluación & $\begin{array}{l}\text { Análisis funcional de la conducta problema } \\
\text { Elaboración de hipótesis funcionales } \\
\text { Devolución de los resultados de evaluación }\end{array}$ \\
\hline & Intervención & $\begin{array}{l}\text { Entrenamiento en relajación } \\
\text { Respiración diafragmática o relajación pasiva }\end{array}$ \\
\hline 4 & Intervención & Psicoeducación (enfermedad y estrés) \\
\hline 5 & Intervención & Entrenamiento en autoinstrucciones \\
\hline 6 & Intervención & Identificación del problema (solución de problemas) \\
\hline 7 & Intervención & Generación de alternativas (solución de problemas) \\
\hline 8 & Intervención & Toma de decisiones (solución de problemas) \\
\hline 9 & Mantenimiento & Plan de acción \\
\hline \multirow{2}{*}{10} & Mantenimiento & Plan de acción \\
\hline & Evaluación postintervención & Aplicación de instrumentos \\
\hline & Seguimiento** & $\begin{array}{l}\text { Monitoreo } \\
\text { Evaluación }\end{array}$ \\
\hline
\end{tabular}

Nota: *En el caso de confirmar o descartar algún diagnóstico diferencial. ${ }^{* *} \mathrm{Al}$ mes, a los tres y seis meses posteriores a la intervención. Elaboración propia

\subsection{Sistema de Registros}

Dentro de la evaluación e intervención conductual, el terapeuta hace uso de distintos registros que le permitirán obtener más información y especificidad de la conducta problema. Los registros empleados dependerán del tipo de evento que se desee registrar y de los objetivos de la terapia (Cepeda, López, Plancarte, Moreno, \& Alvarado, 2014). Los autorregistros son la herramienta de evaluación conductual que más utilidad y viabilidad tienen en la aplicación clínica, ya que el paciente puede dar detalles específicos de su comportamiento, pensamiento y otras variables (Caballo, 1998). Enseguida, se describen cada uno de los registros que se utilizarán en la propuesta de intervención, además, en la figura 17 se muestra el proceso para la utilización de registros.

\subsubsection{Escalas visuales análogas}

Una escala visual análoga (EVA) consiste en una línea horizontal de aproximadamente 10 centímetros en cuyos extremos se encuentran las expresiones extremas de un síntoma. En el lado izquierdo se ubica la ausencia y en el lado derecho la mayor intensidad. El paciente 
Figura 17

Flujograma sobre la implementación de registros

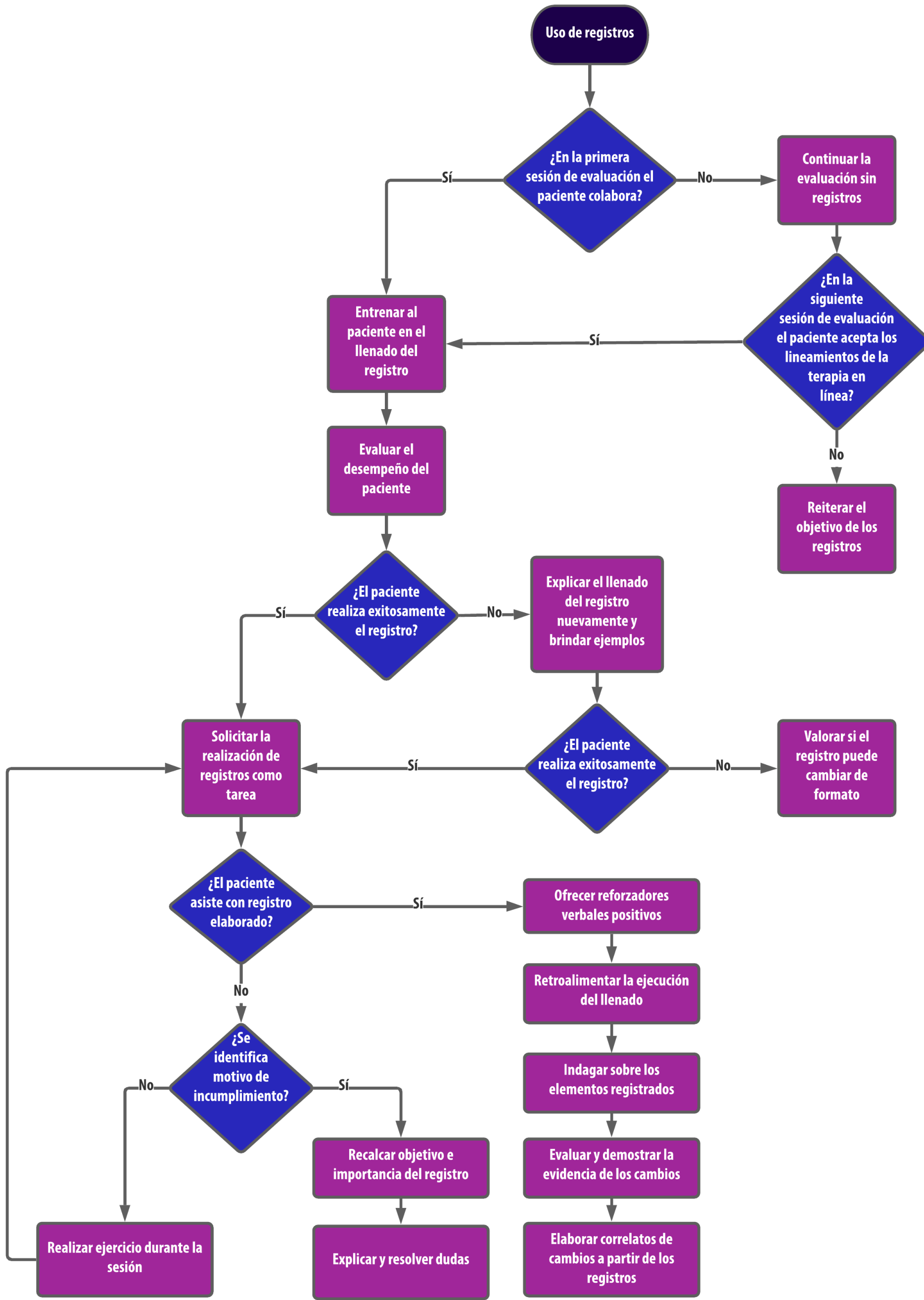

Nota: Elaboración propia. 
deberá marcar en la línea el punto que indique la intensidad que siente (Vicente, Delgado, Moya, Ramírez \& Capdevilla, 2018). Las EVA's han sido utilizadas para medir la intensidad de dolor y han sido adaptadas para registrar los niveles de relajación de un paciente antes y después de emplear alguna técnica con el objetivo de identificar su efectividad.

La EVA empleada en esta intervención constará de una línea horizontal, que en el lado izquierdo se encuentre "nada relajado" y en el lado derecho "totalmente relajado". El paciente deberá indicar en la línea cómo se siente antes de emplear la técnica y después de hacerla. ${ }^{3}$

\subsubsection{Registro de frecuencia cardiaca}

El registro de las variables fisiológicas se utiliza como indicador de la conducta observada, ya que la respuesta fisiológica subyace a la conducta. Ante un evento estresante, el individuo presenta reacciones fisiológicas como aumento en frecuencia cardiaca, en la temperatura corporal, en la frecuencia respiratoria, en la presión arterial, entre otras. Por lo tanto, realizar una evaluación fisiológica permite medir de manera fiable la activación y contrastar los cambios. De igual manera, el registro permitirá al paciente identificar que puede modificar su respuesta fisiológica a partir de un entrenamiento en relajación (Caballo, 1998; Cepeda et al., 2014; Díaz, 1996). Para fines de la intervención se le solicitará al paciente que realice el registro de la frecuencia cardiaca antes y después del entrenamiento en relajación obtenida por la aplicación digital Ritmo cardíaco-Monitor ${ }^{\circledast}$ (para sistema operativo Android) y Heart Rate Free ${ }^{\circledast}$ (para sistema operativo iOS) o de manera análoga, con la finalidad de que identifique los efectos del entrenamiento. ${ }^{3}$

\subsubsection{Registro de eventos estresantes}

Al hablar de estrés es necesario que el paciente reconozca los eventos que percibe como estresantes, por lo cual entrenar al paciente para que identifique las circunstancias específicas o condiciones ambientales que le producen la respuesta estresante ya sea cognitiva, motora o fisiológica con relación a la enfermedad será de gran utilidad para la detección de los problemas psicosociales del paciente (Suárez, 2010). El registro consistirá en que el paciente enliste una serie de situaciones estresantes con relación a la enfermedad crónica degenerativa que padece, ya sean situaciones sociales, económicas, ambientales, etc. ${ }^{3}$

\subsubsection{Registro de autoinstrucciones}

Para la ejecución de la técnica de autoinstrucciones se deberá definir la tarea a realizar, la cual irá acompañada de autoverbalizaciones que guíen dicha conducta. Inicialmente, el paciente deberá identificar el autodiálogo que tiene ante situaciones evaluadas como estresantes; se le solicitará que identifique y registre el tipo de verbalizaciones que mantiene en dichas

3 Ver en los anexos del manual Viviendo con Enfermedad Renal Crónica: pautas y sugerencias para manejar mi estrés. Disponible en: https://tinyurl.com/enrenyes 
situaciones y, con ello, reconocer si estos facilitan la ejecución de la tarea, o deberán eliminarse o sustituirse. En este registro se le solicitará al paciente que escriba al menos tres autoverbalizaciones que sean útiles ante eventos estresantes. ${ }^{4}$

\subsubsection{Identificación del problema}

En la técnica de solución de problemas existen distintas fases; dentro de esta propuesta se utilizan las siguientes: identificación del problema, generación de alternativas de solución y toma de decisiones.

La identificación del problema servirá al paciente para definir y formular su problema. En este se recopilará información relevante que esté basada en hechos y no en suposiciones. El paciente deberá describir los hechos en términos claros, precisos y objetivos, identificando los factores involucrados en la situación. Para esto el paciente deberá escribir brevemente el problema y responder a las preguntas ¿Qué ocurre?, ¿Quién o quiénes están involucrados?, ¿Cuándo ocurre?, ¿Dónde ocurre? y ¿Cómo ocurre? Responder estas preguntas ayudará al paciente a esclarecer y definir el problema (Nezu \& Nezu, 1991). ${ }^{4}$

\subsubsection{Generación de alternativas}

La siguiente fase es la generación de alternativas, la cual tiene como objetivo obtener la mayor cantidad posible de opciones que maximice la probabilidad de encontrar la mejor solución. Para favorecer la lluvia de ideas se deben considerar los elementos de cantidad, aplazamiento de juicio y variedad, los cuales fueron descritos a detalle en el apartado de elección y descripción de las técnicas. El registro de esta fase consiste en una lista del 1 al 10, donde se le pide al paciente que anote las ideas que surjan considerando los tres elementos mencionados. La cantidad de alternativas puede variar, pero se recomienda que sean mínimo cinco. $^{4}$

\subsubsection{Toma de decisiones}

En esta fase se analizan los costos y beneficios de cada una de las alternativas propuestas con el fin de identificar la(s) más efectiva(s). Para esto el paciente deberá anticiparse a los resultados de la solución evaluada. El registro incluye ocho columnas. En la primera, se enumeran las alternativas generadas; en la segunda, se escriben cuáles son las consecuencias positivas inmediatas; en la tercera, cuáles son las consecuencias positivas a largo plazo; en la cuarta, cuáles son las consecuencias negativas inmediatas; en la quinta, cuáles son las consecuencias negativas a largo plazo; en la sexta, cuáles son los efectos a nivel personal; en la séptima, cuáles son los efectos a nivel social; y en la octava, con base en lo descrito en las columnas anteriores, se responde a la pregunta ¿Puedo llevarlo a cabo ${ }^{4}$

$4 \quad$ Ver en los anexos del manual Viviendo con Enfermedad Renal Crónica: pautas y sugerencias para manejar mi estrés. Disponible en: https://tinyurl.com/enrenyes 
En caso de que queden dos alternativas al final y se esté indeciso de cuál emplear, se recomienda utilizar un registro, el cual consiste en dos columnas, la primera hace referencia a las ventajas de la alternativa y la otra a las desventajas. El objetivo es realizar este análisis con las dos últimas alternativas para dilucidar qué opción ejecutar primero. ${ }^{5}$

\subsection{Mantenimiento}

El mantenimiento hace referencia a conservar los cambios aprendidos y las metas logradas durante el tiempo; se refiere a los objetivos terapéuticos. De acuerdo con Caballo (1998), en estas sesiones se deberá registrar el progreso, fomentar el empleo continuo de estrategias, e identificar y cambiar otras conductas, pensamientos y ambientes relacionados a la conducta problema.

Para las sesiones de mantenimiento se deberá realizar una hipótesis de mantenimiento, la cual surge del AFC y de la(s) hipótesis funcional(es), dicha hipótesis de mantenimiento estará organizada de tal manera que se enfoque en los problemas funcionales del paciente, los objetivos terapéuticos y el repertorio de aprendizaje adquiridos durante el proceso terapéutico (Baldovino, 2016). La tarea del terapeuta es promover el cambio en el paciente a través de la retroalimentación y el reforzamiento, por lo cual deberá indagar si las estrategias adquiridas en las sesiones terapéuticas fueron empleadas; uno de los elementos importantes de esta sesión será analizar en conjunto con el paciente los cambios obtenidos a lo largo de las sesiones previas a través de la representación gráfica de los registros y, con ello, observar el progreso, discutir los cambios conseguidos, mencionar los aspectos que se deben seguir trabajando, y dar retroalimentación respecto a las acciones para mantenerlos (Medina et al., 2012). Finalmente, se deberá establecer una vía de contacto para realizar sesiones de apoyo solo en el caso de situaciones inmanejables, crisis o recaídas.

\subsection{Seguimiento}

El seguimiento se define como la evaluación posterior a la intervención, variando en un lapso de semanas hasta años. Este tiempo va a depender del objetivo principal del seguimiento, por ejemplo, si se está realizando una investigación, podría realizarse por años, pero si es en terapia, usualmente la evaluación se realiza semanas o meses más tarde. El principal objetivo de esta etapa es valorar si se están manteniendo las conductas aprendidas sin la intervención formal. En esa misma línea, esta evaluación permite tomar decisiones con respecto a continuar con la intervención o dar de alta al paciente. Se recomienda realizar la evaluación de seguimiento en el mismo escenario donde fue evaluado por primera vez, ya que de esta forma se equiparan las condiciones de evaluación y se pueden obtener resultados más eficaces (Kazdin, 1996).

$5 \quad$ Ver en los anexos del manual Viviendo con Enfermedad Renal Crónica: pautas y sugerencias para manejar mi estrés. Disponible en: https://tinyurl.com/enrenyes 
De acuerdo con Lira, Cruz y Ayala (2012), las recomendaciones a considerar antes de la primera sesión de seguimiento son preparar los instrumentos que se van a aplicar, tener presente el número de seguimientos que se va a realizar y revisar el expediente del paciente, así como los registros. Se sugiere que se realicen seguimientos al primer mes, al tercero y al sexto, y al finalizar cada sesión agendar la próxima cita.

El seguimiento como sistema organizado proporcionará ventajas terapéuticas que son difíciles de obtener de otra manera. Los cuatro objetivos del seguimiento son los siguientes: (a) evaluar el mantenimiento del cambio, (b) obtener indicadores que demuestren la eficacia de la intervención, (c) reforzar el proceso terapéutico, y (d) identificar las posibles recaídas y prevenirlas. La planificación del seguimiento se realizará en conjunto con el paciente en las sesiones de cierre.

\subsubsection{Intervención en crisis}

Para Slaikeu (2000), una crisis se define como un estado temporal de desorganización caracterizado por la incapacidad del individuo para manejar situaciones, utilizando métodos para la solución de problemas que no son acordes con la circunstancia. Entre los factores que incrementan o potencian una crisis se encuentran: la gravedad del suceso precipitante, los recursos personales del individuo y los contactos sociales concurrentes al momento de la crisis.

De acuerdo con Caplan (1961), una persona se encuentra en crisis cuando enfrenta un obstáculo que parece insuperable aun utilizando las estrategias de solución de problemas, generando un periodo de desorganización y malestar emocional. Brammer (1973) define a la crisis como un estado de desorganización en el que los individuos se enfrentan a la frustración o interrupción de objetivos importantes de su vida y a no encontrar alternativa para afrontar los eventos estresantes.

Por otra parte, Salazar, Caballo y González (2007) refieren que los eventos desencadenantes de las crisis suelen ser catástrofes naturales como terremotos, inundaciones, huracanes, tsunamis, entre otros, y aquellos desastres provocados por las acciones de los humanos, por ejemplo, incendios accidentes viales, aéreos, guerras, y atentados terroristas. En el caso particular de esta guía los eventos relacionados con la enfermedad (e. g., diagnóstico, tratamiento farmacológico y no farmacológico, procedimientos quirúrgicos, visitas al médico) pueden catalogarse como situaciones de crisis, ya que son altamente estresantes y amenazantes para el paciente, generando malestar emocional y la percepción de no tener los recursos suficientes para afrontar y controlar la situación.

La intervención en crisis es un componente necesario dentro del proceso terapéutico ya que, a pesar de que varias personas son capaces de responder con eficacia a las situaciones estresantes, existen otros individuos que al enfrentarse a un evento catastrófico simplemente no pueden controlarlo (Stone \& Conley, 2004). 
De acuerdo con Salazar et al. (2007), los objetivos de la intervención en crisis son los siguientes:

1. Construir una relación paciente-terapeuta que se caracterice por ser colaborativa y empática.

2. Evaluar las dimensiones de la crisis y del suceso desencadenante, así como el impacto personal, social y contextual.

3. Apoyar al individuo y a la comunidad afectada para que tengan cierto nivel de control ante la situación.

4. Desarrollar o fortalecer las habilidades y las estrategias de afrontamiento del individuo con la finalidad de hacerle frente a la situación estresante.

En la tabla 18 se describen las características de la intervención en crisis.

\section{Tabla 18}

\section{Características de la intervención en crisis}

Características

Estructurada

Directividad

Trabajo en conjunto

Enfoque proactivo

Perspectiva ecológica
Objetivo

Plantear un esquema que dirija el accionar del terapeuta.

Guiar el proceso terapéutico a través de la formulación de hipótesis, fomentar en el paciente la búsqueda de recursos y entrenarlo a utilizar a su favor los estilos de afrontamiento.

Relación terapeuta-paciente en donde ambos tengan un papel activo en la intervención.

Asumir la solución de problemas como la principal estrategia.

Considerar los grupos sociales en los que el paciente está inmerso y buscar la relación entre ellos para favorecer la solución de la crisis.

Nota: Elaboración propia a partir de "La intervención psicológica cognitivo-conductual en las crisis asociadas a desastres: una revisión teórica" por I. C. Salazar, V. E. Caballo y D. C. González, 2007, Psicología Conductual, pp. 393-394.

De acuerdo con Salazar et al. (2007), una adecuada evaluación de la crisis debe considerar cuáles son las características del evento desencadenante, qué procesos están involucrados en el funcionamiento psicológico del individuo, cuál es el repertorio conductual (e. g., déficits y excesos), cuáles son los antecedentes individuales (e. g., tendencias de comportamiento) y cuáles son las características del ambiente.

Por otro lado, Lazarus (1992) propuso el modelo multimodal BASIC-ID, que describe siete modalidades de funcionamiento en las cuales el individuo interactúa; de acuerdo con este autor, una evaluación precisa de la crisis se da a partir de una correcta evaluación de cada uno de los elementos de las modalidades descritas y de sus interacciones con las demás. En la tabla 19 se muestran los elementos que componen el modelo. 
Tabla 19

Elementos sobre el modelo BASIC-ID

\begin{tabular}{ll}
\multicolumn{1}{c}{ Modalidades } & \multicolumn{1}{c}{ Elementos } \\
Conducta & Actos, hábitos y respuestas motoras observables y medibles \\
\hline Afecto & Emociones, estados de ánimo y sentimientos \\
\hline Sensación & Los cinco sentidos (vista, olfato, gusto, tacto y oído) \\
\hline Imágenes & Sueños, fantasías, recuerdos, imágenes de sí mismos e imágenes auditivas como melodías o sonidos \\
\hline Cognicición & Actitudes, valores, opiniones e ideas \\
\hline Relaciones Interpersonales & Interacciones significativas con otras personas \\
\hline Drogas/Biología & Drogas, nutrición, higiene, ejercicio e insumos fisiológicos
\end{tabular}

Nota: Elaboración propia a partir de "The multimodal approach to the treatment of minor depression" por A. Lazarus, 1992, American Journal of Psychotherapy, 46, 50-57.

En el caso particular del paciente con ERC, situaciones como el recién diagnóstico, los cambios en la alimentación (e. g., restricción del consumo de líquidos), las adecuaciones de la actividad física, el tratamiento sustitutivo (e. g., diálisis peritoneal, hemodiálisis, trasplante renal), visitas frecuentes al hospital, adaptaciones en la vivienda, modificaciones en el aspecto laboral (e. g., cambiar de trabajo o incluso dejar de hacerlo) y los cambios físicos (e. g., imagen corporal) son eventos que los pacientes perciben como estresantes y que podrían desencadenar en crisis. En ese sentido, el especialista en MC debe estar capacitado para identificar los siguientes elementos: qué evento desencadenó la crisis, qué factores están involucrados en la crisis, cuáles son las emociones que está experimentando el paciente, cuáles son las respuestas conductuales ante la crisis, cuál es la historia de la enfermedad, cuáles son los recursos y estrategias de afrontamiento, y cuál es la red de apoyo con la que cuenta el paciente.

\subsubsection{Monitoreo}

El monitoreo es un proceso continuo para la evaluación cotidiana del estado general del paciente, los resultados de esta evaluación pueden modificar el rumbo de la intervención, ya que nos indicará si se está cumpliendo con los objetivos de las sesiones, por lo tanto, ayuda al terapeuta a controlar y supervisar el estado actual del paciente; además, permite verificar si se están realizando las actividades solicitadas y, de no ser así, identificar las posibles barreras o limitaciones (Urrego \& Rodríguez, 2012).

El monitoreo es una herramienta por medio de la cual el terapeuta de manera sistemática recabará la información de los resultados, no implica una sesión sino una serie de cuestionamientos del estado de salud y la percepción de los resultados. Este breve contacto favorece el reforzamiento al paciente y facilita identificar la ruta del proceso terapéutico, y puede realizarse por vía telefónica o mensajería. 


\subsection{Evaluación de satisfacción}

La TCC ha resultado ser efectiva y exitosa ante diversas problemáticas psicológicas. Sin embargo, el acceso a esta atención se ha visto obstaculizada por la pandemia del COVID-19, situación que ha favorecido la incorporación de alternativas terapéuticas basadas en tecnologías como la terapia en línea. A pesar de que esta terapia tiene ventajas como: acceso remoto, confidencialidad, reducción de la inhibición atención temprana, eficiencia económica, entre otras, resulta relevante realizar una evaluación de satisfacción en la que se conozca la opinión de los pacientes sobre los aspectos que conforman la terapia en línea (aplicaciones utilizadas, facilidad de envío de registros, infografías, cuestionarios, entre otros), lo cual permitiría identificar qué aspectos se podrían mejorar y así continuar trabajando para brindar una atención profesional (Clarke et al., 2009; Flores, Cárdenas, Durán, \& De la Rosa, 2014; Gutiérrez, 2020). Por tal motivo, al finalizar la intervención el paciente realizará una evaluación de satisfacción que estará disponible en la plataforma Google Forms ${ }^{\circledR}$.

\subsection{Cartas descriptivas}

\section{Tabla 20}

\section{Carta descriptiva de la sesión 1}

\begin{tabular}{|c|c|}
\hline Objetivo de la sesión & El terapeuta identificará la problemática asociada al estrés y otras variables emocionales. \\
\hline Procedimiento & Evaluación. \\
\hline Técnica de evaluación & Entrevista conductual, observación y reporte verbal. \\
\hline Inicio de sesión & $\begin{array}{l}\text { Dará la bienvenida al paciente. } \\
\text { Establecerá rapport y se presentará. } \\
\text { Explicará modalidad online para la atención. }\end{array}$ \\
\hline \multicolumn{2}{|l|}{ Durante la sesión } \\
\hline \multicolumn{2}{|c|}{$\begin{array}{l}\text { 1. Objetivo: El paciente recabará información general sobre los resultados de la batería de pruebas respondidas } \\
\text { previamente. }\end{array}$} \\
\hline Actividades del terapeuta & $\begin{array}{l}\text { Evaluará los resultados obtenidos a partir de la batería de pruebas que respondió el paciente } \\
\text { previamente en la etapa de envío de datos. } \\
\text { Brindará información y retroalimentación sobre el desempeño en los resultados obtenidos } \\
\text { de la batería aplicada que incluye los siguientes instrumentos: } \\
\text { - Escala de Ansiedad y Depresión Hospitalaria (HADS) (Zigmond \& Snaith, 1983) } \\
\text { - Escala de estrés percibido (PSS-14) (Cohen et al., 1983) } \\
\text { - Breve Check list de Afrontamiento (Abaroa et al., 2020) } \\
\text { - Síntomas de estrés } \\
\text { Responderá dudas. }\end{array}$ \\
\hline Actividades del paciente & $\begin{array}{l}\text { Escuchará al terapeuta. } \\
\text { Realizará preguntas. }\end{array}$ \\
\hline \multicolumn{2}{|c|}{ 2. Objetivo: El paciente identificará los derechos y responsabilidades de la terapia en línea. } \\
\hline Actividades del terapeuta & $\begin{array}{l}\text { Proporcionará información sobre el modelo de la TCC. } \\
\text { Explicará la modalidad de trabajo a través de uso de TIC's. } \\
\text { Enviará infografías de las indicaciones y sugerencias para las sesiones en línea.' } \\
\text { Enviará y ejecutará la lectura del Consentimiento Informado (CI) (Anexo 1). }\end{array}$ \\
\hline
\end{tabular}




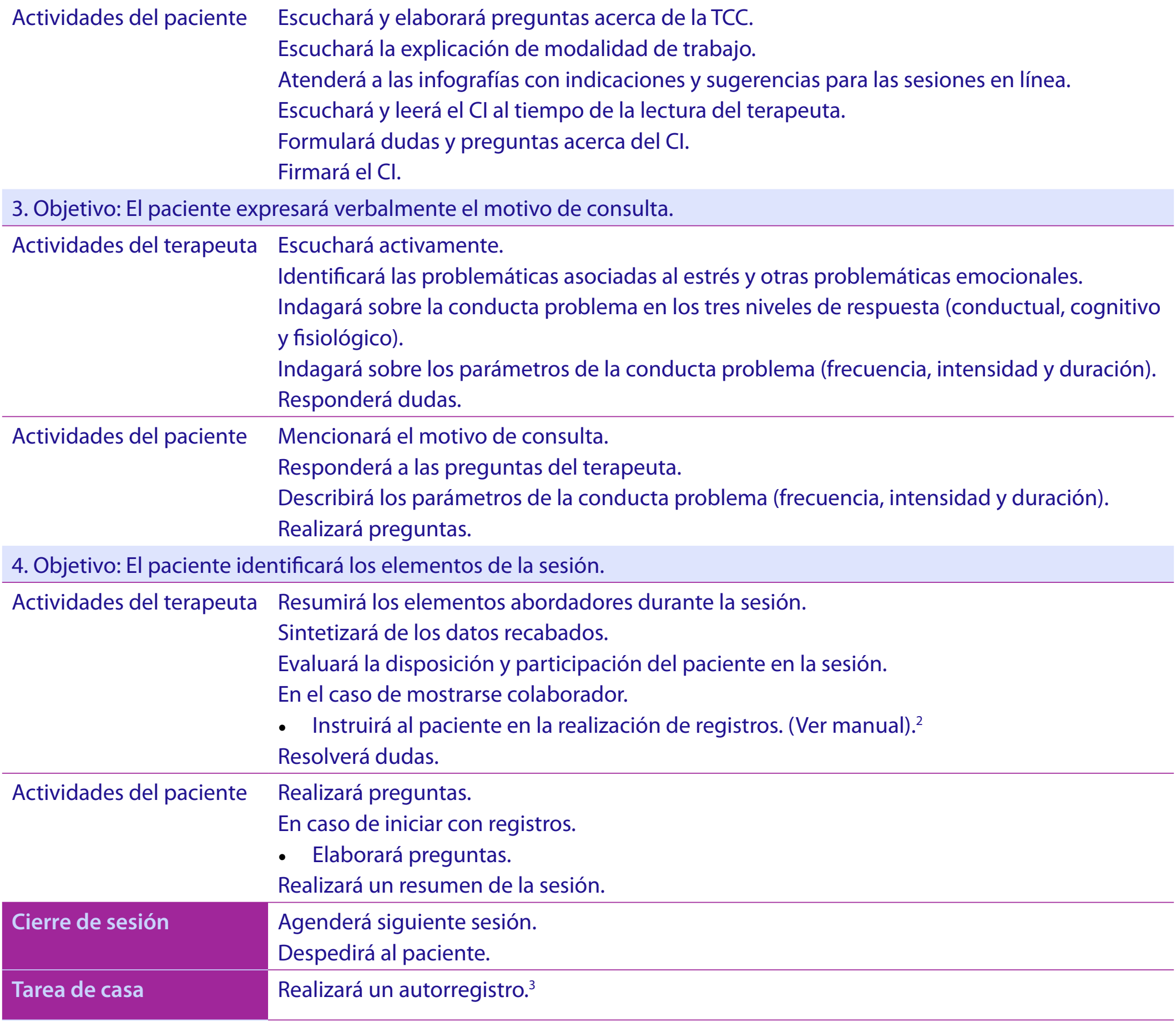

Nota: Elaboración propia. ${ }^{1}$ Disponibles en https://tinyurl.com/apsiel ${ }^{2}$ Disponible en https://tinyurl.com/gpperc ${ }^{3}$ Considerando las características, problemática y colaboración del paciente para la implementación del registro.

\section{Tabla 21}

\section{Carta descriptiva de la sesión 2}

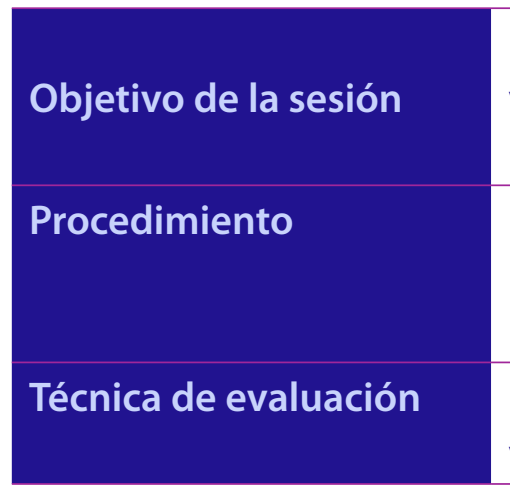

El terapeuta proseguirá con la evaluación de la problemática asociada al estrés y otras variables emocionales.

El terapeuta brindará psicoeducación de la técnica de relajación.

Evaluación.

Psicoeducación en relajación: beneficios y pasos de la respiración diafragmática profunda o rítmica.

Entrevista conductual, registro de relajación mediante Escala Visual Análoga (EVA), reporte verbal y observación. 


\begin{tabular}{ll}
\hline Inicio de sesión & $\begin{array}{l}\text { Saludará al paciente. } \\
\text { Continuará con el rapport. } \\
\text { Realizará un resumen de la sesión anterior. }\end{array}$ \\
\hline
\end{tabular}

\section{Durante la sesión}

1. Objetivo: El paciente expresará verbalmente la conducta problema relacionada al estrés u otras problemáticas emocionales asociadas.

Actividades del terapeuta Escuchará activamente.

Indagará la presencia de algún malestar emocional y los parámetros de este (frecuencia e intensidad).

Proseguirá con la entrevista conductual para identificar estímulos, respuestas y consecuencias derivadas de estas, además de determinar las posibles variables mediadoras. Elaborará, acorde con la información recabada, un análisis topográfico y funcional de la conducta (AFC).

Elaborará hipótesis funcionales relacionadas a los datos obtenidos durante la evaluación con base en el AFC.

- Efectuará una evaluación complementaria, en caso de ser necesaria la confirmación de un diagnóstico diferencial (e. g., depresión) a partir del uso de instrumentos validados. ${ }^{1}$ Resolverá dudas.

Actividades del paciente Responderá a las preguntas elaboradas por el terapeuta.

- Responderá la evaluación complementaria en caso de que el terapeuta lo indique. Realizará preguntas.

2. Objetivo: El paciente identificará la relación entre la relajación y la respiración.

Actividades del terapeuta Brindará la explicación de la técnica de relajación y el entrenamiento en respiración con apoyo de un video. ${ }^{2}$

Solicitará un resumen verbal de la explicación proporcionada.

Resolverá dudas.

Actividades del paciente Escuchará y observará el video de entrenamiento en respiración.

Proporcionará el resumen verbal de la explicación brindada.

Realizará preguntas.

Criterio de cambio El paciente verbalizará mínimo tres beneficios de la implementación de la técnica de relajación.

3. Objetivo: El paciente identificará el uso de los registros de relajación por medio de las Escalas Visuales Análogas (EVA).

Actividades del terapeuta Instruirá al paciente en el uso de los registros de relajación, específicamente en la EVA de relajación. (Ver manual). ${ }^{3}$

Responderá dudas.

Actividades del paciente Efectuará el llenado del registro de la EVA de relajación.

Expresará dudas.

Criterio de cambio El paciente escribirá mínimo un ejemplo del estado de relajación en el registro.

4. Objetivo: El paciente identificará el uso de las aplicaciones digitales para apoyo a la intervención.

Actividades del terapeuta Expondrá el uso de aplicaciones digitales para la retroalimentación fisiológica del desempeño en el entrenamiento en respiración.

Expondrá la relación entre el uso de las aplicaciones digitales, el registro y apoyo a la intervención.

Pedirá la realización de tareas.

Resolverá dudas.

Actividades del paciente Escuchará la explicación del uso de las aplicaciones digitales para la retroalimentación fisiológica del entrenamiento en respiración y del registro de variables fisiológicas. Realizará preguntas. 


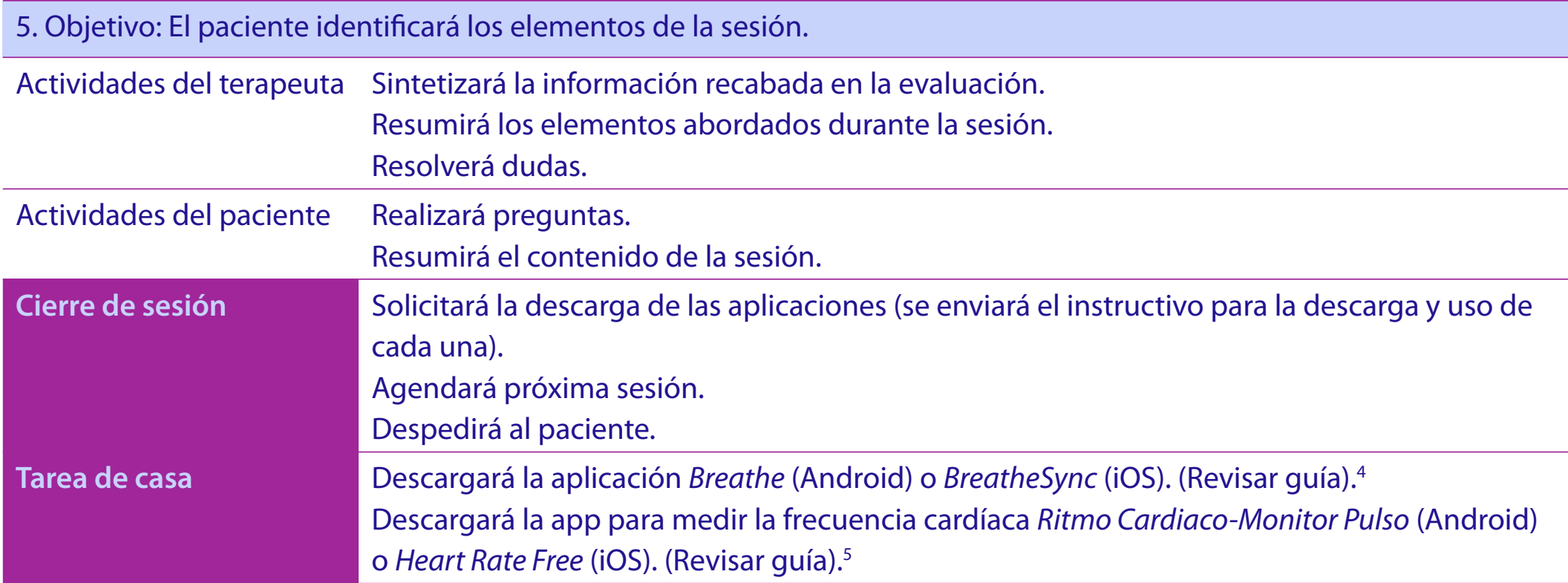

Nota: Elaboración propia. 'Para la evaluación complementaria, el terapeuta utilizará instrumentos validados y checklists disponibles en el repertorio digital. Disponible en https://tinyurl.com/evalini ${ }^{2}$ Disponible en https://tinyurl.com/enrenyes ${ }^{3}$ Disponible en https://tinyurl.com/gpperc ${ }^{4}$ Disponible en https://tinyurl.com/apfres ${ }^{5}$ Disponible en http://qartuppi.com/2021/ appfreccard.pdf

\section{Tabla 22}

\section{Carta descriptiva de la sesión 3}

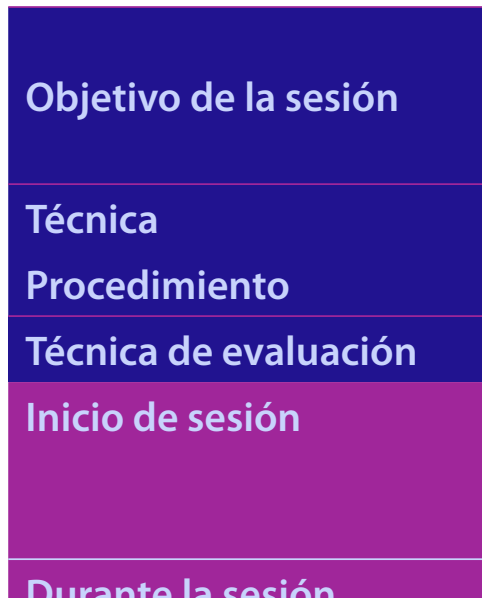

El terapeuta brindará psicoeducación en la técnica de respiración diafragmática o rítmica (tipos de respiración, beneficios ante el estrés y pasos). El terapeuta instruirá al paciente en la técnica en respiración diafragmática o rítmica. Respiración diafragmática o rítmica. Psicoeducación (tipos de respiración, beneficios y pasos).

Registros, reporte tanto verbal como escrito, y observación.

Saludará al paciente.

Continuará con el rapport.

Realizará un resumen de la sesión anterior.

\section{Durante la sesión}

1. Objetivo: El paciente identificará las generalidades del AFC.

Actividades del terapeuta Proporcionará las generalidades acerca del AFC del paciente. Responderá dudas.

Actividades del paciente Escuchará al terapeuta. Realizará preguntas.

2. Objetivo: El paciente identificará los síntomas fisiológicos del estrés.

Actividades del terapeuta Explicará sobre los síntomas medibles del estrés (variables fisiológicas). ${ }^{1}$ Resolverá dudas.

Pedirá un resumen verbal de la información presentada.

Actividades del paciente Escuchará y observará el video.

Realizará preguntas.

Resumirá la información brindada.

Criterio de cambio El paciente verbalizará mínimo tres síntomas fisiológicos relacionados con el estrés. 
3. Objetivo: El paciente señalará la relación entre la respiración diafragmática o rítmica y la reducción de los síntomas de estrés.

Actividades del terapeuta Explicará la relación entre la respiración diafragmática o rítmica y la reducción de los síntomas de estrés.

Resolverá dudas.

Solicitará un resumen acerca de la información brindada.

Actividades del paciente Escuchará la explicación de la relación entre respiración y la reducción de los síntomas de estrés.

Elaborará preguntas.

Elaborará un resumen verbal sobre la relación entre la respiración y la reducción de síntomas de estrés.

4. Objetivo: El paciente identificará los distintos tipos de respiración.

Actividades del terapeuta Proporcionará la explicación sobre los distintos tipos de respiración con apoyo del manual ${ }^{1}$ y de un video. ${ }^{2}$

Resolverá dudas.

Solicitará un resumen verbal acerca de la información presentada.

Actividades del paciente Escuchará y observará el video.

Realizará preguntas.

Realizará un resumen verbal de la información brindada.

Criterio de cambio El paciente verbalizará mínimo tres tipos de respiración.

5. Objetivo: El paciente señalará los beneficios relacionados a la respiración rítmica o diafragmática.

Actividades del terapeuta Expondrá los beneficios de la respiración diafragmática o rítmica con apoyo del manual ${ }^{1}$ y de un video. ${ }^{2}$

Resolverá dudas.

Solicitará un resumen de la información brindada.

Actividades del paciente Escuchará y observará el video.

Realizará preguntas.

Realizará un resumen verbal de la información brindada.

Criterio de cambio El paciente verbalizará al menos tres beneficios de la respiración diafragmática o rítmica.

6. Objetivo: El paciente señalará el uso de la aplicación digital para la retroalimentación de la respiración.

Actividades del terapeuta Instruirá en el uso de la app Breathe o BreatheSync. ${ }^{3}$

Resolverá dudas.

Actividades del paciente Señalará el uso de la app Breathe o BreatheSync y su relación con los ejercicios de respiración.

Realizará preguntas.

Criterio de cambio El paciente utilizará mínimo una vez la app Breathe o BreatheSync.

7. Objetivo: El paciente señalará el uso de la aplicación digital para el registro de la frecuencia cardiaca.

Actividades del terapeuta Instruirá en el uso de la app Ritmo Cardiaco-Monitor Pulso o Heart Rate Free. ${ }^{4}$

Resolverá dudas.

Actividades del paciente Señalará la relación entre el uso y beneficio de la app Ritmo Cardiaco-Monitor Pulso o Heart Rate Free.

Realizará preguntas.

Criterio de cambio El paciente ejemplificará mínimo una vez el uso de la app Ritmo Cardiaco-Monitor Pulso o Heart Rate Free y lo registrará. (Ver manual). ${ }^{1}$ 


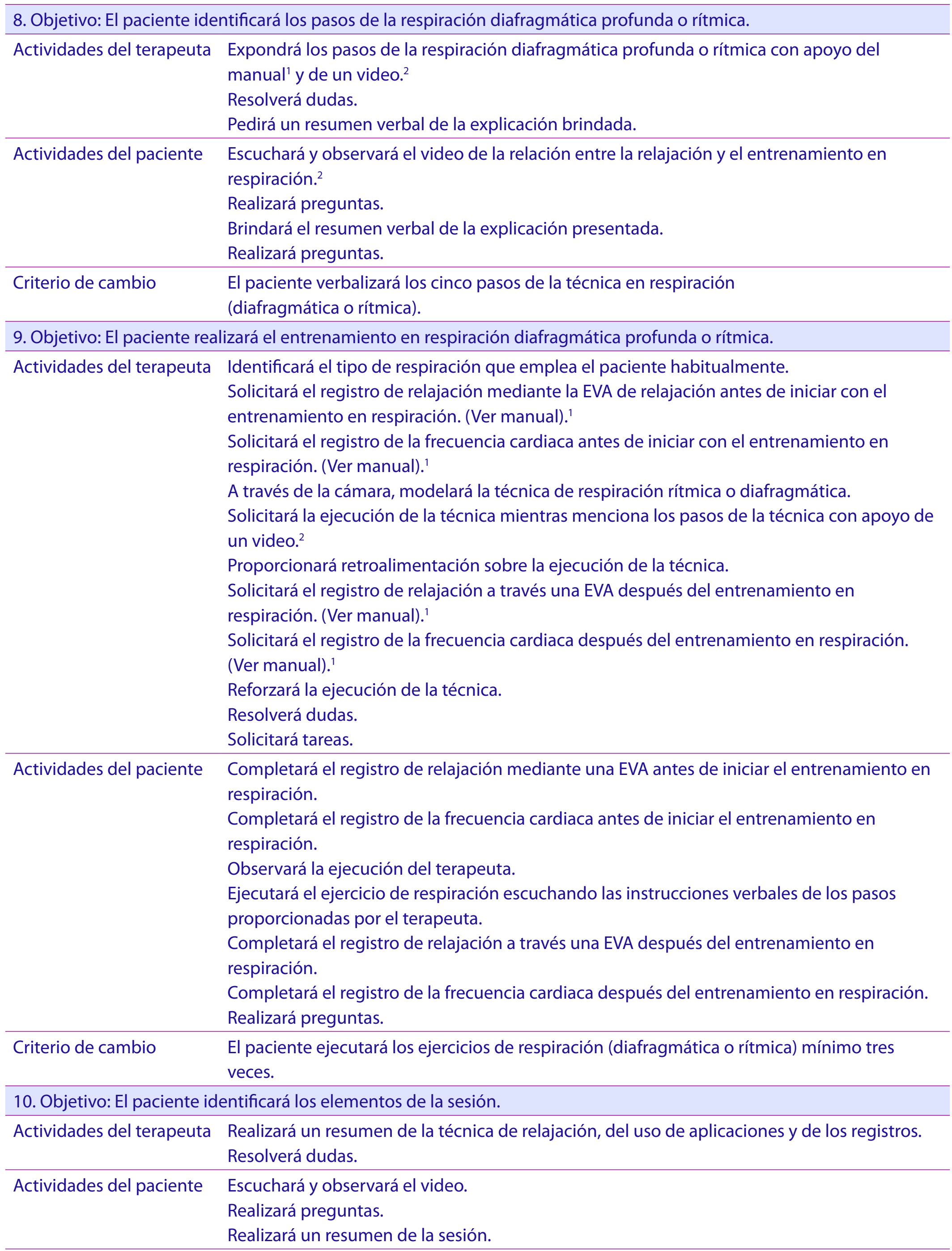




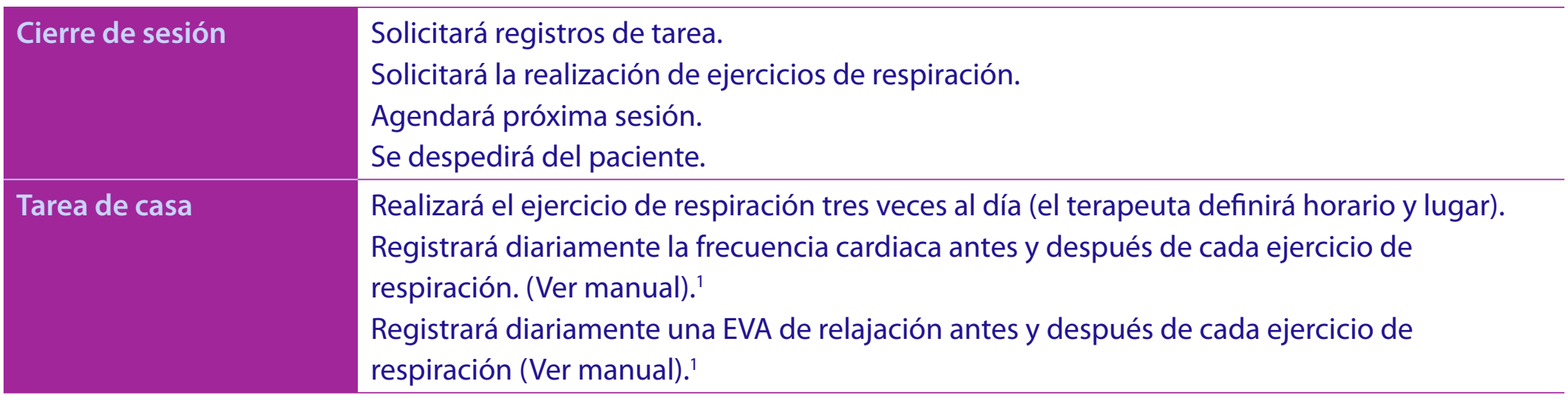

Nota: Elaboración propia. 'Disponible en https://tinyurl.com/gpperc ${ }^{2}$ Disponible en https://tinyurl.com/enrenyes ${ }^{3}$ Se omitirá el uso de la aplicación para la retroalimentación de la respiración, en el caso de que el paciente no cuente con ella. ${ }^{4}$ Se entrenará en la toma de frecuencia cardiaca análoga, si el paciente no cuenta con la aplicación para este fin.

\section{Tabla 23}

\section{Carta descriptiva de la sesión 4}

\begin{tabular}{|c|c|}
\hline Objetivo de la sesión & $\begin{array}{l}\text { El terapeuta proporcionará psicoeducación de las generalidades médicas de la Enfermedad } \\
\text { Renal Crónica (ERC): factores de riesgo, síntomas, complicaciones y tratamiento. } \\
\text { El terapeuta instruirá al paciente en la identificación de eventos estresantes relacionados } \\
\text { con la enfermedad. }\end{array}$ \\
\hline Procedimiento & Psicoeducación de enfermedad, estrés y estilos de afrontamiento. \\
\hline Técnica de evaluación & Observación, registro, cuestionario, reporte verbal y escrito. \\
\hline Inicio de sesión & $\begin{array}{l}\text { Saludará al paciente. } \\
\text { Continuará con el rapport. } \\
\text { Realizará un resumen de la sesión anterior. }\end{array}$ \\
\hline \multicolumn{2}{|l|}{ Durante la sesión } \\
\hline \multicolumn{2}{|c|}{ 1. Objetivo: El paciente recibirá retroalimentación de los registros (tarea). } \\
\hline Actividades del terapeuta & $\begin{array}{l}\text { Examinará los registros realizados en casa. } \\
\text { Proporcionará retroalimentación sobre los registros. } \\
\text { Resolverá dudas. }\end{array}$ \\
\hline Actividades del paciente & $\begin{array}{l}\text { Escuchará al terapeuta. } \\
\text { Realizará preguntas. }\end{array}$ \\
\hline \multicolumn{2}{|c|}{ 2. Objetivo: El paciente identificará los factores de riesgo, signos, síntomas, complicaciones y tratamiento de la ERC. } \\
\hline Actividades del terapeuta & $\begin{array}{l}\text { Expondrá los factores de riesgo, signos, síntomas, complicaciones y tratamiento de la ERC. } \\
\text { (Ver manual). }{ }^{1} \\
\text { Proporcionará ejemplos. } \\
\text { Pedirá ejemplos. } \\
\text { Resolverá dudas. }\end{array}$ \\
\hline Actividades del paciente & $\begin{array}{l}\text { Escuchará activamente la explicación. } \\
\text { Proporcionará ejemplos. } \\
\text { Realizará preguntas. }\end{array}$ \\
\hline Criterio de cambio & $\begin{array}{l}\text { El paciente responderá cinco de las seis preguntas del cuestionario: } \\
\text { ¿Qué es ERC? } \\
\text { ¿Cuáles son los factores de riesgo? } \\
\text { ¿Cuáles son los signos? } \\
\text { ¿Cuáles son los síntomas? } \\
\text { ¿Cuáles son las complicaciones? Menciona dos complicaciones } \\
\text { ¿Cuál es la base del tratamiento de ERC? }\end{array}$ \\
\hline
\end{tabular}




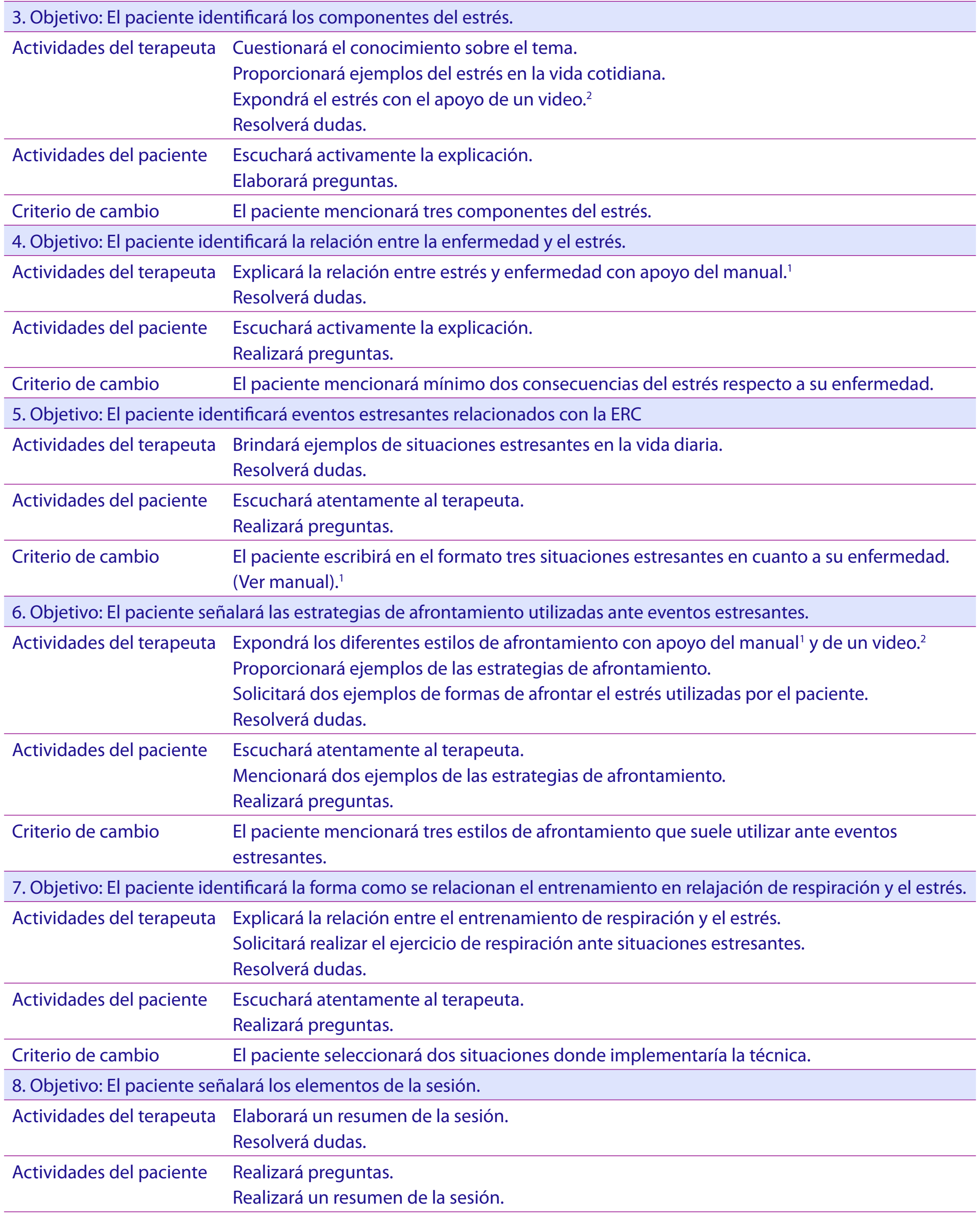




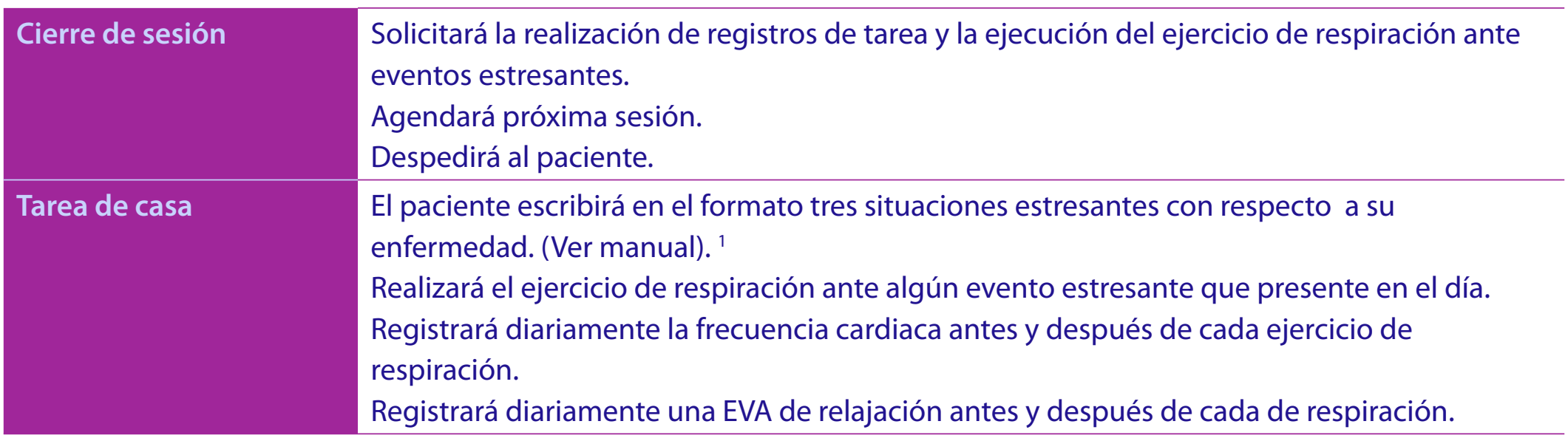

Nota: Elaboración propia. ${ }^{1}$ Disponible en https://tinyurl.com/gpperc ${ }^{2}$ Disponible en https://tinyurl.com/enrenyes

\section{Tabla 24 \\ Carta descriptiva de la sesión 5}

\section{Objetivo de la sesión \\ Técnica \\ Procedimiento \\ Técnica de evaluación \\ Inicio de sesión}

El terapeuta instruirá al paciente en la ejecución de la técnica de autoinstrucciones ante situaciones estresantes.

Autoinstrucciones.

Psicoeducación, modelamiento y ensayo conductual.

Observación, registro, reporte verbal y escrito.

Saludará al paciente.

Continuará con el rapport.

Realizará un resumen de la sesión anterior.

\begin{tabular}{|c|c|}
\hline \multicolumn{2}{|l|}{ Durante la sesión } \\
\hline Actividades del terapeuta & $\begin{array}{l}\text { Examinará los registros realizados en casa. } \\
\text { Proporcionará retroalimentación sobre los registros. } \\
\text { Resolverá dudas. }\end{array}$ \\
\hline Actividades del paciente & $\begin{array}{l}\text { Escuchará al terapeuta. } \\
\text { Realizará preguntas. }\end{array}$ \\
\hline \multicolumn{2}{|c|}{ 2. Objetivo: El paciente señalará los pasos para la técnica de autoinstrucciones. } \\
\hline Actividades del terapeuta & $\begin{array}{l}\text { Expondrá la psicoeducación de la técnica de autoinstrucciones con el apoyo del manual' y } \\
\text { de un video. } \\
\text { Especificará los pasos para implementar la técnica en una tarea determinada. } \\
\text { Resolverá dudas. }\end{array}$ \\
\hline Actividades del paciente & $\begin{array}{l}\text { Identificará los pasos para realizar la técnica de autoinstrucciones. } \\
\text { Realizará preguntas. }\end{array}$ \\
\hline Criterio de cambio & $\begin{array}{l}\text { El paciente mencionará mínimo cuatro de los pasos para la implementación de la técnica de } \\
\text { autoinstrucciones. }\end{array}$ \\
\hline \multicolumn{2}{|c|}{ 3. Objetivo: El paciente elaborará autoinstrucciones para un evento estresante. } \\
\hline Actividades del terapeuta & $\begin{array}{l}\text { Solicitará al paciente seleccionar y escribir un evento estresante. (Ver manual). }{ }^{1} \\
\text { Facilitará la realización de autoinstrucciones para ese evento. } \\
\text { Resolverá dudas. }\end{array}$ \\
\hline Actividades del paciente & $\begin{array}{l}\text { Seleccionará y escribirá un evento estresante. } \\
\text { Realizará preguntas. }\end{array}$ \\
\hline Criterio de cambio & $\begin{array}{l}\text { El paciente enlistará mínimo tres autoinstrucciones para evento estresante seleccionado. } \\
\text { (Ver manual). }{ }^{1}\end{array}$ \\
\hline
\end{tabular}




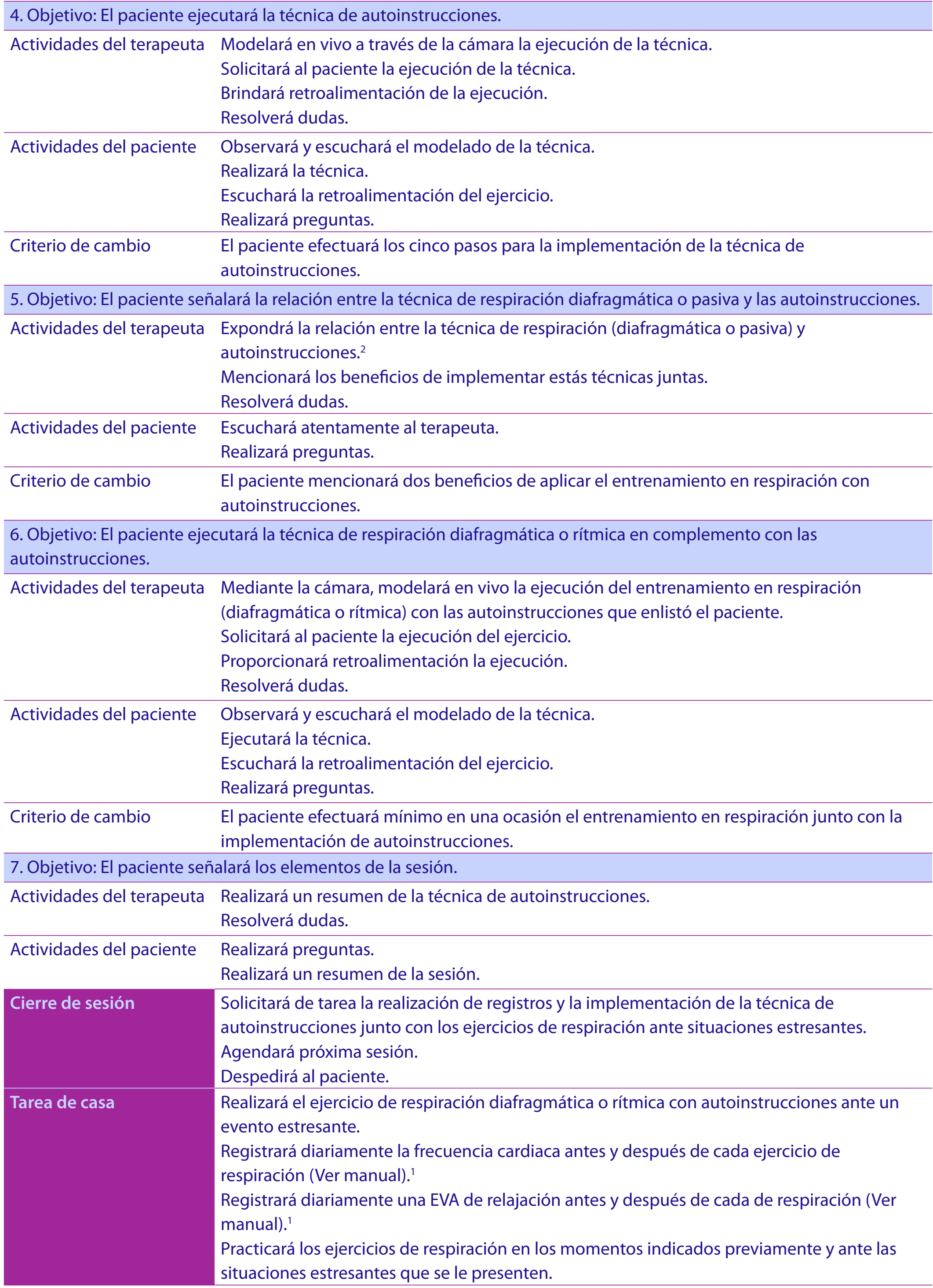

Nota: Elaboración propia. ${ }^{1}$ Disponible en https://tinyurl.com/gpperc ${ }^{2}$ Disponible en https://tinyurl.com/enrenyes 


\section{Tabla 25}

\section{Carta descriptiva de la sesión 6}

\begin{tabular}{|c|c|}
\hline Objetivo de la sesión & $\begin{array}{l}\text { El terapeuta instruirá al paciente en la técnica de solución de problemas (identificación de } \\
\text { problemas). }\end{array}$ \\
\hline Técnica & Solución de problemas. \\
\hline Procedimiento & $\begin{array}{l}\text { Psicoeducación en identificación del problema (paso 1) de la técnica de solución de } \\
\text { problemas. }\end{array}$ \\
\hline Técnica de evaluación & Registro de identificación de problema, observación y reporte verbal. \\
\hline Inicio de sesión & $\begin{array}{l}\text { Saludará al paciente. } \\
\text { Continuará con el rapport. } \\
\text { Realizará un resumen de la sesión anterior. }\end{array}$ \\
\hline \multicolumn{2}{|l|}{ Durante la sesión } \\
\hline \multicolumn{2}{|c|}{ 1. Objetivo: El paciente recibirá retroalimentación de los registros (tarea). } \\
\hline Actividades del terapeuta & $\begin{array}{l}\text { Examinará los registros realizados en casa. } \\
\text { Proporcionará retroalimentación sobre los registros. } \\
\text { Resolverá dudas. }\end{array}$ \\
\hline Actividades del paciente & $\begin{array}{l}\text { Escuchará al terapeuta. } \\
\text { Realizará preguntas. }\end{array}$ \\
\hline \multicolumn{2}{|c|}{ 2. Objetivo: El paciente identificará los elementos de la técnica de solución de problemas (SP). } \\
\hline Actividades del terapeuta & $\begin{array}{l}\text { Expondrá la técnica de SP con apoyo del manual }{ }^{1} \text { y de un video. } \\
\text { Solicitará explicación de la técnica. } \\
\text { Resolverá dudas. }\end{array}$ \\
\hline Actividades del paciente & $\begin{array}{l}\text { Escuchará y observará el video. } \\
\text { Resumirá la técnica. } \\
\text { Realizará preguntas }\end{array}$ \\
\hline Criterio de cambio & El paciente verbalizará mínimo dos características de la técnica. \\
\hline \multicolumn{2}{|c|}{ 3. Objetivo: El paciente identificará la relación entre la técnica de SP y el manejo de estrés. } \\
\hline Actividades del terapeuta & $\begin{array}{l}\text { Brindará la explicación sobre la relación entre la técnica de SP y el manejo de estrés. } \\
\text { Proporcionará ejemplos. } \\
\text { Solicitará ejemplos. } \\
\text { Resolverá dudas. }\end{array}$ \\
\hline Actividades del paciente & $\begin{array}{l}\text { Escuchará la explicación. } \\
\text { Proporcionará ejemplos. } \\
\text { Realizará preguntas. }\end{array}$ \\
\hline Criterio de cambio & $\begin{array}{l}\text { El paciente mencionará mínimo dos beneficios de implementar la técnica de SP para el } \\
\text { manejo de estrés. }\end{array}$ \\
\hline \multicolumn{2}{|c|}{ 4. Objetivo: El paciente identificará los elementos de un problema (el qué, quién/quiénes, dónde, cuándo y cómo). } \\
\hline Actividades del terapeuta & $\begin{array}{l}\text { Expondrá la importancia de la identificación del problema en apoyo del manual }{ }^{1} \text { y de un } \\
\text { video. }^{2} \\
\text { Proporcionará ejemplos. } \\
\text { Solicitará ejemplos. } \\
\text { Explicará el llenado del registro de identificación de problema. (Ver manual). }{ }^{1} \\
\text { Resolverá dudas. }\end{array}$ \\
\hline
\end{tabular}




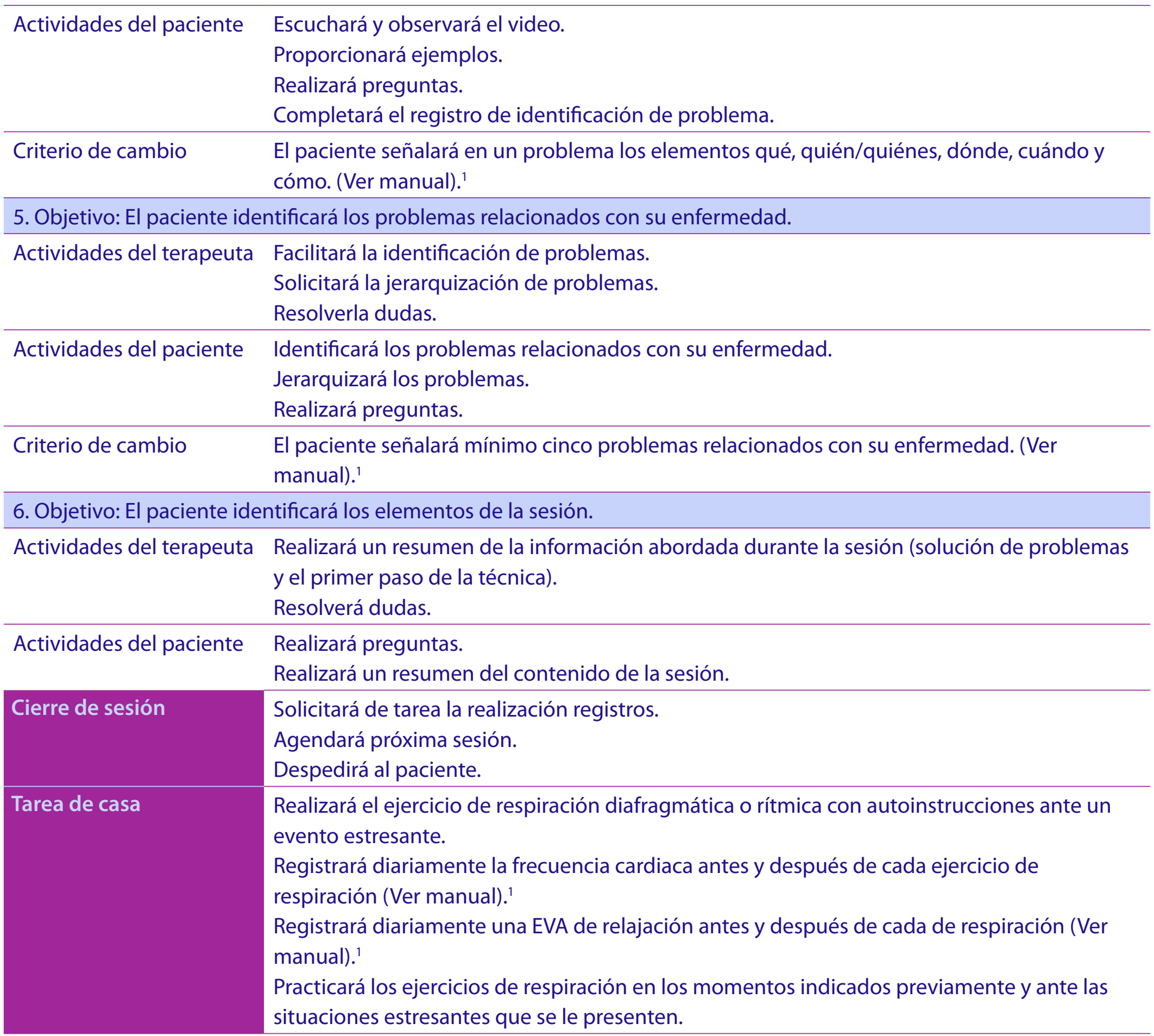

Nota: Elaboración propia. 'Disponible en https://tinyurl.com/gpperc ${ }^{2}$ Disponible en https://tinyurl.com/enrenyes

\section{Tabla 26}

\section{Carta descriptiva de la sesión 7}

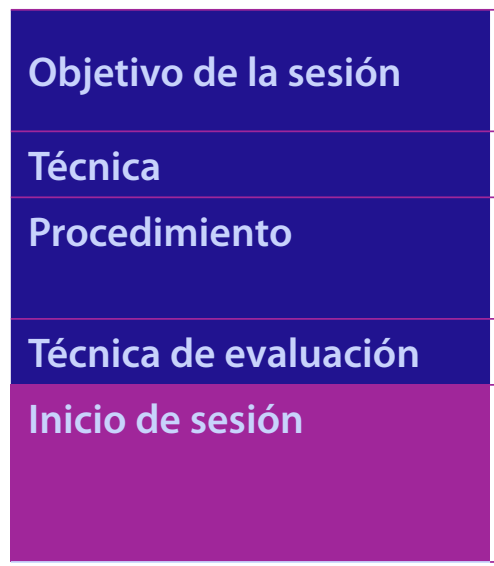

El terapeuta instruirá al paciente en la técnica de solución de problemas (generación de alternativas).

Solución de problemas.

Psicoeducación en generación de alternativas (paso 2) de la técnica de solución de problemas.

Registro de generación de alternativas, observación, reporte verbal y escrito.

Saludará al paciente.

Continuará con el rapport.

Realizará un resumen de la sesión anterior. 
Durante la sesión

1. Objetivo: El paciente recibirá retroalimentación de los registros realizados en casa y los de la sesión anterior (SP).

Actividades del terapeuta Revisará los registros realizados en casa.

Proporcionará retroalimentación sobre los registros.

Resolverá dudas.

Actividades del paciente Escuchará al terapeuta.

Realizará preguntas.

2. Objetivo: El paciente generará alternativas de solución.

Actividades del terapeuta Expondrá la importancia de la generación de alternativas de acuerdo con los criterios de cantidad, aplazamiento de juicio y variedad con apoyo del manual ${ }^{1}$ y de un video. ${ }^{2}$

Proporcionará ejemplos.

Solicitará ejemplos.

Explicará el llenado del registro de generación de alternativas. (Ver manual). ${ }^{1}$

Resolverá dudas.

Actividades del paciente Escuchará y observará el video.

Brindará ejemplos.

Realizará preguntas

Completará el registro de generación de alternativas.

Criterio de cambio El paciente enlistará mínimo cinco alternativas con los criterios del paso en el registro de generación de alternativas. (Ver manual). ${ }^{1}$

3. Objetivo: El paciente identificará los elementos de la sesión.

Actividades del terapeuta Realizará un resumen de los elementos de la sesión.

Resolverá dudas.

Actividades del paciente Realizará preguntas.

Realizará un resumen de la sesión.

Cierre de sesión

Solicitará de tarea la realización registros.

Solicitará la generación de alternativas para el segundo problema.

Agendará próxima sesión.

Despedirá al paciente.

Tarea de casa

Registrará cinco alternativas de solución atendiendo a los criterios (cantidad, aplazamiento de juicio y variedad) para el segundo problema de su lista elaborada la sesión previa. (Ver manual). ${ }^{1}$

Realizará el ejercicio de respiración diafragmática o rítmica con autoinstrucciones ante un evento estresante.

Registrará diariamente la frecuencia cardiaca antes y después de cada ejercicio de respiración. (Ver manual). ${ }^{1}$

Registrará diariamente una EVA de relajación antes y después de cada de respiración. (Ver manual). ${ }^{1}$

Practicará los ejercicios de respiración en los momentos indicados previamente y ante las situaciones estresantes que se le presenten.

Nota: Elaboración propia. 'Disponible en https://tinyurl.com/gpperc ${ }^{2}$ Disponible en https://tinyurl.com/enrenyes 
Tabla 27

Carta descriptiva de la sesión 8

\begin{tabular}{|c|c|}
\hline Objetivo de la sesión & $\begin{array}{l}\text { El terapeuta instruirá al paciente en la técnica de solución de problemas (toma de } \\
\text { decisiones). }\end{array}$ \\
\hline Técnica & Solución de problemas. \\
\hline Procedimiento & Psicoeducación en la toma de decisiones (paso 3) de la técnica de solución de problemas. \\
\hline Técnica de evaluación & Registro de costo y beneficio, observación, reporte verbal y escrito. \\
\hline Inicio de sesión & $\begin{array}{l}\text { Saludará al paciente. } \\
\text { Continuará con el rapport. } \\
\text { Realizará un resumen de la sesión anterior. }\end{array}$ \\
\hline \multicolumn{2}{|l|}{ Durante la sesión } \\
\hline \multicolumn{2}{|c|}{ 1. Objetivo: El paciente recibirá retroalimentación de los registros realizados en casa y los de la sesión anterior (SP). } \\
\hline Actividades del terapeuta & $\begin{array}{l}\text { Examinará los registros realizados en casa. } \\
\text { Proporcionará retroalimentación sobre los registros. } \\
\text { Resolverá dudas }\end{array}$ \\
\hline Actividades del paciente & $\begin{array}{l}\text { Escuchará al terapeuta. } \\
\text { Realizará preguntas. }\end{array}$ \\
\hline \multicolumn{2}{|c|}{ 2. Objetivo: El paciente identificará las ventajas y desventajas de las alternativas de solución. } \\
\hline Actividades del terapeuta & $\begin{array}{l}\text { Expondrá el paso } 3 \text { de la técnica: la toma de decisiones, con apoyo del manual }{ }^{1} \text { y de un } \\
\text { video. }^{2} \\
\text { Proporcionará ejemplos. } \\
\text { Solicitará ejemplos. } \\
\text { Explicará el llenado del registro de toma de decisiones y el análisis costo-beneficio. } \\
\text { (Ver manual). }{ }^{1}\end{array}$ \\
\hline Actividades del paciente & $\begin{array}{l}\text { Escuchará y observará el video. } \\
\text { Brindará ejemplos. } \\
\text { Realizará preguntas. } \\
\text { Completará el registro. } \\
\text { Escribirá ventajas y desventajas de cada alternativa. }\end{array}$ \\
\hline Criterio de cambio & El paciente enlistará mínimo dos ventajas y dos desventajas de cada alternativa. \\
\hline \multicolumn{2}{|c|}{ 3. Objetivo: El paciente seleccionará una alternativa de solución. } \\
\hline Actividades del terapeuta & $\begin{array}{l}\text { Incitará la realización del análisis de las ventajas y desventajas de cada alternativa planteada. } \\
\text { Resolverá dudas. }\end{array}$ \\
\hline Actividades del paciente & Analizará las ventajas y desventajas de las alternativas enlistadas. \\
\hline Criterio de cambio & El paciente seleccionará máximo dos alternativas de solución. \\
\hline \multicolumn{2}{|c|}{ 4. Objetivo: El paciente identificará los elementos de la sesión. } \\
\hline Actividades del terapeuta & $\begin{array}{l}\text { Realizará un resumen de lo realizado en la sesión. } \\
\text { Resolverá dudas. }\end{array}$ \\
\hline Actividades del paciente & $\begin{array}{l}\text { Realizará preguntas. } \\
\text { Realizará un resumen de la sesión. }\end{array}$ \\
\hline Cierre de sesión & $\begin{array}{l}\text { Solicitará de tarea la realización de los registros. } \\
\text { Agendará próxima sesión. } \\
\text { Recordará que faltan dos sesiones para finalizar la intervención. } \\
\text { Despedirá al paciente. }\end{array}$ \\
\hline
\end{tabular}




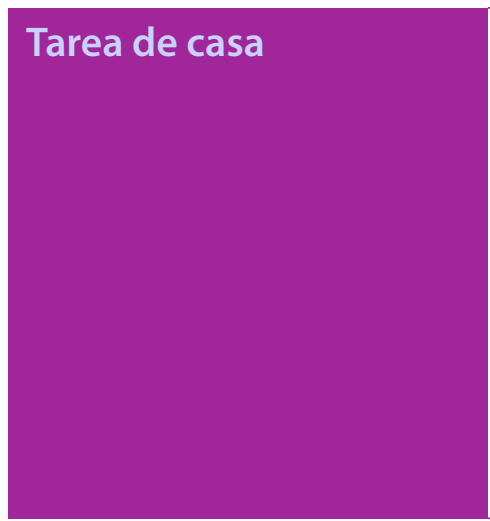

Realizará el plan de ejecución. ${ }^{3}$

Realizará el ejercicio de respiración diafragmática o rítmica con autoinstrucciones ante un evento estresante.

Registrará diariamente la frecuencia cardiaca antes y después de cada ejercicio de respiración. (Ver manual). ${ }^{1}$

Registrará diariamente una EVA de relajación antes y después de cada de respiración. (Ver manual). ${ }^{1}$

Practicará los ejercicios de respiración en los momentos indicados previamente y ante las situaciones estresantes que se le presenten.

Nota: Elaboración propia. 'Disponible en https://tinyurl.com/gpperc ${ }^{2}$ Disponible en https://tinyurl.com/enrenyes ${ }^{3}$ El terapeuta sopesará la necesidad de implementar otras técnicas cognitivo-conductuales con base en las características y habilidades del paciente.

\section{Tabla 28}

\section{Carta descriptiva de la sesión 9}

\section{Objetivo de la sesión \\ Procedimiento \\ Técnica de evaluación \\ Inicio de sesión}

El terapeuta instruirá al paciente en la elaboración de planes de acción.

Psicoeducación y plan de acción.

Registro plan de acción, reporte verbal, reporte escrito y observación.

Saludará al paciente.

Reiterará que es la penúltima sesión.

Continuará con el rapport.

Realizará un resumen de la sesión anterior.

\section{Durante la sesión}

1. Objetivo: El paciente obtendrá retroalimentación de los registros realizados en casa.

Actividades del terapeuta Revisará los registros realizados en casa.

Proporcionará retroalimentación sobre los registros.

Resolverá dudas.

Actividades del paciente Escuchará al terapeuta.

Realizará preguntas.

2. Objetivo: El paciente señalará las condiciones en las que practica las técnicas.

Actividades del terapeuta Indagará sobre la práctica de las técnicas entrenadas durante la intervención. Solicitará la descripción del momento y condiciones en que pone en práctica las técnicas.

Actividades del paciente Escuchará al terapeuta. Indicará el momento en que practica las técnicas.

Describirá las condiciones (dónde, cuándo, con quién y ante qué situaciones) en que implementa las técnicas.

Criterio de cambio El paciente describirá al menos dos situaciones donde las puso a prueba.

3. Objetivo: El paciente señalará situaciones problemáticas que interrumpen la implementación de las técnicas.

Actividades del terapeuta Expondrá la relevancia de señalar estas situaciones y su relación para mejorar el desempeño en las técnicas y la efectividad de los resultados.

Retomará la información recabada mediante los registros.

Cuestionará sobre situaciones que pudieron intervenir en la aplicación de las técnicas.

Actividades del paciente Escuchará al terapeuta.

Especificará los eventos que intervienen en la implementación de las técnicas.

Especificará las condiciones que impiden la implementación de las técnicas.

Criterio de cambio

El paciente señalará como mínimo dos condiciones que impiden la implantación de las técnicas. 
4. Objetivo: El paciente identificará la relación entre situaciones problemáticas, la efectividad de la implementación de las técnicas y el estrés.

Actividades del terapeuta Explicará la relación entre las técnicas de manejo de estrés entrenadas y las situaciones que impiden su práctica.

Expondrá la relevancia de identificar esas situaciones en cuanto al manejo de estrés con apoyo del manual. ${ }^{1}$

Solicitará realizar un resumen de lo expuesto.

Actividades del paciente Escuchará al terapeuta.

Realizará un resumen de lo expuesto.

5. Objetivo: El paciente producirá un plan de acción.

Actividades del terapeuta Especificará la función de un plan de acción.

Recuperará la información obtenida en la sesión (condiciones de práctica y situaciones problema).

Solicitará al paciente que seleccione dos condiciones que impidan la práctica de las técnicas (barreras) y las anote en el registro de plan de acción (Ver manual). ${ }^{1}$

Solicitará al paciente que brinde tres soluciones o alternativas implementando la técnica de solución de problemas ante esas barreras y las anote en el registro de plan de acción.

Preguntando: ¿Qué podría hacer para cambiar estás situaciones? o ¿Cómo haría que las técnicas fuesen más efectivas o mejores ante esta situación?

Proporcionará retroalimentación sobre la ejecución del paciente.

Explicará que la elección de la alternativa para implementar una solución puede basarse en funcionalidad o facilidad.

Solicitará la selección de la alternativa señalándolo en el registro.

Actividades del paciente Escuchará al terapeuta.

Seleccionará dos situaciones que sean una barrera en la implementación de las técnicas y las anotará en el registro.

Brindará tres soluciones a cada barrera y las escribirá en el registro.

Seleccionará una solución para cada barrera y las señalará en el registro.

Criterio de cambio El paciente enlistará mínimo dos soluciones a cada barrera en el registro.

6. Objetivo: El paciente identificará los elementos de la sesión.

Actividades del terapeuta Realizará un resumen de la sesión acerca del plan de acción elaborado. Resolverá dudas.

Actividades del paciente Escuchará al terapeuta. Realizará preguntas.

Cierre de sesión

Solicitará de tareas la elaboración de registros y la implementación del plan de acción. Programará la siguiente sesión y mencionará que será la última.

Despedirá al paciente.

Tarea de casa

Realizará el ejercicio de respiración tres veces al día (el terapeuta definirá el horario y lugar).

Registrará diariamente la frecuencia cardiaca antes y después de cada ejercicio de respiración. (Ver manual). ${ }^{1}$

Registrará diariamente una EVA de relajación antes y después de cada de respiración. (Ver manual). ${ }^{1}$

Practicará los ejercicios de respiración ante situaciones estresantes.

Implementará el plan de acción.

Nota: Elaboración propia. 'Disponible en https://tinyurl.com/gpperc 


\section{Tabla 29}

\section{Carta descriptiva de la sesión 10}

\begin{tabular}{|c|c|}
\hline Objetivo de la sesión & $\begin{array}{l}\text { El terapeuta evaluará los resultados del plan de acción. } \\
\text { El terapeuta evaluará el progreso del paciente con respecto a la intervención. }\end{array}$ \\
\hline Procedimiento & Plan de acción y evaluación post-intervención. \\
\hline Técnica de evaluación & $\begin{array}{l}\text { Registro de plan de acción, reporte escrito, reporte verbal y evaluación (Batería de } \\
\text { instrumentos). }\end{array}$ \\
\hline Inicio de sesión & $\begin{array}{l}\text { Saludará al paciente. } \\
\text { Continuará con el rapport. } \\
\text { Recordará que es la última sesión de la intervención. } \\
\text { Mencionará que de ser necesario la intervención puede extenderse. } \\
\text { Realizará un resumen de la sesión anterior. }\end{array}$ \\
\hline \multicolumn{2}{|l|}{ Durante la sesión } \\
\hline \multicolumn{2}{|c|}{ 1. Objetivo: El paciente recibirá retroalimentación de los registros (tarea). } \\
\hline Actividades del terapeuta & $\begin{array}{l}\text { Examinará los registros realizados en casa. } \\
\text { Proporcionará retroalimentación sobre los registros. } \\
\text { Resolverá dudas. }\end{array}$ \\
\hline Actividad del paciente & $\begin{array}{l}\text { Escuchará al terapeuta. } \\
\text { Realizará preguntas. }\end{array}$ \\
\hline \multicolumn{2}{|c|}{ 2. Objetivo: El paciente elaborará plan de acción. } \\
\hline Actividades del terapeuta & $\begin{array}{l}\text { Preguntará por la aplicación del plan de acción de la sesión pasada y sus resultados. } \\
\text { Indagará si el paciente identificó otras barreras en la implementación de las técnicas. } \\
\text { En caso de haberlas identificado solicitará al paciente: } \\
\text { - Señalar las barreras identificadas. } \\
\text { - Realizar un plan de acción para cada barrera con base en el registro. } \\
\text { - Seleccionar una solución para cada barrera. } \\
\text { En caso de no haberlas identificado solicitará al paciente: } \\
\text { - Describir las condiciones en que implementó las técnicas en la última semana. } \\
\text { - Señalar las barreras durante la implementación de las técnicas. } \\
\text { - Realizar un plan de acción para cada barrera con base en el registro. } \\
\text { - Seleccionar una solución para cada barrera. } \\
\text { Resolverá dudas. }\end{array}$ \\
\hline Actividades del paciente & $\begin{array}{l}\text { Describirá el plan de acción implementado y sus resultados. } \\
\text { En caso de que haya identificado otras barreras: } \\
\text { - Señalará si identificó alguna otra barrera en la implementación de las técnicas. } \\
\text { - Elaborará un plan de acción de acuerdo con el registro para cada barrera. } \\
\text { - Seleccionará una solución para cada barrera. } \\
\text { En caso de no haber identificado otras barreras: } \\
\text { - Describirá las condiciones en que implementó las técnicas en la última semana. } \\
\text { - Señalará si identifica alguna otra barrera en la implementación de las técnicas. } \\
\text { - Elaborará un plan de acción de acuerdo con el registro para cada barrera. } \\
\text { - Seleccionará una solución para cada barrera. } \\
\text { Realizará preguntas. }\end{array}$ \\
\hline Criterio de cambio & $\begin{array}{l}\text { El paciente elaborará un plan de acción de al menos una situación barrera en la } \\
\text { implementación de técnicas. }\end{array}$ \\
\hline
\end{tabular}




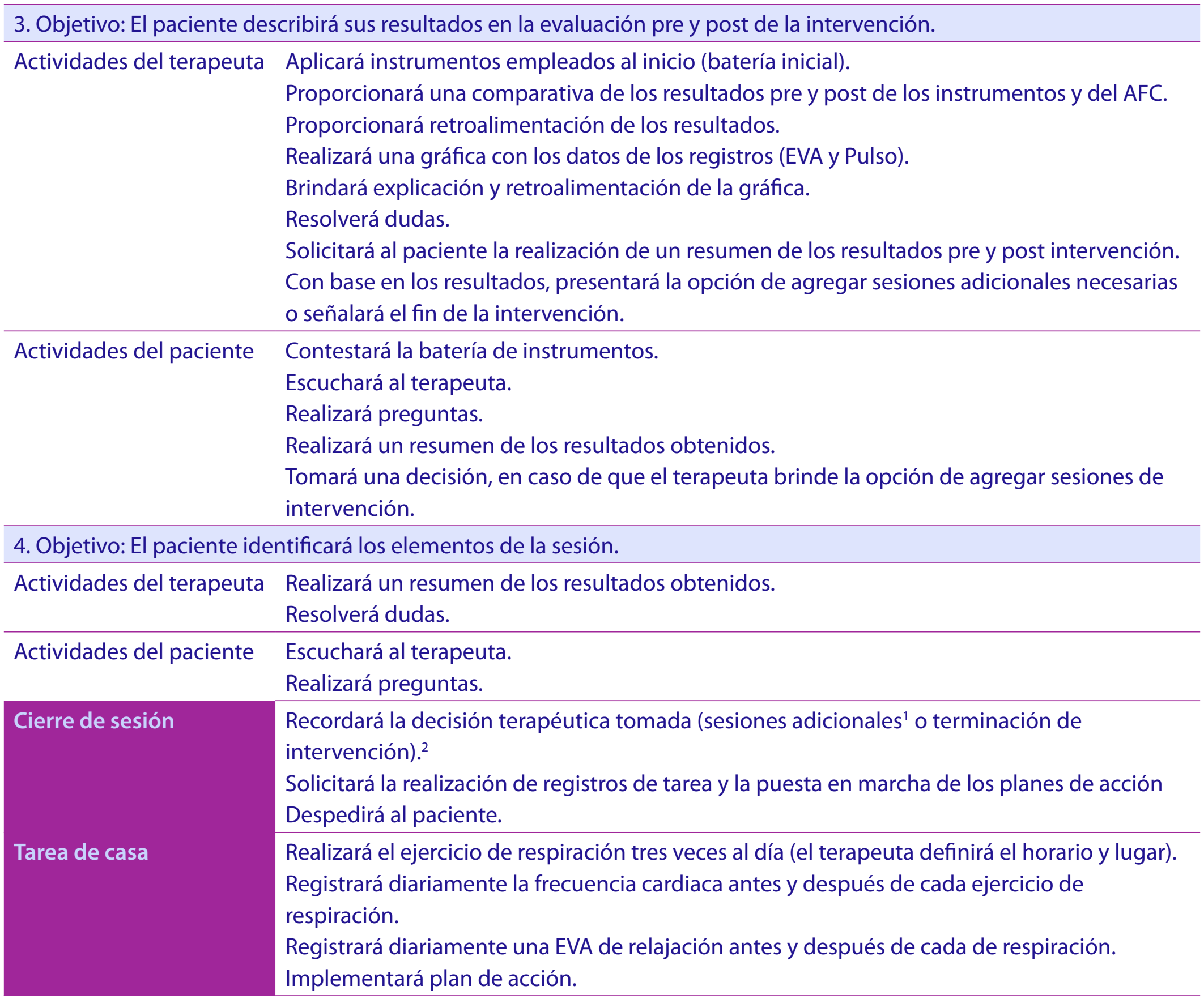

Nota: Elaboración propia. 'Si se termina la intervención: agradecerá al paciente su tiempo, agendará sesión de seguimiento, solicitará que conteste una encuesta de opinión sobre la intervención online y enviará la encuesta. ${ }^{2} \mathrm{Si}$ se añaden sesiones: indicará el plan para la siguiente sesión, agendará siguiente sesión de intervención y despedirá al paciente.

\section{Tabla 30}

\section{Carta descriptiva de seguimiento}

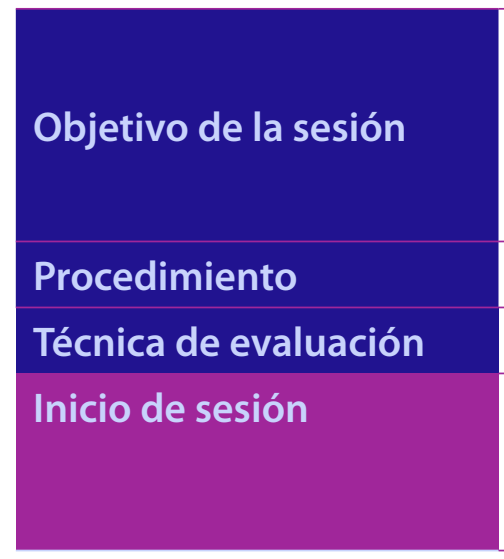

El terapeuta realizará monitoreo.

El terapeuta evaluará el mantenimiento de la práctica de las técnicas en el paciente.

El terapeuta evaluará las dificultades y beneficios de la intervención para el paciente.

El terapeuta evaluará la incidencia de comorbilidades psicológicas.

Evaluación y plan de acción.

Reporte verbal, reporte escrito y evaluación (Batería de instrumentos).

Saludará al paciente.

Establecerá el rapport con una mayor duración.

Realizará un resumen de la intervención. 
Durante la sesión

1. Objetivo: El paciente recibirá retroalimentación de los registros (tarea).

Actividades del terapeuta Examinará los registros realizados en casa.

Proporcionará retroalimentación sobre los registros.

Resolverá dudas.

Actividad del paciente Escuchará al terapeuta.

Realizará preguntas.

2. Objetivo: El paciente identificará la importancia de los seguimientos.

Actividades del terapeuta Expondrá el objetivo y la relevancia de continuar con los seguimientos y seguir monitoreando su respuesta ante el estrés.

Solicitará al paciente un resumen de lo expuesto.

Actividad del paciente Realizará un resumen de la importancia de los seguimientos y monitoreo de su actividad.

3. Objetivo: El paciente identificará los cambios que ha tenido en el desempeño del manejo de estrés.

Actividades del terapeuta Indagará sobre el manejo del estrés del paciente: síntomas de estrés e implementación de técnicas.

Aplicará al paciente batería de instrumentos empleados al inicio.

Brindará retroalimentación al desempeño del paciente.

- Si implementa las técnicas: reforzará y resaltará la importancia de continuar así. Continúa con la sesión.

- Si no utiliza las técnicas: invitará al proceso de nuevo. Indicará que el entrenamiento y la práctica requiere de más tiempo. Normalizará el necesitar más tiempo. Agendará sesión para intervención terapéutica.

- Si se presenta con elevada sintomatología de estrés se realiza la aplicación del protocolo de crisis. Agendará sesión para intervención terapéutica.

Cuestionará sobre las consecuencias del entrenamiento en el manejo de estrés.

Pudiendo usar las siguientes preguntas: ¿Cómo se siente al controlar su estrés? o ¿Qué

beneficios y complicaciones ha tenido del entrenamiento?

Solicitará al paciente la elaboración de un resumen de los resultados pre y postintervención, y seguimiento.

Actividades del paciente Contestará la batería de instrumentos.

Escuchará al terapeuta.

Responderá a las preguntas solicitadas por el terapeuta.

Indicará los cambios que ha generado el entrenamiento en el manejo de estrés.

Señalará las consecuencias de la intervención.

Realizará un resumen de los resultados obtenidos.

Criterio de cambio El paciente señalará al menos dos dificultades y beneficios del manejo de estrés.

4. Objetivo: El paciente realizará un plan de acción en caso de ser necesario.

Actividades del terapeuta Cuestionará la identificación de nuevas barreras que dificulten la implementación de las técnicas.

Si identificó:

- Realizarán colaborativamente planes de acción para esas situaciones usando el registro.

Si no identificó:

- Solicitará la descripción de las condiciones ante la práctica de las técnicas en la cotidianidad para encontrar barreras.

Si aún con la descripción no se identifican barreras: proseguirá con la sesión.

Reiterará la importancia del plan de acción respecto a las estrategias para el manejo de estrés. 


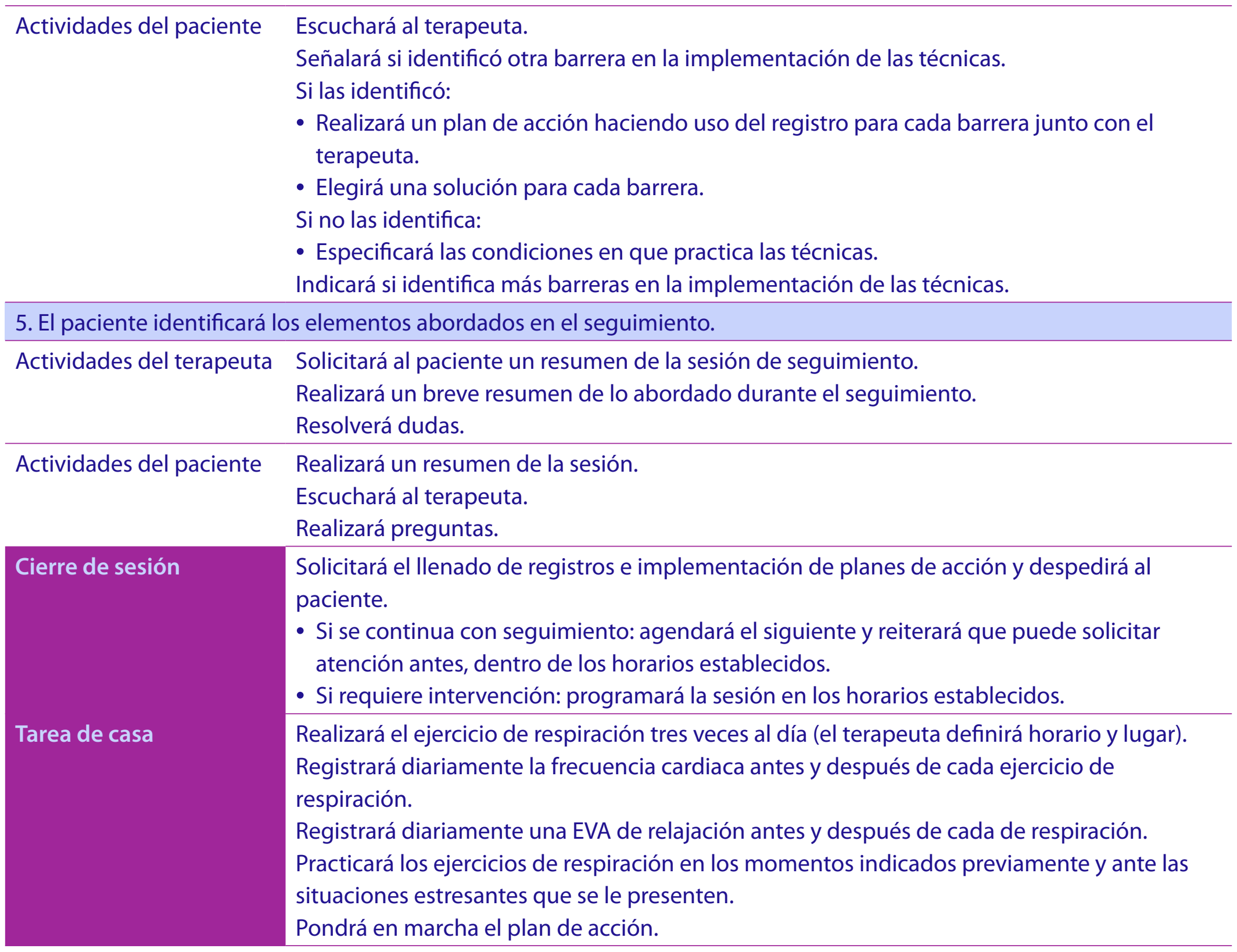

Nota: Elaboración propia. Si en algún momento de la intervención el paciente acude con una elevada sintomatología de estrés, el terapeuta aplicará el protocolo de intervención en crisis. 


\section{Referencias}

Abaroa, M. F., González, A., Ortega, A. Reyes, E. L., \& Reynoso, L. (2020). Desarrollo de un nuevo instrumento: Breve Checklist de Afrontamiento. Eureka, 17(2), 7-24.

Ahmad, A., Wan J., Zainuddin, Z., \& Mohamad, Y. (2020). Effectiveness of cognitive behavior therapy on depression among hemodialysis patients: A systematic review of literature. Cogent Psychology, 7(1), 1-13. https://doi.org/10.1080/23311908.2020.1794680

Albarrán, L., \& Macías, T. (2007). Aportaciones para un modelo psicoeducativo en el servicio de psiquiatría del Hospital Civil Fray Antonio Alcalde en Guadalajara, Jalisco, México. Investigación en salud, 9(2), 118-124. Recuperado de https://www.medigraphic.com/ cgi-bin/new/resumen.cgi?IDARTICULO=18757

Alcázar, R., L. \& Otero, A. (2008). Enfermedad crónica renal avanzada. Nefrología, (3), 3-6.

Allam, M. F., \& Arjona, O. (2013). Health promotion or pharmacological treatment for chronic diseases? Journal of preventive medicine and hygiene, 54(1), 11-13. Recuperado de https://pubmed.ncbi.nlm.nih.gov/24396999/

Alwan, A., MacLean, D. R., Riley, L. M., d'Espaignet, E.T., Mathers, C. D., Stevens, G. A., \& Bettcher, D. (2010). Monitoring and surveillance of chronic non-communicable diseases: progress and capacity in high-burden countries. The Lancet, 376(9755), 1861-1868. https://doi. org/10.1016/s0140-6736(10)61853-3

American Psychological Association. (2014). Guidelines for Clinical Supervision in Health Service Psychology. Recuperado de http://apa.org/about/policy/guidelines-supervision.pdf American Psychological Association. (2020). Dictionary of Psychology. Recuperado de https:// dictionary.apa.org

Anguiano, S. A., Mora, M. A., Reynoso, L., \& Vega, C. Z. (2017). Prevalencia de ansiedad y depresión en pacientes hospitalizados. Eureka, 14(1), 24-38. Recuperado de https:// docs.bvsalud.org/biblioref/2018/06/905744/eureka-14-1-9.pdf

Association of State and Provincial Psychology Boards (2015). ASPPB Supervision Guidelines for Education and Training leading to Licensure as a Health Service. Recuperado de https://cdn.ymaws.com/www.asppb.net/resource/resmgr/Guidelines/January_Draft_ Supervision_Gu.pdf 
Atri, A., \& Sharma, M. (2007). Psychoeducation. Californian Journal of Health Promotion, 5(4), 32-39. https://doi.org/10.32398/cjhp.v5i4.1266

Ayala, H., Reyes, I., Macotela, S., Acle, G., Vázquez, F., Seligson, I., \& Reynoso, L. (1998). Proyecto de adecuación del Programa de maestría y doctorado en psicología.

Baldovino, I. H. (2016). Formulación e intervención clínica de un caso de depresión y ansiedad asociado a privación de la libertad desde una perspectiva transdiagnóstica (Tesis de Maestría). Universidad del Norte, Colombia. Recuperado de https://manglar.uninorte. edu.co/bitstream/handle/10584/5817/22790282.pdf?sequence=1\&isAllowed=y

Barrio, J.A., García, M.R., López, M., \& Bedia, M. (2006) Control del estrés. International Journal of Developmental and Educational Psychology, 2(1), 429-439. Recuperado de https:// www.redalyc.org/pdf/3498/349832312036.pdf

Bauml, J. (2006). Psychoeducation: A basic psychotherapeutic intervention for patients with schizophrenia and their families. Schizophrenia Bulletin, 32(1), S1-S9. https://doi. org/10.1093/schbul/sbl017

Bernard, P., Romain, A., Caudroit, J., Chevance, G., Carayol, M., Gourlan, M., \& Dancause, K. (2018). Cognitive behavior therapy combined with exercise for adults with chronic diseases: systematic review and meta-analysis. Health Psychology, 37(5), 433-450. https://doi.org/ 10.1037/hea0000578

Bikbov, B., Purcell, C. A., Levey, A. S., Smith, M., Abdoli, A., Abebe, M., .. Vos, T. (2020). Global, regional, and national burden of chronic kidney disease, 1990-2017: a systematic analysis for the Global Burden of Disease Study 2017. The Lancet, 395(10225), 709-733. https://doi.org/10.1016/s0140-6736(20)30045-3

Blanco, C., Estupiñá, F. J., Labrador, F. J., Fernández-Arias, I., Bernardo-de-Quirós, M., \& Gómez, L. (2014). Uso de técnicas de relajación en una clínica de psicología. Anales de Psicología, 30(2), 403-411. https://doi.org/10.6018/analesps.30.2.158451

Borstnar, C. R., \& Cardellach, F. (2020). Farreras-Rozman. Medicina interna XVII. España: Elsevier. Brammer, L. M. (1973). The helping relationship: Process and skills. New Jersey: Prentice Hall.

Bravo, M., \& Mora, M. (2014). Análisis Funcional y diseño de intervención en el ámbito hospitalario. En A. Becerra \& L. Reynoso (Coords.), Medicina Conductual: Teoría y práctica (pp. 101-128). México: Qartuppi. https://doi.org/10.29410/QTP.14.01

Brooks, S., Webster, R., Smith, L., Brooks-Woodland, L., Wessely, S., Greenberg, N., \& Rubin, G. (2020). The psychological impact of quarantine and how to reduce it: rapid review of the evidence. The Lancet, 395, 912-20. https://doi.org/10.1016/S0140-6736 (20)30460-8

Bruce, M. A., Beech, B. M., Sims, M., Brown, T. N., Wyatt, S. B., Taylor, H. A., .. Crook, E. (2009). Social Environmental Stressors, Psychological Factors, and Kidney Disease. Journal of Investigative Medicine, 57(4), 583-589. https://doi.org/10.2310/jim.0b013e31819dbb91 
Bruce, M. A., Griffith, D. M., \& Thorpe, R. J. (2015). Stress and the Kidney. Advances in Chronic Kidney Disease, 22(1), 46-53. https://doi.org/10.1053/j.ackd.2014.06.008

Bulacio, J. M., Vieyra, C., \& Mongiello, E. (2010). Uso de la psicoeducación como estrategia terapéutica. Cartel. Centro Integral Clínico, Docente y de Investigación en Salud Mental. Recuperado de https://www.aacademica.org/000-029/16.pdf

Caballo,V.(1998).Manualparael tratamiento cognitivo-conductualdelos trastornospsicológicos. Formulación clínica, medicina conductual y trastornos de relación. España: Siglo XXI.

Caballo, V., \& Anguiano, S. (2002). Estrés y estilos de personalidad. En L. Reynoso e I. Seligson (Coords.), Psicología y Salud. México: UNAM-CONACYT.

Cano, F. J., Rodríguez, L., \& García, J. (2007). Adaptación española del Inventario de Estrategias de Afrontamiento. Actas Españolas de Psiquiatría, 35(1), 29-39. Recuperado de https:// fjcano.info/images/test/CSI_art_esp.pdf

Cao, X., Masood, A., Luqman, A., \& Ali, A. (2018). Excessive use of mobile social networking sites and poor academic performance: Antecedents and consequences from stressorstrain-outcome perspective. Computers in Human Behavior, 85, 163-174. https://doi. org/10.1016/j.chb.2018.03.023

Caplan, G. (1961). An approach to community mental health. New York: Grune and Stratton.

Cárdenas, I. (2013). Criterios para seleccionar tecnologías educativas y estrategias didácticas, en el colegio Guillermo León Valencia. Educación y Ciencia, 16, 37-52. https://doi. org/10.19053/01207105.3239

Casado, M., \& Laguna-Bonilla, S. (2017). Trastorno de síntomas somáticos: de la sospecha de simulación al tratamiento cognitivo-conductual. Clínica y Salud, 28(3), 131-138. https:// doi.org/10.1016/j.clysa.2017.05.004

Cea-Ugarte, J. I., González-Pinto, A., \& Cabo-González, O. M. (2015). Efectos de la respiración controlada sobre los síntomas de estrés y ansiedad en una población de 55 a 65 años: estudio piloto. Gerokomos, 26(1), 18-22. https://doi.org/10.4321/s1134$928 \times 2015000100005$

Centro Nacional de Excelencia Tecnológica en Salud (CENETEC). (2009). Prevención, diagnóstico y tratamiento de la Enfermedad Renal Crónica Temprana. México: Secretaría de Salud. Recuperado de http://www.cenetec.salud.gob.mx/descargas/ gpc/CatalogoMaestro/335_IMSS_09_Enfermedad_Renal_Cronica_Temprana/EyR_ IMSS_335_09.pdf

Centro Nacional de Excelencia Tecnológica en Salud (CENETEC). (2014). Tratamiento sustitutivo de la función renal. Diálisis y hemodiálisis en la Insuficiencia Renal Crónica en el segundo y tercer nivel de atención. México: Secretaría de Salud. Recuperado de http://www. cenetec.salud.gob.mx/descargas/gpc/CatalogoMaestro/335_IMSS_09_Enfermedad_ Renal_Cronica_Temprana/EyR_IMSS_335_09.pdf

Cepeda, M., López, M., Plancarte, P., Moreno, D., \& Alvarado, I. (2014). El proceso de investigación. 
Medición y observación. México: Universidad Nacional Autónoma de México. Facultad de Estudios Superiores Iztacala.

Chan, R., Dear, B. F., Titov, N., Chow, J., \& Suranyi, M. (2016). Examining internet-delivered cognitive behaviour therapy for patients with chronic kidney disease on haemodialysis: A feasibility open trial. Journal of Psychosomatic Research, 89, 78-84. https://doi. org/10.1016/j.jpsychores.2016.08.012

Clarke, G., Kelleher, C., Hornbrook, M., Debar, L., Dickerson, J., \& Gullion, C. (2009). Randomized effectiveness trial of an Internet, pure self-help, cognitive behavioral intervention for depressive symptoms in young adults. Cognitive Behavior Therapy, 38(4) 222-234. https://doi.org/10.1080/16506070802675353

Cohen, S., Kamarck, T., \& Mermelstein, R. (1983). A global measure of perceived stress. Journal of health and social behavior, 24(4), 385-396. https://doi.org/10.2307/2136404

Consejo General de la Psicología. (2017). Guía para la práctica de la telepsicología. España: COP. https://doi.org/10.23923/cop.telepsicologia.2017

Cuevas, C. J., \& Moreno, P. E. (2017). Psicoeducación: intervención de enfermería para el cuidado de la familia en su rol de cuidadora. Enfermería Universitaria, 14(3), 207-218. https://doi.org/10.1016/j.reu.2017.06.003

Cukor, D., Ver Halen, N., Asher, D. R., Coplan, J. D., Weedon, J., Wyka, K. E., ... Kimmel, P. L. (2013). Psychosocial Intervention Improves Depression, Quality of Life, and Fluid Adherence in Hemodialysis. Journal of the American Society of Nephrology, 25(1), 196-206. https://doi. org/10.1681/asn.2012111134

D'Zurilla, J., \& Nezu, M. (1999). Problem-Solving Therapy: A social competence approach to clinical intervention. New York: Springer.

De Barcelona, U., Botella, E., Quero, C., Serrano, S., Baños, B., \& García-Palacios, R. (2009). Avances en los tratamientos psicológicos: la utilización de las nuevas tecnologías de la información y la comunicación. Anuario de Psicología, 40(2), 155-170. Recuperado de https://www.redalyc.org/pdf/970/97017660002.pdf

De la Torre, M., \& Pardo, R. (2018). Guía para la intervención telepsicológica. Colegio Oficial de Psicólogos de Madrid. Recuperado de https://www.copmadrid.org/web/publicaciones/ guia-para-la-intervencion-telepsicologica

Dehesa, E., Correa, R., Olvera, D., González, C., Baizabal, R., \& Orozco, R. (2016). Transcultural adaptation and validation of the Mexican version of the kidney disease questionnaire KDQOL-SF36 version 1.3. Quality ofLife Research, 26(1), 193-198. https://doi.org/10.1007/ s11136-016-1365-8

Dekker, J., Stauder, A., \& Penedo, F. J. (2017). Proposal for an Update of the Definition and Scope of Behavioral Medicine. International Journal of Behavioral Medicine, 24(1), 1-4. https://doi.org/10.1007/s12529-016-9610-7

Del Arco R., Tornero, M. J., \& García, C. (2014). Intervención cognitivo-conductual en el 
manejo de obsesiones y compulsiones de lavado en una niña con trastorno obsesivocompulsivo. Revista de Psicología Clínica con Niños y Adolescentes, 1(2), 141-148. Recuperado de https://www.redalyc.org/pdf/4771/477147184005.pdf

Díaz, M. (1996). Evaluación psicofisiológica del estrés: desarrollo de un programa de evaluación (Tesis). Universidad Nacional de Educación a Distancia, España. Recuperado de https:// dialnet.unirioja.es/servlet/tesis?codigo $=40785$

Dongil-Collado, E. (2008). Reestructuración cognitiva, un caso de estrés postraumático. Ansiedad y estrés, 14(2), 265-288. Recuperado de https://www.researchgate.net/ publication/39141207_Tratamiento_cognitivo-conductual_en_un_caso_de_estres_ postraumatico_por_accidente_de_trafico

Duan, L., \& Zhu, G. (2020). Psychological interventions for people affected by the COVID-19 epidemic. The Lancet Psychiatry, 7(4), 300-302. https://doi.org/10.1016/S22150366(20)30073-0

Duarte, P., Miyazaki, M., Blay, S., \& Sesso, R. (2009). Cognitive-behavioral group therapy is an effective treatment for major depression in hemodialysis patients. Kidney International, 76, 414-421. https://doi.org/10.1038/ki.2009.156

Espinosa-Cuevas, M. (2016). Enfermedad renal. Gaceta Médica de México, 152(1), 90-96. Recuperado de https://www.anmm.org.mx/GMM/2016/s1/GMM_152_2016_S1_090096.pdf

Fernández-Ballesteros, R. (2013). Evaluación psicológica. Conceptos, métodos y estudios de caso. España: Pirámide.

Flores, G., \& Díaz-Loving, R. (2002). Asertividad: una alternativa para el óptimo manejo de las relaciones personales. México: Porrúa.

Flores, J., Alvo, M., Borja, H., Morales, J., Vega, J., Zúñiga, C., Müller, H., \& Müzenmayer, J. (2009). Enfermedad renal crónica:Clasificación, identificación, manejoy complicaciones. Revista Médica de Chile, 137(1), 137-177. https://doi.org/10.4067/S0034-98872009000100026

Flores, L., Cárdenas, G., Durán, X., \& De la Rosa, A. (2014). Psicoterapia vía internet: aplicación de un programa de intervención cognitivo conductual para pacientes con depresión. Psicología Iberoamericana, 22(1), 7-15. Recuperado de https://www.redalyc.org/ pdf/1339/133944229002.pdf

Foreman, K., Marquez, N., Dolgert, A., Fukutaki, K., Fullman, N., McGaughey, M., \& Murray, C. (2018). Forecasting life expectancy, years of life lost, and all-cause and cause-specific mortality for 250 causes of death: reference and alternative scenarios for 2016-40 for 195 countries and territories. The Lancet, 392(10159), 2052-2090. https://doi.org/10.1016/ s0140-6736(18)31694-5

Gavino, A., L. (2006). Guía de Técnicas de terapia de Conducta. España: Pirámide. 
Ghosh, S., \& Verma, K. (2018). Stress and its effect on noncommunicable disease: An insight. Journal of Social Health and Diabetes, 6(1), 15-15. https://doi.org/10.4103/JSHD. JSHD_32_17

Goldman (1988). Toward a definition of psychoeducation. Hospital and Community Psychiatry, 39(6), 666-668. https://doi.org/10.1176/ps.39.6.666

González, M. T., \& Landero, R. (2007). Factor structure of Perceived Stress Scale (PSS) in a sample from Mexico. The Spanish Journal of Psychology, 10, 199-206. Recuperado de https://www.cambridge.org/core/journals/spanish-journal-of-psychology/article/ abs/div-classtitlefactor-structure-of-the-perceived-stress-scale-pss-in-a-sample-frommexicodiv/072A8FE9A0472C342C5577A56EDF3EF5

Gutiérrez, M. (2020). Propuesta de atención para los servicios de psicoterapia en línea (telepsicoterapia) derivados del COVID-19 en México. Psicología y Salud, 30(1), 133136. Recuperado de https://psicologiaysalud.uv.mx/index.php/psicysalud/article/ view/2640

Hays, R. D., Kallich, J. D., Mapes, D. L., Coons, S. J., \& Carter, W. B. (1994). Development of the kidney disease quality of life (KDQOL TM) instrument. Quality of life Research, 3(5), 329338. https://doi.org/10.1007/BF00451725

Heber, E., Ebert, D. D., Lehr, D., Cuijpers, P., Berking, M., Nobis, S., \& Riper, H. (2017). The Benefit of Web- and Computer-Based Interventions for Stress: A Systematic Review and MetaAnalysis. Journal of Medical Internet Research, 19(2), e32. https://doi.org/10.2196/ jmir.5774

Herrera, F. (Coord.). (2016). Introducción. En Historia natural de 78 enfermedades: Manual gráfico. México: Universidad de Sonora/El Manual Moderno.

Herrera, D., Coria, G. A., Muñoz, D. A., Graillet, O., Aranda, G. E., Rojas, F., Hernández, M. E., \& Nafissa, I. (2017). Impacto del estrés psicosocial en la salud. Neurobiología (Revista electrónica). Recuperado de https://www.uv.mx/eneurobiologia/vols/2017/17/ Herrera/HTML.html

Horne, R., \& Hankins, M. (2002). The Medication Adherence Report Scale. Brighton, UK: Center for Health Care Research.

Hurtado-Aréstegui, A. (2016). Manejo de la enfermedad renal crónica. Revista de la Sociedad Peruana de Medicina, 19(2), 50-54. https://doi.org/10.36393/spmi.v19i2.253

Inchausti, F., García-Poveda, N. V., Prado-Abril, J., \& Sánchez-Reales, S. (2020). La psicología clínica ante la pandemia COVID-19 en España. Clínica y salud. 31(2), 105-10. https://doi. org/10.5093/clysa2020a11

Instituto Mexicano del Seguro Social (IMSS). (2019). Prevención, Diagnóstico y Tratamiento de la Enfermedad Renal Crónica. México: IMSS. Recuperado de http://www.imss.gob.mx/ sites/all/statics/guiasclinicas/335GER.pdf 
Instituto Nacional de Estadística y Geografía (INEGI). (2016). Estadísticas vitales 2016. Base de datos. México: INEGI. Recuperado de https://www.inegi.org.mx/rnm/index.php/ catalog/292

Instituto Nacional de Salud Pública (INSP). (2020). La enfermedad renal crónica en México. Recuperado de https://www.insp.mx/avisos/5296-enfermedad-renal-cronica-mexico. html

International Society of Neprhrology (2013). KDIGO 2012. Clinical Practice Guideline for the Evaluation and Management of Chronic Kidney Disease. Kidney International Supplements, 3(1), 136-150. https://doi.org/10.1038/kisup.2012.74

Jager, K. J., Kovesdy, C., Langham, R., Rosenberg, M., Jha, V., \& Zoccali, C. (2019). A single number for advocacy and communication-worldwide more than 850 million individuals have kidney diseases. Kidney International, 96(5), 1048-1050. https://doi.org/ 10.1016/j. kint.2019.07.012

Joint Task Force for the Development of Telepsychology Guidelines for Psychologists. (2013). Guidelines for the practice of telepsychology. American Psychologist, 68(9), 791-800. https://doi.org/10.1037/a0035001

Kaholokula, J., Bello, I., Nacapoy, A., \& Hayes, S. (2009). Evaluación conductual y análisis funcional. En C. Richard, \& S. Huprich (Eds.), Clinical Psychology: Assessment, Treatment, and Research (pp.1-43). Burlington, MA: Elsevier Academic Press.

Kaholokula, J., Godoy, A., O’Brien, W., Haynes, S. N., \& Gavino, A. (2013). Análisis funcional en evaluación conductual y formulación de casos clínicos. Clínica y Salud, 24(2), 117-127. https://doi.org/10.5093/cl2013a13

Kazdin, M. (1996). Modificación de conducta y sus aplicaciones prácticas. México: Manual Moderno.

Labrador, F. (2008). Técnicas de autocontrol. En F. Labrador (Ed.), Técnicas de modificación de conducta (pp. 387-393). México: Pirámide.

Labrador, F. (2011). Situaciones difíciles en terapia. España: Pirámide.

Labrador, F., De Arce, F., \& Florit, A. (1996). Entrenamiento en respiración frente a entrenamiento en relajación: Diferencias en medidas psicofisiológicas. Análisis y Modificación de Conducta, 22, 93-114.

Larios, F., González, L., Montes, R., González, F., Morán, A., Solano, P., Oceguera, A., Montero, M., \& Daneri, A. (2019). Eficacia de las técnicas de relajación en la disminución de tensión, ansiedad y estrés percibidos por pacientes con cáncer bajo tratamiento de quimioterapia. Gaceta Mexicana de Oncología, 17(2), 42-47. https://doi.org/10.24875/j. gamo.m18000138

Lazarus, A. A. (1992). The multimodal approach to the treatment of minor depression. American Journal of Psychotherapy, 46(1), 50-57. https://doi.org/10.1176/appi. psychotherapy.1992.46.1.50 
Lazarus, R., \& Folkman, S. (1984). Stress, appraisal, and coping. Nueva York: Springer.

Leavell, H., \& Clark, E. (1958). Preventive medicine for the doctor in his community. An epidemiologic approach. New York: McGraw-Hill.

Lerma, A., Pérez, H., Bermudez, L., Peralta, M., Robles, R., \& Lerma, C. (2017). Brief cognitive behavioural intervention for depression and anxiety symptoms improves quality of life in chronic haemodialysis patients. Psychology and Psychotherapy: Theory, Research and Practice, 90, 105-123. https://doi.org/10.1111/papt.12098

Lira, J., Cruz, S., \& Ayala, H. (2012). Manual del Terapeuta para la Aplicación de la Intervención Breve Motivacional para Fumadores (IBMF). México: Secretaría de Salud.

Lugo, l., Pérez, Y., \& Sánchez, C. (2018). Validación de la escala de ansiedad y depresión hospitalaria en pacientes con ERC en hemodiálisis. En R. Díaz, L. Reyes, \& F. López (Eds.), Aportes actuales a la psicología social. volumen IV (pp. 1209-1225). México: Amepso.

Lugo, I., \& Vega, C.Z. (2020). Propiedades psicométricas de la Medication Adherence Report Scale-Asthma en adultos asmáticos mexicanos. Psicología y Salud, 30(2), 275-285. https://doi.org/10.25009/pys.v30i2.2663

Luyckx, V., Tonelli, M. \& Stanifer, J. (2018). La carga global de la insuficiencia renal y los objetivos de desarrollo sostenible. Boletín de la Organización Mundial de la Salud, 98(96), 369-440. https://doi.org/10.2471/BLT.17.206441

Ma, X., Yue, Z., Gong, Z., Zhang, H., Duan, N., Shi, Y., Wei, G., \& Li, Y. (2017). The Effect of Diaphragmatic Breathing on Attention, Negative Affect and Stress in Healthy Adults. Frontiers in Psychology, 8, 874. https://doi.org/10.3389/fpsyg.2017.00874

Macías, J.J.,\&Valero, L. (2018). La psicoterapia on-line ante los retos y peligros de la intervención psicológica a distancia. Apuntes de Psicología, 36(1), 107-113. Recuperado de https:// www.researchgate.net/publication/328307157_La_psicoterapia_on-line_ante_los_ retos_y_peligros_de_la_intervencion_psicologica_a_distancia

Marín, E., \& Mosteiro, C. (2012). Protocolo de intervención psicológica en los Centros de Atención a Drogodependientes de Madrid Salud. Servicios de Asistencia de Madrid. Recuperado de https://pnsd.sanidad.gob.es/pnsd/buenasPracticas/protocolos/pdf/ ProtocoloPsicologico.pdf

Marrow, C., Hollyoake, K., Hamer, D., \& Kenrick, C. (2002). Clinical supervision using video conferencing technology: A reflective account. Journal of Nursing Management, 10, 275-282. https://doi.org/10.1046/j.1365-2834.2002.00313.x

Martínez, C. (2020). Intervención y psicoterapia en crisis en tiempos de coronavirus (para psicólogas/os clínicos y psicoterapeutas. Recuperado de http://midap.org/wpcontent/uploads/2020/04/INTERVENCIÓN-Y-PSICOTERAPIA-EN-CRISIS_ClaudioMart\%C3\%ADnez_abrio2020.pdf 
Medina, M., Chávez, M., López, F., Félix, V., Gordillo, T., \& Morales, S. (2012). Manual del Terapeuta para la Aplicación de la Intervención Breve para Usuarios de Marihuana. México:Secretaría de Salud.

Mehta, S., Peynenburg, V., \& Hadjistavropoulos, H. (2019). Internet-delivered cognitive behaviour therapy for chronic health conditions: a systematic review and meta-analysis. Journal of Behavioral Medicine, 42, 169-187. https://doi.org/10.1007/s10865-018-9984-x

Meichenbaum, D. (1977). Cognitive behaviour modification. Cognitive Behaviour Therapy, 6(4), 185-192. https://doi.org/10.1007/978-1-4757-9739-8

Meichenbaum, D. (2002). Manual de inoculación de estrés. Barcelona: Martínez Roca.

Melchy, Z. (2015). Adherencia a la dieta en pacientes con Diabetes Mellitus Tipo 2. Un programa de intervención desde la Medicina Conductual (Tesis de Maestría). UNAM: FES Iztacala, México.

Monroe, S., \& Slavich, G. (2016). Psychological Stressors: Overview. In G. Fink (Ed.), Stress: Concepts, Cognition, Emotion, and Behavior (pp. 109-115). San Diego: ElSevier.

Moral, J., \& Cázares, F. (2014).Validación de la escala de estrés percibido (pss-14) en la población de dentistas colegiados de monterrey: validación de la escala de estrés percibido. Ansiedad y Estrés, 20(2-3), 193-209. Recuperado de https://www.researchgate.net/ publication/325229462_Validacion_de_la_Escala_de_Estres_percibido_PSS-14_en_ la_poblacion_de_dentistas_colegiados_de_Monterrey

Morales, T., Alfaro, O., Sánchez, S., Guevara, U., \& Vázquez, F. (2007). Ansiedad y depresión por dolor crónico neuropático y nociceptivo. Revista Médica del Instituto Mexicano del Seguro Social, 46(5), 479-484. Recuperado de https://www.redalyc.org/ pdf/4577/457745523004.pdf

Myers, S., Endres, M., Ruddy, M., \& Zelikovsky, N. (2012). Psychology graduate training in the era of online social networking. Training and Education in Professional Psychology, 6, 2836. https://doi.org/10.1037/a0026388

Nadort, E., Schouten, R. W., Dekker, F. W., Honig, A., van Oppen, P., \& Siegert, C. E. H. (2019). The (cost) effectiveness of guided internet-based self-help CBT for dialysis patients with symptoms of depression: study protocol of a randomised controlled trial. $B M C$ Psychiatry, 19(372). https://doi.org/10.1186/s12888-019-2363-5

National Institute of Diabetes and Digestive and Kidney Disease (NIDDK). (2017). What is ChronicKidneyDisease?Recuperadodehttps://www.niddk.nih.gov/health-information/ kidney-disease/chronic-kidney-disease-ckd/what-is-chronic-kidney-disease

National Kidney Foundation (NKF). (2002). Chronic KidneyDisease:Evaluation, Classification and Stratification. Recuperado de https://www.kidney.org.uk/?gclid=CjwKCAjw6qqDBhBEiwACBs6x3CBvoPgJtTtQ4B6MLju2DQvh23qiJxG0616a4iT5szDaztknV0myRoCSoQQA VD_BwE 
Nava, C., Ollua, P., Vega, C. Z., \& Soria, R. (2010). Inventario de Estrategias de Afrontamiento: una replicación. Psicología y Salud, 20(2), 213-220. https://doi.org/10.25009/pys.v20i2.604

Nezu, A. \& Nezu, C. (1991). Entrenamiento en solución de problemas. En V. Caballo (director), Manual de Técnicas de Terapia y Modificación de Conducta (pp. 527-553). Madrid: Siglo XXI.

Nezu, A. M., Nezu, C. M., \& Salber, K. E. (2013). Problem-solving therapy for cancer patients. Psicooncología, 10(2-3), 217-231. https://doi.org/10.5209/rev_PSIC.2013.v10.n23.43445

Ng, C. Z., Tang, S. C., Chan, M., Tran, B. X., Ho, C. S., Tam, W. W., \& Ho, R. C. (2019). A systematic review and meta-analysis of randomized controlled trials of cognitive behavioral therapy for hemodialysis patients with depression. Journal of Psychosomatic Research, 126(109834). https://doi.org/10.1016/j.jpsychores.2019.109834

Nickelson, D. (1998). Telehealth and the evolving health care system: Strategic opportunities for professional psychology. Professional Psychology: Research and Practice, 29(6), 527535. https://doi.org/10.1037/0735-7028.29.6.527

Norelli, S. K., Long, A., \& Krepps, J. M. (2020). Relaxation Techniques. In StatPearls. StatPearls Publishing.

Nozaki, C., Oka, M., \& Chaboyer, W. (2005). The effects of a cognitive behavioural therapy programme for self-care on haemodialysis patients. International Journal of Nursing Practice, 11(5), 228-236. https://doi.org/2443/10.1111/j.1440-172X.2005.00525.x

Organización de las Naciones Unidas para la Educación (UNESCO). (2020). ¿Quéayuda pueden proporcionar las tecnologías inteligentes durante la pandemia? Recuperado de https:// es.unesco.org/news/que-ayuda-pueden-proporcionar-tecnologias-inteligentesdurante-pandemia

Organización Panamericana de la Salud (OPS)/Organización Mundial de la Salud (OMS). (2015). La OPS/OMS y la Sociedad Latinoamericana de Nefrología llaman a prevenir la enfermedad renal y a mejorar el acceso al tratamiento. Recuperado de https://www. paho.org/col/index.php?option=com_content\&view=article\&id=2331:la-opsoms-yla-sociedad-latinoamericana-de-nefrologia-llaman-a-prevenir-la-enfermedad-renal-ya-mejorar-el-acceso-al-tratamiento\&ltemid $=487$

Organización Panamericana de la Salud (OPS)/Organización Mundial de la Salud (OMS). (2017). Manual para el cuidado de personas con enfermedades crónicas no transmisibles: manejo integral en el primer nivel de atención. Argentina: Ministerio de Salud de la Nación/OPS/OMS. Recuperado de https://iris.paho.org/bitstream/ handle/10665.2/34520/9789503802397_spa.pdf?sequence=1\&isAllowed=y

Organización Panamericana de la Salud (OPS)/Organización Mundial de la Salud (OMS). (2018). CKD silent killer infographic. Recuperado de https://www.paho.org/hq/index. php?option=com_docman\&view=list\&format=html\&layout=default\&slug=infograph ics-7689\&ltemid=270\&lang=es 
Payne, M., Eaton, C., Mee, L., \&Blount, R. (2012).Promoting Medication Adherence and Regimen Responsibility in Two Adolescents on Hemodialysis for End-Stage Renal Disease: A Case Study. Clinical Case Studies, 12(2), 95-110. https://doi.org/10.1177/1534650112467079

Pedraza-Banderas, G. L., \& Valero, C. Z.V. (2018). Versión actualizada de la escala de adherencia terapéutica. Revista Digital Internacional de Psicología y Ciencia Social, 4(2), 214-232. https://doi.org/10.22402/j.rdipycs.unam.4.2.2018.186.214-232

Perpiña, C. (2012). Manual de la entrevista psicológica. Saber escuchar, saber preguntar. España: Pirámide.

Picariello, F., Moss, R., Macdougall, I., Norton, S., Da Silva, M., Farrington, K., \& Chilcot, J. (2018). Cognitive-behavioural therapy (CBT) for renal fatigue (BReF): a feasibility randomisedcontrolled trial of CBT for the management of fatigue in haemodialysis (HD) patients. BMJ Open, 8(3). https://doi.org/10.1136/bmjopen-2017-020842

Pinillos, Y., Herazo, Y., Gil, J., \& Ramos, J. (2019). Actividad física y calidad de vida en personas con enfermedad renal crónica. Revista Médica de Chile, 147, 153-160. https://doi. org/10.4067/s0034-98872019000200153

Rachlin, H. (2000). The science of self-control. Cambridge, MA: Harvard University Press.

Rentería, A., \& Valladares, P. (2018). Psicoterapia cognitivo conductual técnicas y procedimientos. México: UNAM-FESI.

Reynoso, L. (2002). Lista chequeable de ansiedad (Documento no publicado).

Reynoso, L. (2011). El trabajo de los psicólogos especializados en medicina conductual en México. En H. Martínez, J. J. Irigoyen, F. Cabrera, J. Varela, P. Covarrubias, \& A. Jiménez (Eds.), Estudios sobre comportamiento y aplicaciones Volumen II (pp. 173-203). Guadalajara: SINCA/COECYTJAL.

Reynoso, L. (2014). Medicina Conductual: Introducción. En L. Reynoso, \& A. L. Becerra (2014). Medicina Conductual: Teoría y Práctica. México: Qartuppi. https://doi.org/10.29410/ QTP.14.01

Reynoso, L., \& Becerra, A. L. (2013). Lista de datos de ansiedad ante procedimientos dentales. (Documento ex professo). Validado por expertos de diferentes especialidades de Odontología y Cirujanos Dentistas, docentes de la Carrera de Odontología de la FES Iztacala.

Reynoso, L., \& Seligson, I. (1998). Proyecto de creación de la residencia en Medicina Conductual (Documento no publicado).

Reynoso, L., Becerra, A., \& Lugo, V. (2019). Trastorno de estrés postraumático en adultos. Intervención cognitivo-conductual para víctimas de sismos. México: Qartuppi. https:// doi.org/10.29410/QTP.19.02

Reynoso, L., \& Seligson, I. (2005). Psicología clínica de la salud: un enfoque conductual. México: El Manual Moderno. 
Ruíz, M., Díaz, M., \& Villalobos, A. (2012). Manual de técnicas de intervención cognitivo conductuales. España: Desclée De Brouwer.

Russell, M., Scott, A., Boggero, I., \& Carlson, C. (2016). Inclusion of a rest period in diaphragmatic breathing increases high frequency heart rate variability: Implications for behavioral therapy. Psychophysiology, 54(3), 358-365. https://doi.org/10.1111/psyp.12791

Salazar, I., Caballo, V., \& González, D. (2007). La intervención psicológica cognitivo-conductual en la crisis asociada a desastres: una revisión teórica. Psicología Conductual, 15(3), 389405. Recuperado de https://dialnet.unirioja.es/servlet/articulo?codigo $=2491858$

Sharp, J., Wild, M., Gumley, A., \& Deighan, C. (2005). A Cognitive Behavioral Group Approach to Enhance Adherence to Hemodialysis Fluid Restrictions: A Randomized Controlled Trial. American Journal of Kidney Diseases, 45(6), 1046-1057. https://doi.org/10.1053/j. ajkd.2005.02.032

Slaikeu, K. (2000). Intervención en crisis: Manual para práctica e investigación. México: Manual Moderno.

Smyth, J. M., \& Zawadzki, M. J. (2016). Behavioral Medicine. Encyclopedia of Mental Health, 156-162. https://doi.org/10.1016/b978-0-12-397045-9.00148-8

Society of Behavioral Medicine (SBM). (2020). What Is Behavioral Medicine? Recuperado de https://www.sbm.org/about/behavioral-medicine\#: :text=Behavioral\%20 medicine $\% 20$ is\%20the $\% 20$ interdisciplinary, these $\% 20$ techniques $\% 20$ to $\% 20$ prevention\%2C\%20diagnosis\%2C

Sohn, B., Oh, Y., Choi, J., Song, J., Lim, A., Lee, J., \& Lim, C. (2018). Effectiveness of group cognitive behavioral therapy with mindfulness in end-stage renal disease hemodialysis patients. Kidney Research and Clinical Practice, 37(1), 77-84. https://doi.org/10.23876/j. krcp.2018.37.1.77

Stone, D., \& Conley, J. (2004). A Partnership between Roberts' crisis intervention model and the multicultural competencies. Brief Treatment and Crisis Intervention, 4, 367-375. http://doi.org/10.1093/brief-treatment/mhh030

Suárez, M. (2010). La importancia del análisis de los acontecimientos vitales estresantes en la práctica clínica. Revista Médica La Paz, 16(2), 58-62. Recuperado de http://www.scielo. org.bo/scielo.php?script=sci_arttext\&pid=S1726-89582010000200010

Tamayo y Orozco, J.A., \& Lastiri Quirós, H.S. (2016). La enfermedad renal crónica en México. Hacia una política nacional para enfrentarla. México: CONACYT Intersistemas Editores.

Torres, C. (2010). Diseño, implementación y evaluación de un programa de Intervención Educativa para pacientes con insuficiencia renal Crónica. Revista Latinoamericana de Medicina Conductual, 1(1), 37-46. 
Torres, M. A., Vega, E. G., Vinalay, I., Arenas, G., \& Rodríguez, E. (2015).Validación psicométrica de escalas PSS-14, AFA-R, HDRS, CES-D, EV en puérperas mexicanas con y sin preeclampsia. Enfermería universitaria, 12(3), 122-133. https://doi.org/10.1016/j.reu.2015.08.001

Urrego, Z., \& Rodríguez, C. (2012). Plan de monitoreo y batería de indicadores para el seguimiento y evaluación de estrategias de atención en salud sexual y reproductiva y salud mental en contextos de emergencias humanitarias. Colombia: Ministerio de Salud y Protección Social.

Vallejo-Slocker, L., \& Vallejo, M. (2016). Sobre la desensibilización sistemática. Una técnica superada o renombrada. Acción Psicológica, 13(2), 157-168. https://doi.org/10.5944/ ap.13.2.16539

Vázquez, I., Vital, S., Bravo, M., Jurado, S., \& Reynoso, L. (2009). Retroalimentación biológica y relajación en pacientes con enfermedad renal crónica terminal en tratamiento de hemodiálisis. Journal of Behavior, Health and Social Issues, 1(2), 35-43. https://doi. org/10.5460/jbhsi.v1.2.18801

Vázquez, M. (2001). Técnicas de Relajación y Respiración. Madrid: Síntesis Editorial.

Vicente, M. T., Delgado, S., Bandrés, F., Ramírez, M. V., \& Capdevila, L. (2018). Valoración del dolor. Revisión comparativa de escalas y cuestionarios. Revista de la Sociedad Española del Dolor, 25(4), 228-236. https://doi.org/10.20986/resed.2018.3632/2017

Wang, C., Pan, R., Wan, X., Tan, Y., Xu, L., Ho, C. S., \& Ho, R. C. (2020). Im-mediate psychological responses and associated factors during the initial stage of the 2019 Coronavirus Disease (COVID-19) Epidemic among the general population in China. International Journal of Envi-ronmental Research and Public Health, 17(5), 1-25. https://doi.org/10.3390/ ijerph17051729

Wood, J., Miller, T., \& Hargrove, D. (2005). Clinical Supervision in Rural Settings: A Telehealth Model. Professional Psychology: Research and Practice, 36(2), 173-179. https://doi. org/10.1037/0735-7028.36.2.173

Yamagata, K., Makino, H., Iseki, K., Ito, S., Kimura, K., \& Kusano, E. (2016). Effect of Behavior Modification on Outcome in Early-to Moderate-Stage Chronic Kidney Disease: A ClusterRandomized Trial. PloS One, 11(3), 1-21. https://doi.org/10.1371/journal.pone.0151422

Zigmond, A.S., \& Snaith, R. P. (1983). The hospital anxiety and depression scale.Acta Psychiatrica Scandinavica, 67, 361-370. https://doi.org/10.1111/j.1600-0447.1983.tb09716.x

Zoom Video Communications, Inc. (2020). Zoom about. Recuperado de https://zoom.us/ about

Zou, Y., Zhao, X., Hou, Y., Liu, T., Wu, Q., Huang, Y., \& Wang, X. (2017). Meta-Analysis of Effects of Voluntary Slow Breathing Exercises for Control of Heart Rate and Blood Pressure in Patients with Cardiovascular Diseases. The American Journal of Cardiology, 120(1), 148153. https://doi.org/10.1016/j.amjcard.2017.03.247 
Zúñiga, C., Dapueto, J., Müller, H., Kirsten L., Alid, R., \& Ortiz, L. (2009). Evaluación de la calidad de vida en pacientes en hemodiálisis crónica mediante el cuestionario "Kidney Disease Quality of Life (KDQOL-36)". Revista médica de Chile, 137(2), 200-207. https://dx.doi. org/10.4067/S0034-98872009000200003 
Anexos 


\author{
UNIVERSIDAD NACIONAL AUTÓNOMA DE MÉXICO \\ FACULTAD DE ESTUDIOS SUPERIORES IZTACALA \\ Programa de Maestría y Doctorado en Psicología \\ Residencia en Medicina Conductual
}

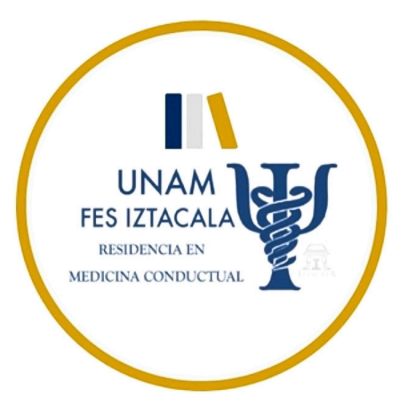

Fecha I

\section{Consentimiento informado}

Estimado(a) paciente:

Por favor lea con atención el siguiente formato, si tiene alguna duda puede aclararla con el (la) psicólogo (a) a cargo.

La Universidad Nacional Autónoma de México a través de la Residencia en Medicina Conductual sede FES Iztacala, le ofrece participar voluntariamente a recibir atención psicológica en línea para pacientes con enfermedades crónico degenerativas, cuidadores y personal de salud, por psicólogos titulados que actualmente están cursando estudios de posgrado en psicología.

A partir de un enfoque cognitivo conductual, en la terapia psicológica se establece una relación paciente-terapeuta, ambos trabajan en colaboración en la búsqueda de un objetivo común: favorecer la adquisición de estrategias psicológicas para la modificación del comportamiento y estilo de vida.

Antes de decidir iniciar el proceso, es muy importante que entienda con claridad sus derechos y responsabilidades como paciente.

El proceso de atención psicológica inicia con la evaluación, en la cual se recolectan datos que permiten comprender su caso; posteriormente se proporciona una intervención desde el enfoque cognitivo-conductual. La duración de la evaluación e intervención puede extenderse dependiendo de su cooperación, su asistencia a las sesiones y la naturaleza de su problemática. Es importante que llegue al término de la evaluación e intervención psicológica para lograr el objetivo terapéutico deseado.

La atención psicológica se brindará a través de las Tecnologías de Información y Comunicación (TICS) utilizando aparatos electrónicos para el fin expuesto, a partir de diversas plataformas (redes sociales, Zoom, Gmail, Hangouts, Microsoft teams, entre otras).

Durante el proceso obtendrá beneficios, sin embargo, también se presentarán riesgos e incomodidades, debido a que durante las sesiones se abordan temas delicados que le pueden provocar respuestas emocionales de tristeza, enojo, llanto, entre otros; para que el terapeuta le pueda brindar la atención que requiere y se obtengan resultados favorables es 
necesario que proporcione toda la información que se le solicite de forma veraz y confiable. Durante o después de la evaluación, se podría realizar una canalización a otros profesionales, programas e instituciones debido a la naturaleza de la problemática. Por otro lado, al hacer uso de las TICs también puede haber riesgos como comunicación intermitente, lentitud o fallas en la conexión.

Es importante considerar que la atención psicológica en línea, presenta los mismos beneficios de la modalidad presencial como mejorar la calidad de vida, disminuir el malestar emocional y adquisición de estrategias para la modificación del comportamiento. Adicionalmente, la modalidad a distancia promueve ciertas ventajas tales como: disposición de tiempo dentro del horario de atención, atención a medidas sanitarias y evitar desplazamiento a un consultorio físico.

La decisión de participar en la intervención es completamente voluntaria, destacando la importancia de la puntualidad y asistencia a la sesión. No habrá ninguna consecuencia desfavorable para usted, en caso de no aceptar la invitación. Si decide participar, puede retirarse en el momento que lo desee, pudiendo informar o no, las razones de su decisión, las cuales serán respetadas en su integridad.

La información de sus datos personales son de carácter confidencial; no serán divulgados a terceros ajenos, ni su identidad. De igual manera, se protegerán los datos evitando cualquier robo o divulgación de información. En el caso de que su información fuera utilizada con fines de investigación se eliminará cualquier fuente de información de identificación personal, respetando su derecho a la confidencialidad de la información. Finalmente, cabe mencionar que la intervención será completamente gratuita, en ningún momento se le solicitará alguna remuneración económica o material.

Yo acepto la evaluación e intervención psicológica señalada en el presente escrito. A su vez, expreso que se me proporcionó información sobre el derecho de poder retirarme de la atención psicológica en línea y todas mis dudas han sido aclaradas.

Nombre completo y firma del paciente

Número de teléfono para localizarlo en caso necesario

Nombre y firma del terapeuta

Acepto

Contacto:

Lic. en Psicología:

Cédula Profesional:

Teléfono:

Correo electrónico: 


\section{UNIVERSIDAD NACIONAL AUTÓNOMA DE MÉXICO FACULTAD DE ESTUDIOS SUPERIORES IZTACALA Programa de Maestría y Doctorado en Psicología Residencia en Medicina Conductual}

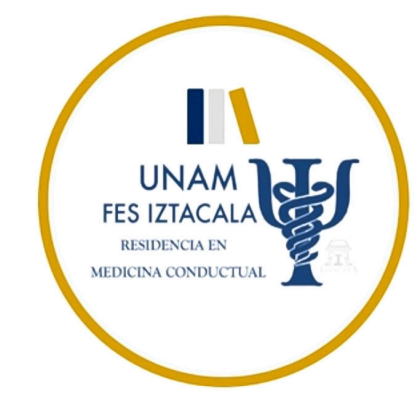

\section{Breve Checklist de Afrontamiento}

(Abaroa, González, Ortega, Reyes, \& Reynoso, 2020)

Sin fines de lucro

Nombre del paciente

Fecha

Instrucciones: A continuación, se enlista una serie de comportamientos, por favor indica si realizas alguno de estos ante problemáticas relacionadas con tu salud.

\begin{tabular}{|c|c|}
\hline & Sí \\
\hline \multicolumn{2}{|c|}{ 1. Busco en experiencias pasadas: “Ya estuve así antes?, ¿Qué hice?” } \\
\hline \multicolumn{2}{|l|}{ 2. Busco soluciones extras al problema. } \\
\hline \multicolumn{2}{|l|}{ 3. Consulto al doctor. } \\
\hline \multicolumn{2}{|l|}{ 4. Espero que suceda un milagro. } \\
\hline \multicolumn{2}{|l|}{ 5. Hago un plan de acción y trato de seguirlo. } \\
\hline \multicolumn{2}{|c|}{ 6. Intento hallar consuelo en mi religión o creencia espiritual (rezo/medito). } \\
\hline \multicolumn{2}{|l|}{ 7. Me mantengo ocupado o duermo para no pensar en ello. } \\
\hline \multicolumn{2}{|l|}{ 8. Me echo la culpa de lo que ha sucedido. } \\
\hline \multicolumn{2}{|l|}{ 9. Procuro pensar qué voy a hacer o a decir. } \\
\hline 10. Utilizo alcohol y otras drogas para hacerme sentir mejor. & \\
\hline
\end{tabular}

Gracias por sus respuestas. 


\section{UNIVERSIDAD NACIONAL AUTÓNOMA DE MÉXICO FACULTAD DE ESTUDIOS SUPERIORES IZTACALA Programa de Maestría y Doctorado en Psicología Residencia en Medicina Conductual}

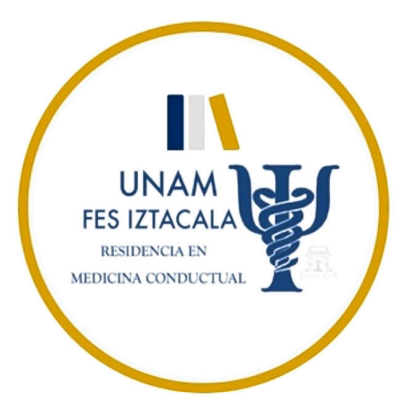

\section{Síntomas de Estrés}

(Reynoso \& Seligson, 2005)

Sin fines de lucro

Nombre del paciente Fecha

Instrucciones: A continuación, se enlistan una variedad de síntomas. Lee cada uno cuidadosamente y decide si eso te ha ocurrido en los últimos dos o tres días.

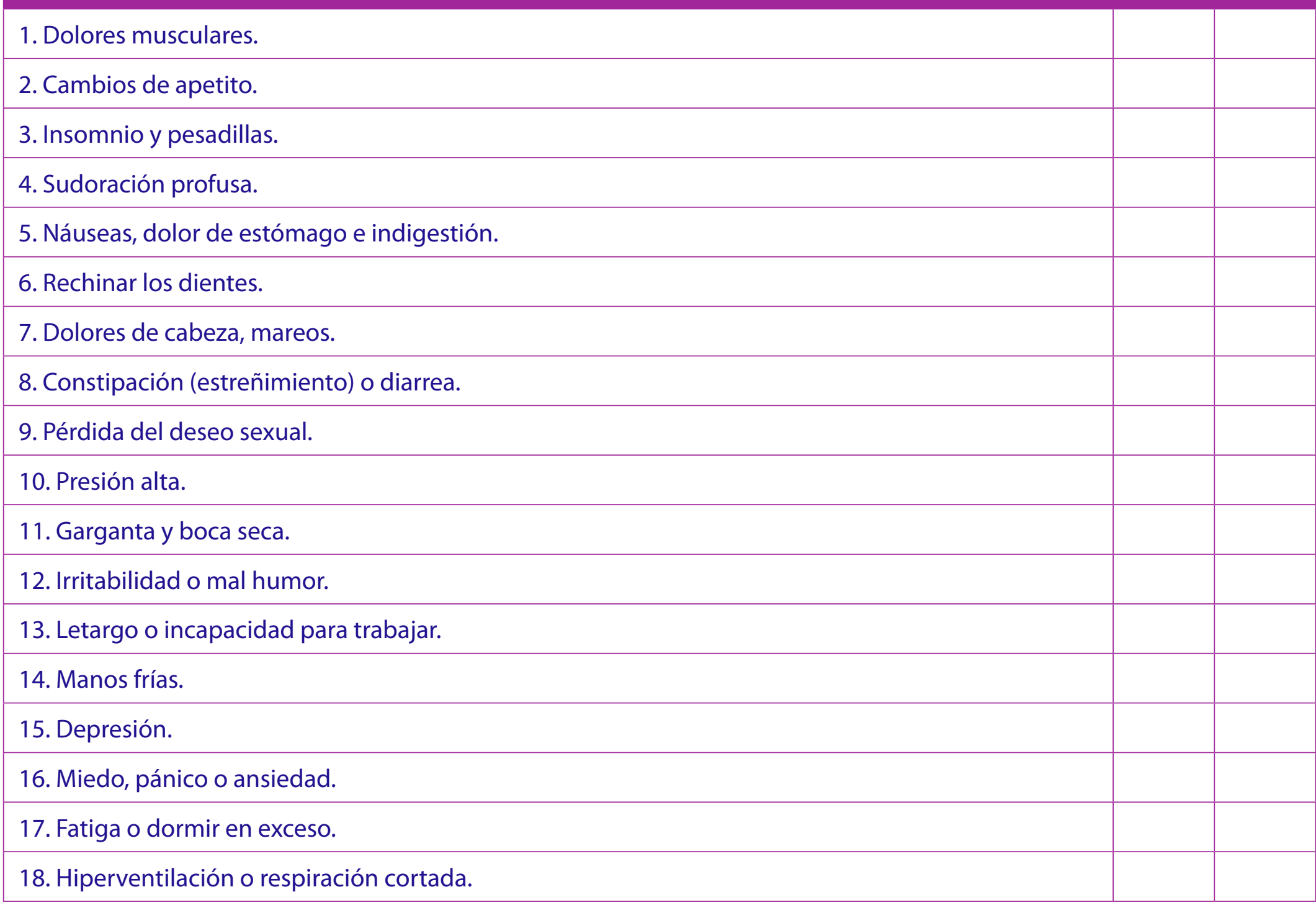


19. Incremento en el número de accidentes menores.

20. Pensamientos de apuro o falta de concentración.

21. Aumento de los lapsus de memoria.

22. Incremento en la frecuencia de los errores.

23. Cambio en las conductas habituales.

24. Falta de ganas de trabajar o jugar.

25. Sentimientos de desesperación o de inutilidad.

26. Pensar constantemente en cosas que no puede cambiar.

27. Sientes que el corazón se te sale del pecho.

28. Tensión muscular, torceduras musculares y tics.

Gracias por sus respuestas. 


\section{UNIVERSIDAD NACIONAL AUTÓNOMA DE MÉXICO FACULTAD DE ESTUDIOS SUPERIORES IZTACALA Programa de Maestría y Doctorado en Psicología Residencia en Medicina Conductual}

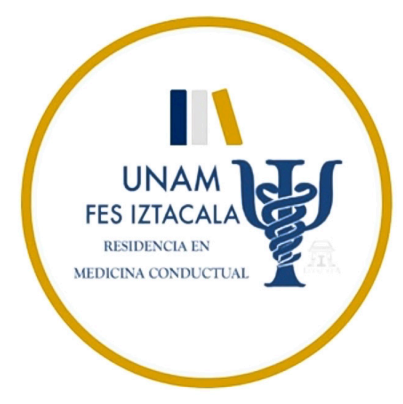

\section{Escala de Ansiedad y Depresión Hospitalaria (HADS)}

(Galindo et al., 2015)

Sin fines de lucro

Nombre del paciente

Fecha

Instrucciones: A continuación, se enlista una serie de enunciados acerca de cómo se siente emocionalmente. Lea cada pregunta y marque con una cruz $(\mathbf{X}$ ) la respuesta que se acerque más a cómo se ha sentido durante la última semana. No es necesario que piense mucho las respuestas.

1. Me siento tenso(a) o nervioso (a):

\begin{tabular}{|l|l|l|l}
\hline a) Todo el día & b) Casi todo el día & c) De vez en cuando & d) Nunca \\
\hline
\end{tabular}

2. Sigo disfrutando con las mismas cosas que siempre:

\begin{tabular}{|l|l|l|l}
\hline a) No en absoluto & b) Rara vez & c) Frecuentemente & d) Casi siempre
\end{tabular}

3. Siento una especie de temor como si algo me fuera a suceder:

\begin{tabular}{|l|l|l|l}
\hline a) Sí y muy intenso & b) Sí, pero no muy intenso & c) Sí, pero no me preocupa & d) No siento nada de eso
\end{tabular}

4. Soy capaz de reírme y ver el lado gracioso de las cosas:

\begin{tabular}{|l|l|l|l|}
\hline a) No, en absoluto & b) Rara vez & c) Frecuentemente & d) Casi siempre \\
\hline
\end{tabular}

5. Tengo la cabeza llena de preocupaciones:

\begin{tabular}{|c|c|c|c|}
\hline a) Todo el día & b) Frecuentemente & c) De vez en cuando & d) Nunca \\
\hline \multicolumn{4}{|l|}{ 6. Me siento alegre: } \\
\hline a) No, en absoluto & b) Rara vez & c) Frecuentemente & d) Casi siempre \\
\hline \multicolumn{4}{|c|}{ 7. Soy capaz de permanecer sentado(a) tranquila y relajadamente: } \\
\hline a) No en absoluto & b) Rara vez & c) Frecuentemente & d) Casi siempre \\
\hline
\end{tabular}


8. Me siento lento(a) y torpe:
a) Todo el día
b) Casi todo el día
c) De vez en cuando
d) Nunca

9. Experimento una sensación de nervios y vacío en el estómago:

\begin{tabular}{|l|l|l|l}
\hline a) Casi siempre & b) Frecuentemente & c) Rara vez & d) No, en absoluto
\end{tabular}

10. He perdido el interés por mi aspecto personal:

\begin{tabular}{|l|l|l|l} 
a) Casi siempre & b) Frecuentemente & c) Rara vez & d) No, en absoluto
\end{tabular}

11. Me siento inquieto(a) como si no pudiera dejarme de mover:

\begin{tabular}{|l|l|l|l}
\hline a) Casi siempre & b) Frecuentemente & c) Rara vez & d) No, en absoluto
\end{tabular}

12. Espero las cosas con ilusión:

\begin{tabular}{|l|l|l|l|}
\hline a) No, en absoluto & b) Rara vez & c) Frecuentemente & d) Casi siempre
\end{tabular}

13. Experimento de repente una sensación de gran angustia o temor:

\begin{tabular}{|l|l|l|l} 
a) Casi siempre & b) Frecuentemente & c) Rara vez & d) No, en absoluto
\end{tabular}

14. Soy capaz de disfrutar con un buen libro, programa de radio o televisión:

\begin{tabular}{|l|l|l|l|}
\hline a) No, en absoluto & b) Rara vez & c) Frecuentemente & d) Casi siempre \\
\hline
\end{tabular}

Gracias por sus respuestas. 


\section{UNIVERSIDAD NACIONAL AUTÓNOMA DE MÉXICO FACULTAD DE ESTUDIOS SUPERIORES IZTACALA Programa de Maestría y Doctorado en Psicología Residencia en Medicina Conductual}

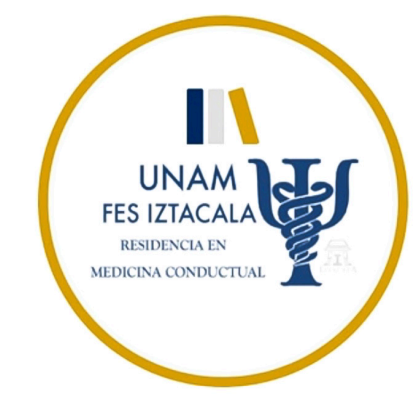

\section{Escala de Estrés Percibido (PSS-14) \\ (González \& Landero, 2007) \\ Sin fines de lucro}

Nombre del paciente Fecha L

Instrucciones: Marca la opción que mejor se adecúe a tu situación actual.

\begin{tabular}{|c|c|c|c|c|c|}
\hline Durante el último mes: & $\frac{\text { ¿ }}{2}$ & 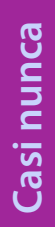 & 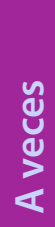 & $\begin{array}{l}\circ \\
\text { 을 } \\
\frac{c}{0} \\
\text { ह } \\
\frac{1}{\alpha}\end{array}$ & 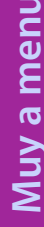 \\
\hline 1. ¿Con qué frecuencia has estado afectado(a) por algo que ha ocurrido inesperadamente? & 0 & 1 & 2 & 3 & 4 \\
\hline 2. ¿Con qué frecuencia te has sentido incapaz de controlar las cosas importantes de tu vida? & 0 & 1 & 2 & 3 & 4 \\
\hline 3. ¿Con qué frecuencia te has sentido nervioso(a) o estresado(a) (Ileno de tensión)? & 0 & 1 & 2 & 3 & 4 \\
\hline 4. ¿Con qué frecuencia has manejado con éxito los pequeños problemas irritantes de la vida? & 0 & 1 & 2 & 3 & 4 \\
\hline 5. ¿Con qué frecuencia has estado seguro(a) sobre tu capacidad de manejar problemas personales? & 0 & 1 & 2 & 3 & 4 \\
\hline 6. ¿Con qué frecuencia has sentido que las cosas te van bien? & 0 & 1 & 2 & 3 & 4 \\
\hline 7. ¿Con qué frecuencia has sentido que no podías afrontar todas las cosas que tenías que hacer? & 0 & 1 & 2 & 3 & 4 \\
\hline 8. ¿Con qué frecuencia has podido controlar las dificultades de tu vida? & 0 & 1 & 2 & 3 & 4 \\
\hline 9. ¿Con qué frecuencia has sentido que tienes el control de todo? & 0 & 1 & 2 & 3 & 4 \\
\hline $\begin{array}{l}\text { 10. ¿Con qué frecuencia has estado enfadado(a) porque las cosas que te han ocurrido estaban } \\
\text { fuera de tu control? }\end{array}$ & 0 & 1 & 2 & 3 & 4 \\
\hline 11. ¿Con qué frecuencia has pensado sobre las cosas que no has terminado (pendientes de hacer)? & 0 & 1 & 2 & 3 & 4 \\
\hline 12. ¿Con qué frecuencia has podido controlar la forma de pasar el tiempo (organizar)? & 0 & 1 & 2 & 3 & 4 \\
\hline $\begin{array}{l}\text { 13. ¿Con qué frecuencia has sentido que las dificultades se acumulan tanto que no puedes } \\
\text { superarlas? }\end{array}$ & 0 & 1 & 2 & 3 & 4 \\
\hline
\end{tabular}




\title{
UNIVERSIDAD NACIONAL AUTÓNOMA DE MÉXICO \\ FACULTAD DE ESTUDIOS SUPERIORES IZTACALA \\ Programa de Maestría y Doctorado en Psicología \\ Residencia en Medicina Conductual
}

\author{
Checklist Ansiedad A \\ Adaptado de Reynoso y Becerra (2013) \\ Sin fines de lucro
}

Nombre del paciente

Fecha

Instrucciones: Se enlistan una variedad de síntomas. Lee cada una cuidadosamente y decide si eso te ha ocurrido en los últimos dos o tres días. Si no te ha ocurrido, marca "No" en el espacio respectivo. Si el evento sí ocurrió, marca "Sí". Por favor contesta de la forma más sincera que te sea posible.

\begin{tabular}{|c|c|c|}
\hline ¿Te ha ocurrido en los últimos dos o tres días? & Sí & No \\
\hline 1. Dolores musculares. & & \\
\hline 2. Cambios de apetito. & & \\
\hline 3. Insomnio y pesadillas. & & \\
\hline 4. Sudoración profusa. & & \\
\hline 5. Náuseas, dolor de estómago e indigestión. & & \\
\hline 6. Rechinar los dientes. & & \\
\hline 7. Constipación (estreñimiento) o diarrea. & & \\
\hline 8. Garganta y boca seca. & & \\
\hline 9. Irritabilidad o mal humor. & & \\
\hline 10. Manos frías. & & \\
\hline 11. Miedo, pánico o ansiedad. & & \\
\hline 12. Fátiga o duermes en exceso. & & \\
\hline 13. Hiperventilación o respiración cortada. & & \\
\hline 14. Pensamientos de apuro o falta de concentración. & & \\
\hline 15. Incremento en la frecuencia de errores. & & \\
\hline 16. Falta de ganas de jugar o trabajar. & & \\
\hline 17. Sentimiento de desesperación o de inutilidad. & & \\
\hline 18. Pensamientos constantes en cosas que no puedes cambiar. & & \\
\hline 19. Tensión muscular, torceduras musculares y tics. & & \\
\hline
\end{tabular}




\section{UNIVERSIDAD NACIONAL AUTÓNOMA DE MÉXICO FACULTAD DE ESTUDIOS SUPERIORES IZTACALA Programa de Maestría y Doctorado en Psicología Residencia en Medicina Conductual}

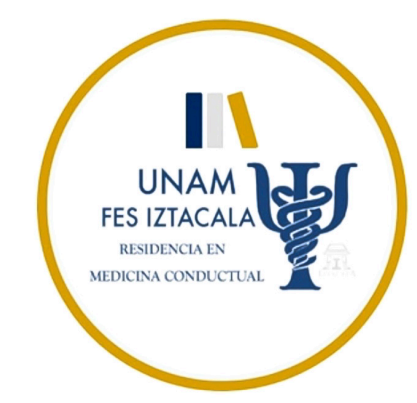

\section{Checklist Ansiedad B \\ Reynoso (2002) \\ Sin fines de lucro}

Nombre del paciente Fecha

Instrucciones: Se enlistan una variedad de síntomas. Lee cada una cuidadosamente y decide si eso te ha ocurrido en los últimos dos o tres días. Si no te ha ocurrido, marca "No"; si el evento sí ocurrió, marca "Sí" en el espacio respectivo. Por favor, contesta de la forma más sincera que te sea posible.

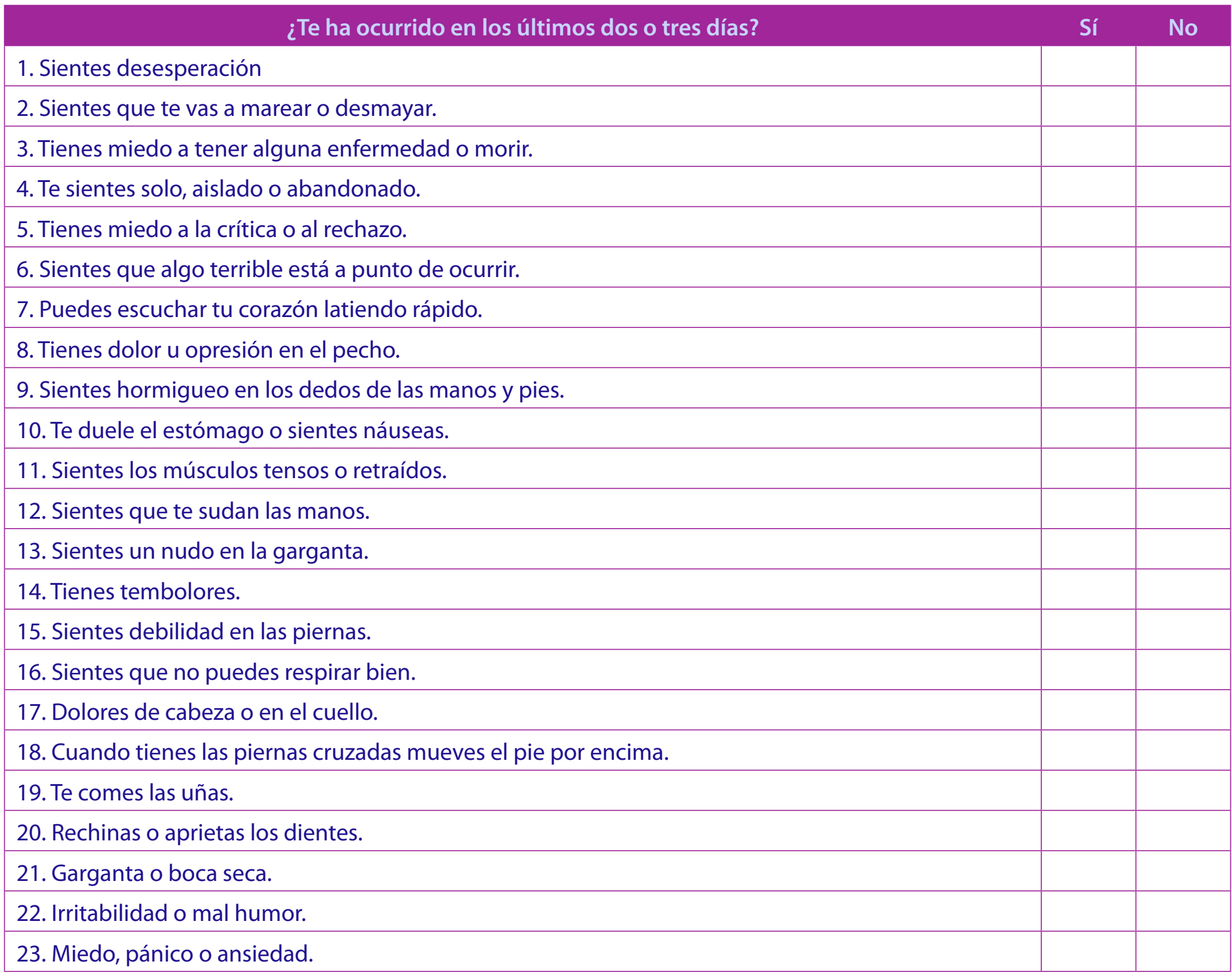




\section{UNIVERSIDAD NACIONAL AUTÓNOMA DE MÉXICO FACULTAD DE ESTUDIOS SUPERIORES IZTACALA Programa de Maestría y Doctorado en Psicología Residencia en Medicina Conductual}

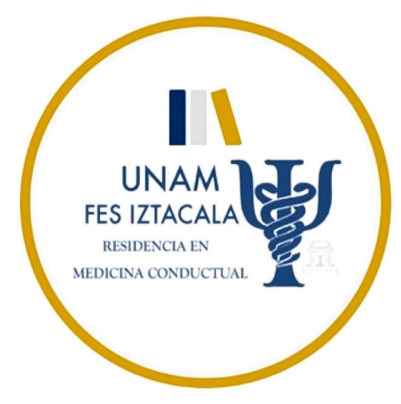

\section{Inventario de Estrategias de Afrontamiento}

(Cano, Rodríguez, \& García, 2007)

Sin fines de lucro

Nombre del paciente Fecha I

Instrucciones: El propósito de este cuestionario es encontrar el tipo de situaciones que causa problemas a las personas en su vida cotidiana y cómo estas se enfrentan a estos problemas.

Piensa durante unos minutos en un hecho o situación que ha sido muy estresante para ti en el último mes. Por estresante entendemos una situación que causa problemas, le hace sentirse a uno mal o que cuesta mucho enfrentarse a ella. Puede ser con la familia, en la escuela, en el trabajo, con los amigos, etc.

Describe esta situación en el espacio en blanco de esta página. Escribe qué ocurrió e incluye detalles como el lugar, quién o quiénes estaban implicados, por qué le diste importancia y qué hiciste. La situación puede estar sucediendo ahora o puede haber sucedido ya. No te preocupes por si está mejor o peor escrito o mejor o peor organizado, solo escríbela tal y como se te ocurra.

Instrucciones: De nuevo piensa unos minutos en la situación o hecho que hayas elegido. Responde a la siguiente lista de afirmaciones basándote en cómo manejaste esta situación. Lee cada frase y determina con un tache $(\mathbf{X})$ el grado en que hiciste lo que cada frase indica en la situación que antes elegiste marcando el número que corresponda:

$\mathbf{0}=$ En absoluto; $\mathbf{1}=$ Un poco; $\mathbf{2}=$ Bastante; $\mathbf{3}=$ Mucho; $\mathbf{4}=$ Totalmente

Asegúrate de que respondas todas las frases. No hay respuestas correctas o incorrectas; solo se evalúa lo que hiciste, pensaste o sentiste en ese momento. 
1. Luché por resolver el problema.

2. Me culpé a mí mismo.

3. Dejé salir mis sentimientos para reducir el estrés.

4. Deseé que la situación nunca hubiera empezado.

5. Encontré a alguien que escuchó mi problema.

6. Repasé el problema una y otra vez en mi mente y al final vi las cosas de una forma diferente.

7. No dejé que me afectara; evité pensar en ello demasiado.

8. Pasé algún tiempo solo.

9. Me esforcé para resolver los problemas de la situación.

10. Me di cuenta de que era personalmente responsable de mis dificultades y me lo reproché.

11. Expresé mis emociones, lo que sentía.

12. Deseé que la situación no existiera o que de alguna manera terminase.

13. Hablé con una persona de confianza.

14. Cambié la forma en que veía la situación para que las cosas no parecieran tan malas.

15. Traté de olvidar por completo el asunto.

16. Evité estar con gente.

17. Hice frente al problema.

18. Me critiqué por lo ocurrido.

19. Analicé mis sentimientos y simplemente los deje salir.

20. Deseé no encontrarme nunca más en esa situación.

21. Dejé que mis amigos me echaran una mano.

22. Me convencí de que las cosas no eran tan malas como parecían.

23. Quité importancia a la situación y no quise preocuparme más.

24. Oculté lo que pensaba y sentía.

25. Supe lo que había que hacer, así que doblé mis esfuerzos y traté con más ímpetu de hacer que las cosas funcionaran.

26. Me recriminé por permitir que esto ocurriera.

27. Dejé desahogar mis emociones.

28. Deseé poder cambiar lo que había sucedido.

29. Pasé algún tiempo con mis amigos.

30. Me pregunté qué era realmente importante y descubrí que las cosas no estaban tan mal después de todo.

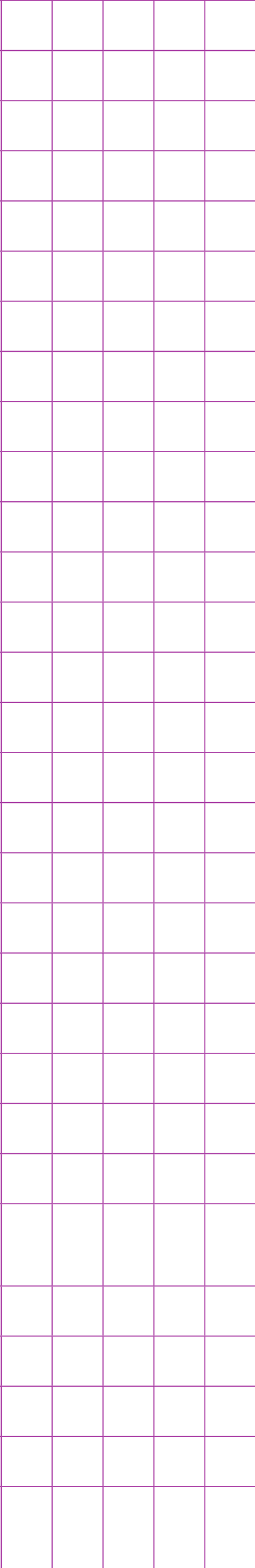




\begin{tabular}{|c|c|c|c|c|c|}
\hline & 0 & 1 & 2 & 3 & 4 \\
\hline 31. Me comporté como si nada hubiera pasado. & & & & & \\
\hline 32. No dejé que nadie supiera como me sentía. & & & & & \\
\hline 33. Mantuve mi postura y luché por lo que querí & & & & & \\
\hline 34. Fue un error mío, así que tenía que sufrir las c & & & & & \\
\hline 35. Mis sentimientos eran abrumadores y estalla & & & & & \\
\hline 36. Me imaginé que las cosas podrían ser diferen & & & & & \\
\hline 37. Pedí consejo a un amigo o familiar que respe & & & & & \\
\hline 38. Me fijé en el lado bueno de las cosas. & & & & & \\
\hline 39. Evité pensar o hacer nada. & & & & & \\
\hline 40. Traté de ocultar mis sentimientos. & & & & & \\
\hline 41. Me consideré capaz de afrontar la situación. & & & & & \\
\hline
\end{tabular}

\section{Gracias por sus respuestas.}




\section{UNIVERSIDAD NACIONAL AUTÓNOMA DE MÉXICO FACULTAD DE ESTUDIOS SUPERIORES IZTACALA Programa de Maestría y Doctorado en Psicología Residencia en Medicina Conductual}

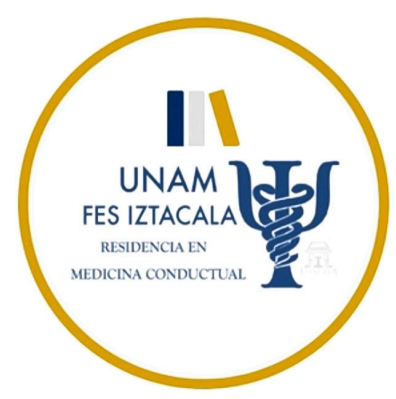

\section{Enfermedad Renal y Calidad de Vida (KDQOL-36)}

(Dehesa et al., 2016)

Sin fines de lucro

Nombre del paciente Fecha

\section{Su salud}

Instrucciones: Este cuestionario incluye preguntas muy variadas sobre su salud y sobre su vida. Nos interesa saber cómo se siente en cada uno de estos aspectos. Marque con una cruz (X) la casilla que mejor corresponda con su respuesta.

1. En general, diría que su salud es?

\begin{tabular}{|c|c|c|c|c|}
\hline Excelente & Muy Buena & Buena & Pasable & Mala \\
\hline 1 & 2 & 3 & 4 & 5 \\
\hline
\end{tabular}

Las siguientes frases se refieren a actividades que usted podría hacer en un día típico. ¿Su estado de salud actual lo limita para hacer estas actividades? Si es así, ¿cuánto?

\begin{tabular}{|l|c|c|c|}
\hline & \multicolumn{1}{c}{$\begin{array}{c}\text { Sí, } \\
\text { me limita mucho }\end{array}$} & $\begin{array}{c}\text { Sí, } \\
\text { me limita un poco }\end{array}$ & $\begin{array}{c}\text { No me limita } \\
\text { en absoluto }\end{array}$ \\
\hline $\begin{array}{l}\text { 2. Actividades moderadas, tales como mover } \\
\text { una mesa, empujar una aspiradora, jugar } \\
\text { boliche o jugar golf. }\end{array}$ & 1 & 2 & 3 \\
\hline 3. Subir varios pisos por la escalera & 1 & 2 & 3 \\
\hline
\end{tabular}

Durante las últimas 4 semanas, ¿ha tenido usted alguno de los siguientes problemas con el trabajo u otras actividades diarias regulares a causa de su salud física?

\begin{tabular}{|l|c|c|}
\hline 4. Ha logrado hacer menos de lo que le hubiera gustado. & 1 & 2 \\
\hline 5. Ha tenido limitaciones en cuanto al tipo de trabajo u otras actividades. & 1 & 2 \\
\hline
\end{tabular}


Durante las últimas 4 semanas, ¿ha tenido usted alguno de los siguientes problemas con el trabajo $\mathrm{u}$ otras actividades diarias regulares a causa de algún problema emocional (como sentirse deprimido o ansioso?

\begin{tabular}{|l|c|c|}
\hline & Sí & No \\
\hline 6. Ha logrado hacer menos de lo que le hubiera gustado. & 1 & 2 \\
\hline 7. Ha hecho el trabajo u otras actividades con menos cuidado de lo usual. & 1 & 2 \\
\hline
\end{tabular}

8. Durante las últimas 4 semanas, ¿cuánto ha dificultado el dolor su trabajo normal (incluyendo tanto el trabajo fuera de casa como los quehaceres domésticos)?

\begin{tabular}{|c|c|c|c|c|}
\hline Nada en absoluto & Un poco & Medianamente & Bastante & Extremadamente \\
\hline 1 & 2 & 3 & 4 & 5 \\
\hline
\end{tabular}

Estas preguntas se refieren a cómo se siente usted y a cómo le han ido las cosas durante las últimas 4 semanas. Por cada pregunta, por favor dé la respuesta que más se acerca a la manera como se ha sentido usted.

¿Cuánto tiempo durante las últimas 4 semanas...

\begin{tabular}{|c|c|c|c|c|c|c|}
\hline & Siempre & $\begin{array}{c}\text { Casi } \\
\text { siempre }\end{array}$ & $\begin{array}{c}\text { Muchas } \\
\text { veces }\end{array}$ & $\begin{array}{c}\text { Algunas } \\
\text { veces }\end{array}$ & $\begin{array}{c}\text { Casi } \\
\text { siempre }\end{array}$ & Nunca \\
\hline 9. se ha sentido tranquilo y sosegado? & 1 & 2 & 3 & 4 & 5 & 6 \\
\hline 10. ha tenido mucha energía? & 1 & 2 & 3 & 4 & 5 & 6 \\
\hline 11. se ha sentido desanimado y triste? & 1 & 2 & 3 & 4 & 5 & 6 \\
\hline
\end{tabular}

12. Durante las últimas 4 semanas, ¿cuánto tiempo su salud física o sus problemas emocionales han dificultado sus actividades sociales (como visitar amigos, parientes, etc.)?

\begin{tabular}{|c|c|c|c|c|}
\hline Siempre & Casi siempre & Algunas veces & Casi nunca & Nunca \\
\hline 1 & 2 & 3 & 4 & 5 \\
\hline
\end{tabular}

\section{Su enfermedad del riñón}

¿En qué medida considera cierta o falsa en su caso cada una de las siguientes afirmaciones?

\begin{tabular}{|l|c|c|c|c|c|} 
& \multicolumn{1}{|c}{$\begin{array}{c}\text { Totalmente } \\
\text { cierto }\end{array}$} & $\begin{array}{c}\text { Bastante } \\
\text { cierto }\end{array}$ & No sé & $\begin{array}{c}\text { Bastante } \\
\text { falso }\end{array}$ \\
\hline $\begin{array}{l}\text { 13. Mi enfermedad del riñón interfiere } \\
\text { demasiado en mi vida. }\end{array}$ & 1 & 2 & 3 & 5 \\
\hline $\begin{array}{l}\text { 14. Mi enfermedad del riñón me ocupa } \\
\text { demasiado tiempo. }\end{array}$ & 1 & 2 & 3 & 4 & 5 \\
\hline
\end{tabular}




\begin{tabular}{|c|c|c|c|c|c|}
\hline & $\begin{array}{l}\text { Totalmente } \\
\text { cierto }\end{array}$ & $\begin{array}{l}\text { Bastante } \\
\text { cierto }\end{array}$ & No sé & $\begin{array}{l}\text { Bastante } \\
\text { falso }\end{array}$ & $\begin{array}{l}\text { Totalmente } \\
\text { falso }\end{array}$ \\
\hline $\begin{array}{l}\text { 15. Me siento frustrado al tener que ocuparme } \\
\text { de mi enfermedad del riñón. }\end{array}$ & 1 & 2 & 3 & 4 & 5 \\
\hline 16. Me siento una carga para la familia. & 1 & 2 & 3 & 4 & 5 \\
\hline
\end{tabular}

Durante las últimas 4 semanas, ¿cuánto le molestó cada una de las siguientes cosas?

\begin{tabular}{|l|c|c|c|c|c|}
\hline & \multicolumn{2}{c}{ Nada } & \multicolumn{2}{c}{ Un poco } & \multicolumn{2}{c|}{ Regular } & Mucho & Muchísimo \\
\hline 17. ¿Dolores musculares? & 1 & 2 & 3 & 4 & 5 \\
\hline 18. ¿Dolor en el pecho? & 1 & 2 & 3 & 4 & 5 \\
\hline 19. ¿Calambres? & 1 & 2 & 3 & 4 & 5 \\
\hline 20. ¿Picazón en la piel? & 1 & 2 & 3 & 4 & 5 \\
\hline 21. ¿Sequedad de piel? & 1 & 2 & 3 & 4 & 5 \\
\hline 22. ¿Falta de aire? & 1 & 2 & 3 & 4 & 5 \\
\hline 23. ¿Desmayos o mareo? & 1 & 2 & 3 & 4 & 5 \\
\hline 24. ¿Falta de apetito? & 1 & 2 & 3 & 4 & 5 \\
\hline 25. ¿Agotado/a, sin fuerzas? & 1 & 2 & 3 & 4 & 5 \\
\hline 26. ¿Entumecimiento (hormigueo) de manos o pies? & 1 & 2 & 3 & 4 & 5 \\
\hline 27. ¿Náuseas o molestias en el estómago? & 1 & 2 & 3 & 4 & 5 \\
\hline 28. ¿Problemas con el catéter? & 1 & 2 & 3 & 4 & 5 \\
\hline
\end{tabular}

\section{Efectos de la enfermedad renal en su vida}

Los efectos de la enfermedad renal molestan a algunas personas en su vida diaria, mientras que a otras no. ¿Cuánto le molesta su enfermedad en cada una de las siguientes áreas?

\begin{tabular}{|c|c|c|c|c|c|}
\hline & Nada & Un poco & Regular & Mucho & Muchísimo \\
\hline 29. ¿Limitación de líquidos? & 1 & 2 & 3 & 4 & 5 \\
\hline 30. ¿Limitaciones en la dieta? & 1 & 2 & 3 & 4 & 5 \\
\hline 31. ¿Su capacidad para trabajar en la casa? & 1 & 2 & 3 & 4 & 5 \\
\hline 32. ¿Su capacidad para viajar? & 1 & 2 & 3 & 4 & 5 \\
\hline 33. ¿Depender de médicos y de otro personal sanitario? & 1 & 2 & 3 & 4 & 5 \\
\hline $\begin{array}{l}\text { 34. ¿Tensión nerviosa o preocupaciones causadas por } \\
\text { su enfermedad? }\end{array}$ & 1 & 2 & 3 & 4 & 5 \\
\hline 35. ¿Su vida sexual? & 1 & 2 & 3 & 4 & 5 \\
\hline 36. ¿Su aspecto físico? & 1 & 2 & 3 & 4 & 5 \\
\hline
\end{tabular}

Gracias por sus respuestas. 


\section{UNIVERSIDAD NACIONAL AUTÓNOMA DE MÉXICO FACULTAD DE ESTUDIOS SUPERIORES IZTACALA Programa de Maestría y Doctorado en Psicología Residencia en Medicina Conductual}

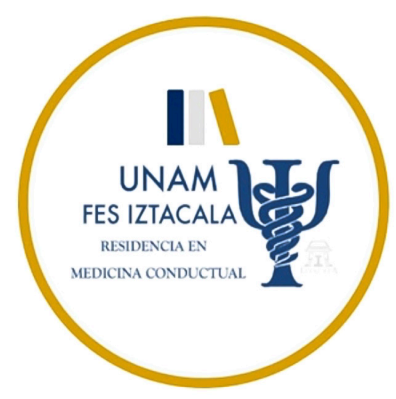

\section{Versión Actualizada de la Escala de Adherencia Terapeútica (Pedraza-Banderas \& Valero, 2018) \\ Sin fines de lucro}

Nombre del paciente Fecha /

Instrucciones: En este instrumento se presentan diversas frases relacionadas a tu salud. Lee cada frase y determina el grado con el que mejor te identificas marcando el número que corresponda: nunca, casi nunca, pocas veces, frecuentemente o casi siempre. Selecciona solo una respuesta por frase. Asegúrate de que respondas todas las frases. No hay respuestas correctas o incorrectas.

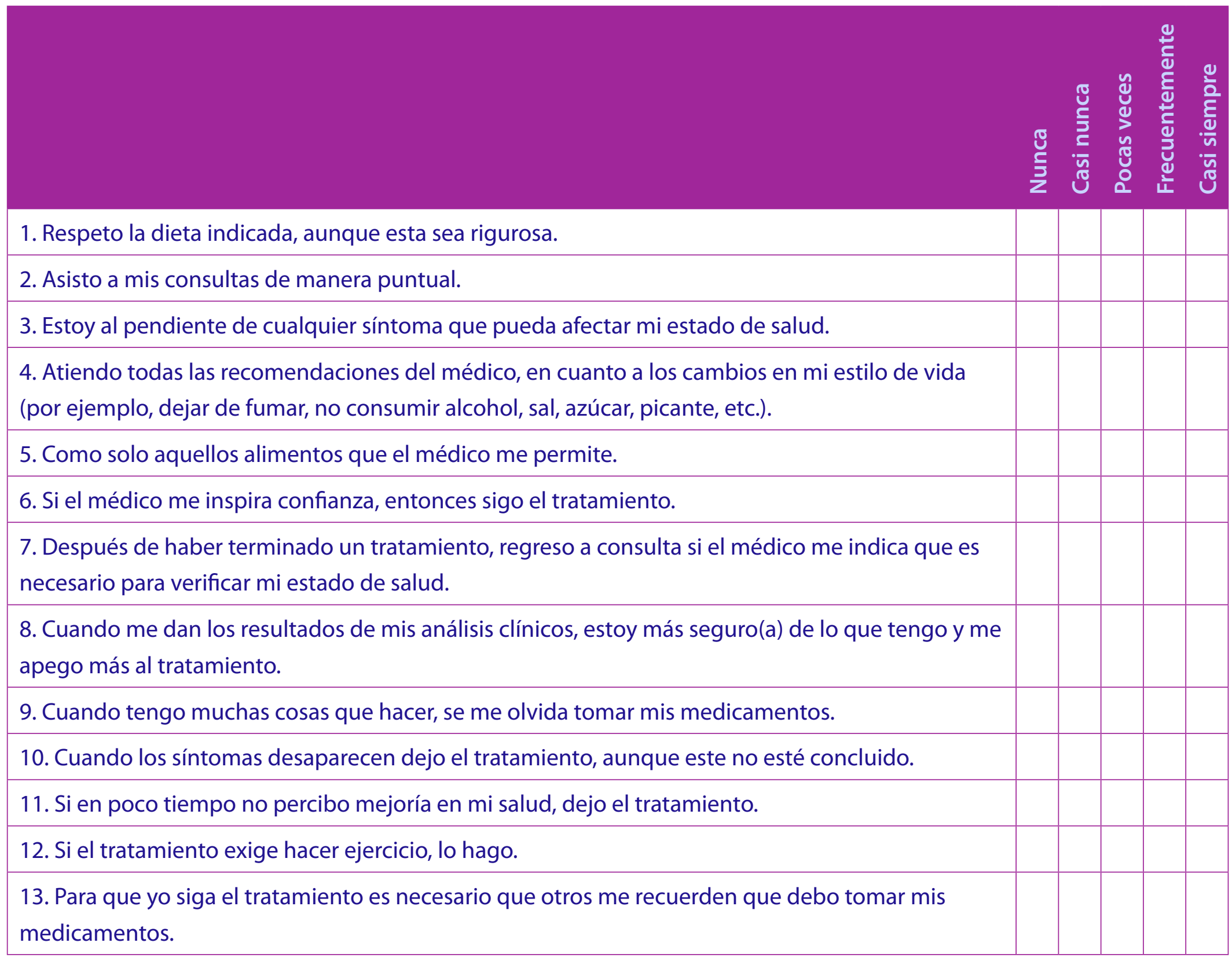




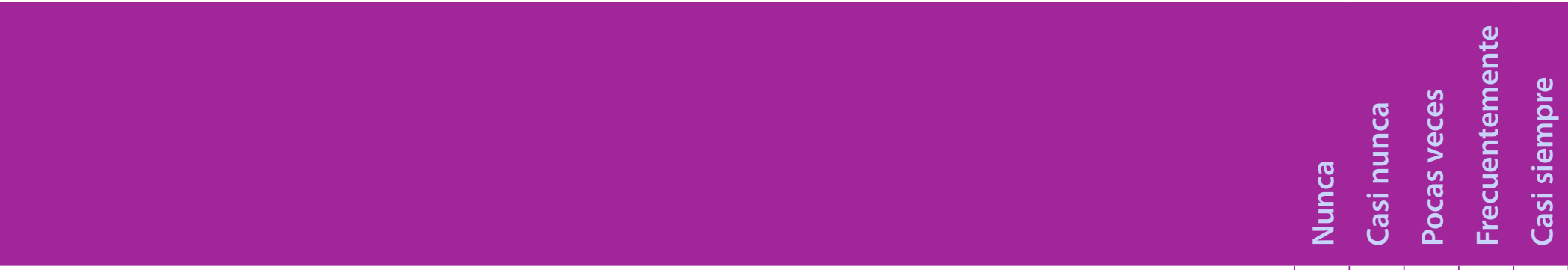

14. Como me lo recomienda el médico, acudo a realizarme análisis.

15. Me inspira confianza que el médico demuestre conocer mi enfermedad.

16. Si se sospecha que mi enfermedad es grave, hago todo lo que esté en mis manos para mejorar.

17. Me apego al tratamiento, aunque este sea complicado.

18. Si el médico me explica detalladamente en qué consiste mi enfermedad y qué es lo que tengo que hacer para mejorar mi salud, entonces me adhiero al tratamiento.

19. Si el medicamento es costoso, ingiero cantidades menores a las indicadas por el médico.

20. Le tengo más confianza a los medicamentos de patente que a los remedios naturales u homeopáticos.

21. Ingiero mis medicamentos respetando la dosis indicada por el médico.

22. Asisto a revisiones periódicas, aunque no me sienta mal.

23. Acudo al médico, únicamente cuando presento algún síntoma.

24. Notar mejoría en mi estado de salud, favorece que me adhiera al tratamiento.

25. Cuando presento síntomas de deterioro, me adhiero más al tratamiento.

26. Realizo las mediciones indicadas en casa, por ejemplo, tomas de presión arterial, el nivel de glucosa, etc.

27. Respeto la dieta indicada por el médico, sin importar el lugar donde me encuentre.

28. Realizo algún tipo de modificación al tratamiento, sin consultarlo con el médico.

29. Hago todo lo que está en mis manos para mantenerme controlado(a).

30. Estoy más seguro(a) de lo que tengo cuando me informan los resultados arrojados en los análisis clínicos.

\section{Gracias por sus respuestas.}




\section{UNIVERSIDAD NACIONAL AUTÓNOMA DE MÉXICO FACULTAD DE ESTUDIOS SUPERIORES IZTACALA \\ Programa de Maestría y Doctorado en Psicología \\ Residencia en Medicina Conductual}

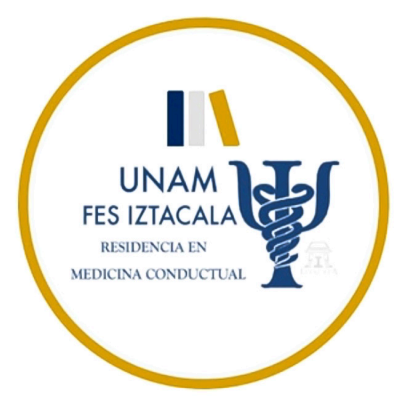

Escala Reporte de Adherencia a la Medicación (MARS)

(Horne \& Hankins, 2002; validado por Lugo \& Vega, 2020)

Sin fines de lucro

Nombre del paciente Fecha -

Instrucciones: Muchas personas encuentran una manera de usar su MEDICAMENTO DE CONTROL que les resulta adecuada y conveniente, y nos interesa saber cómo los usa usted. Por favor lea cada afirmación y responda sinceramente marcando con una $\mathbf{X}$ la casilla que mejor represente la forma en la que usted usa su medicamento.

\begin{tabular}{|c|c|c|c|c|}
\hline Acciones & $\begin{array}{c}\text { Siempre } \\
\text { lo hago } \\
\text { así }\end{array}$ & $\begin{array}{c}\text { Casi } \\
\text { siempre lo } \\
\text { hago así }\end{array}$ & $\begin{array}{c}\text { Pocas } \\
\text { veces lo } \\
\text { hago así }\end{array}$ & $\begin{array}{c}\text { Nunca } \\
\text { lo hago } \\
\text { así }\end{array}$ \\
\hline 1. Uso mi medicamento de CONTROL solo cuando lo necesito. & & & & \\
\hline 2. Uso mi medicamento de CONTROL solo cuando me falta el aire & & & & \\
\hline 3. Decido cuándo no usar mi medicamento de CONTROL. & & & & \\
\hline 4. Trato de no usar mi medicamento de CONTROL. & & & & \\
\hline $\begin{array}{l}\text { 5. Cambio el número de inhalaciones de mi medicamento } \\
\text { de CONTROL. }\end{array}$ & & & & \\
\hline $\begin{array}{l}\text { 6. Dejo de usar mi medicamento de CONTROL por un tiempo } \\
\text { cuando estoy mejor. }\end{array}$ & & & & \\
\hline $\begin{array}{l}\text { 7. Uso mi medicamento de CONTROL menos veces de lo que me } \\
\text { indicó el doctor. }\end{array}$ & & & & \\
\hline
\end{tabular}

Gracias por sus respuestas. 


\section{Reseñas curriculares}

\section{Autores}

\section{Lic. Valeria Olvera Navas}

Licenciada en Psicología con Mención Honorífica por la Facultad de Estudios Superiores Iztacala de la Universidad Nacional Autónoma de México (UNAM). Actualmente cursando la Maestría en Psicología con Residencia en Medicina Conductual. Colaboradora de distintos proyectos del Laboratorio de Análisis de Procesos Psicológicos Superiores. Cuenta con prácticas profesionales en el Hospital de la Mujer en el área de "Embarazo de Alto Riesgo" y en el Hospital General de Valle Ceylán en el departamento de "Violencia". Coordinadora de monitores en el Programa Institucional de Atención al Riesgo Académico en el Colegio de Ciencias y Humanidades. Presidenta del comité organizador de la II Jornada Estudiantil de Investigación y Práctica Conductual. Ha participado como ponente en diversos congresos nacionales e internacionales.

\section{Lic. Marisol Sánchez Beltrán}

Licenciada en psicología por la Facultad de Estudios Superiores Zaragoza, Universidad Nacional Autónoma de México (UNAM); colaboró en un proyecto de investigación en el área de la salud para el Programa de Apoyo a Proyectos de investigación de Innovación Tecnológica. Se ha desarrollado primordialmente en la atención psicológica de pacientes de enfermedades crónicas, con experiencia profesional en cardiología pediátrica en el Centro Médico Nacional, Siglo XXI. Actualmente es alumna del programa de Medicina Conductual por la Facultad de Estudios Superiores Iztacala y residente en el Hospital General de Atizapán de Zaragoza “Dr. Salvador González Herrejón”. 


\section{Lic. Diana Lucero Muñoz Arellano}

Licenciadaen Psicología con Mención Honorífica porla Facultad deEstudiosSuperioreslztacala, Universidad Nacional Autónoma de México (UNAM). Actualmente cursando la Maestría en Psicología con Residencia en Medicina Conductual. Colaboradora en el proyecto Efectividad de dos modalidades intervención para dejar de fumar en la misma institución. Terapeuta en el Centro de apoyo y orientación para estudiantes. Ponente en el II Coloquio: Docencia, Servicio e Investigación en la Psicología Aplicada. Participó en la difusión y sensibilización de la estrategia Atención al consumo de sustancias para la comunidad universitaria. Ponente y capacitadora en diferentes talleres.

\section{Dra. Ana Leticia Becerra Gálvez}

Licenciada en Psicología con Mención Honorífica por la Facultad de Estudios Superiores Iztacala. Maestra en Psicología con Residencia en Medicina Conductual. Doctora en Psicología con Mención Honorífica por la Universidad de las Américas de la Ciudad de México. Docente de la Carrera de Psicología, Facultad de Estudios Superiores Zaragoza, Universidad Nacional Autónoma de México (UNAM). Tutora de la Maestría en Psicología con Residencia en Medicina Conductual, FESI-UNAM. Autora de artículos publicados en revistas nacionales e internacionales. Coordinadora de la obra: Medicina Conductual: Teoría y Práctica (2014) y autora del libro Trastorno de Estrés Postraumático en adultos: Intervención Cognitivo Conductual en Víctimas de Sismos (2019).

\section{Mtro. Leonardo Reynoso Erazo}

Médico Cirujano y Maestro en Modificación de Conducta por la Universidad Nacional Autónoma de México (UNAM); miembro de la Society of Behavioral Medicine, de la American Psychological Association, de la Society for Neuroscience y de la Sociedad Mexicana de Análisis de la Conducta (SMAC); coordinador de la residencia en Medicina Conductual de la FES Iztacala UNAM. Es autor -entre otros- de los siguientes libros: Cuide su corazón, Psicología y Salud, Psicología clínica de la salud: un enfoque conductual, Electrocardiografía, Sistema Cardiovascular, Hipertensión arterial: Manual de intervenciones en actividad física, alimentación y solución de problemas para niños, Medicina Conductual: teoría y práctica, y Trastorno de Estrés postraumático.

\section{Revisores}

\section{Mtro. Isaías Vicente Lugo-González}

Licenciado, Maestro y candidato a Doctor en Psicología, especialista en Medicina Conductual, por Facultad de Estudios Superiores Iztacala de la Universidad Nacional Autónoma de 
México (FESI-UNAM). Profesor de asignatura a nivel Licenciatura y Posgrado en la FESI-UNAM (Residencia en Medicina Conductual, Especialidad de Enfermería Nefrológica y Especialidad de Enfermería y Salud Laboral). Sus líneas de investigación se centran en adherencia a los tratamientos percepción de enfermedad y factores de riesgo conductuales en personas con cáncer, asma, enfermedad renal crónica, sobrepeso y obesidad; en estas áreas ha publicado 15 artículos, cinco capítulos de libro y es coautor de un libro.

\section{Dra. María De Lourdes Rodríguez Campuzano}

Licenciada en Psicología y Maestra de excelencia en Psicología en la Facultad de Estudios Superiores Iztacala, Doctora en Investigación Psicológica en la Universidad Iberoamericana. Profesor Titular C tiempo completo en la FES Iztacala en el Área de Psicología Clínica. Ponente en diversos congresos y eventos tanto nacionales como internacionales. Coordinadora y ponente de talleres y cursos destinados a pacientes con diabetes. Autora de más de 60 artículos en revistas especializadas. Autora del libro Análisis Contingencial, coautora, coordinadora y compiladora de libros especializados, así como de capítulos. Dictaminadora de artículos para revistas especializadas.

\section{Mtra. Cintia Tamara Sánchez}

Licenciada y Maestra en Psicología por la Universidad Nacional Autónoma de México (UNAM), con especialidad en Medicina Conductual. Cuenta con distintas publicaciones en el área de medicina conductual. Ha sido supervisora in situ del Posgrado en Medicina Conductual, con sede en el Hospital Juárez de México. Es Psicóloga adscrita al servicio de Salud Mental del Hospital Juárez de México, en el que colabora en la atención psicológica de pacientes con enfermedades crónico-degenerativas y familiares. Actualmente, colabora en la atención psicológica de pacientes hospitalizados con sospecha o diagnóstico confirmado por COVID-19, en dicho nosocomio.

\section{Mtra. Mariana Alejandra Sierra Murguía}

Licenciada y Maestra en Psicología con Residencia en Medicina Conductual. Especialista en Psico-oncología (Instituto Superior de Estudios Psicológicos de Barcelona). Diplomado en Psicología Bariátrica (Colegio Mexicano de Cirugía de Obesidad y Enfermedades Metabólicas). General BiofeedbackTraining (Behavioral Medicine Training Foundation). Alumna del Doctorado Interinstitucional, Psicología de la Salud. Estancia de investigación (Psico-oncología, Instituto Catalán de Oncología), Barcelona. Fue coordinadora de estudios clínicos (Fundación Clínica Médica Sur), investigadora en Ciencias Médicas y psicóloga clínica (Hospital "Dr. Manuel Gea González"), psico-oncóloga (Cancer Center Tec100, Querétaro), y docente (pregrado, posgrado). Ha participado en publicaciones y congresos nacionales e internacionales. 
Qartuppi, S. de R.L. de C.V. está inscrita de forma definitiva en el Registro Nacional de Instituciones y Empresas Científicas y Tecnológicas (RENIECYT) con el número 1600052.

Qartuppi, S. de R.L. de C.V. es miembro activo de la Cámara Nacional de la Industria Editorial Mexicana (CANIEM) con número de registro 3751 .

Reducción de estrés en pacientes con Enfermedad Renal Crónica

Esta obra se terminó de producir en abril de 2021.

Su edición y diseño estuvieron a cargo de:

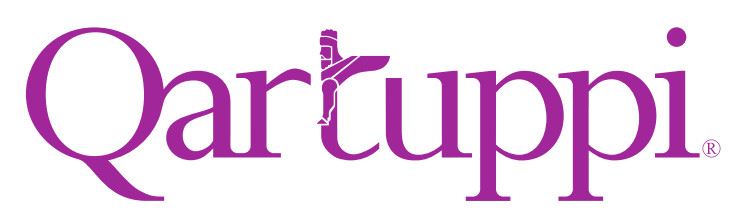

Qartuppi, S. de R.L. de C.V. http://www.qartuppi.com 


\section{(c) (i) () (2)}

Esta obra se edita bajo una Licencia Creative Commons

Atribución-NoComercial-Compartirlgual 4.0 Internacional. 
Vivir con un padecimiento crónico degenerativo como la Enfermedad Renal Crónica (ERC) implica seguir tratamientos e indicaciones, que podrían suponer un reto para los pacientes y llegar a generar situaciones de estrés.

Este libro tiene como objetivo ser una guía flexible de un modelo de intervención psicológica en línea atendiendo condiciones contemporáneas. Se desarrolla una propuesta de trabajo breve, con una metodología cognitivo conductual, proponiendo un enfoque práctico que permite al terapeuta tomar diferentes decisiones y seleccionar técnicas ajustadas a las necesidades de cada paciente, adaptando las estrategias y materiales haciendo uso de las Tecnologías de Información y Comunicación (TIC's).

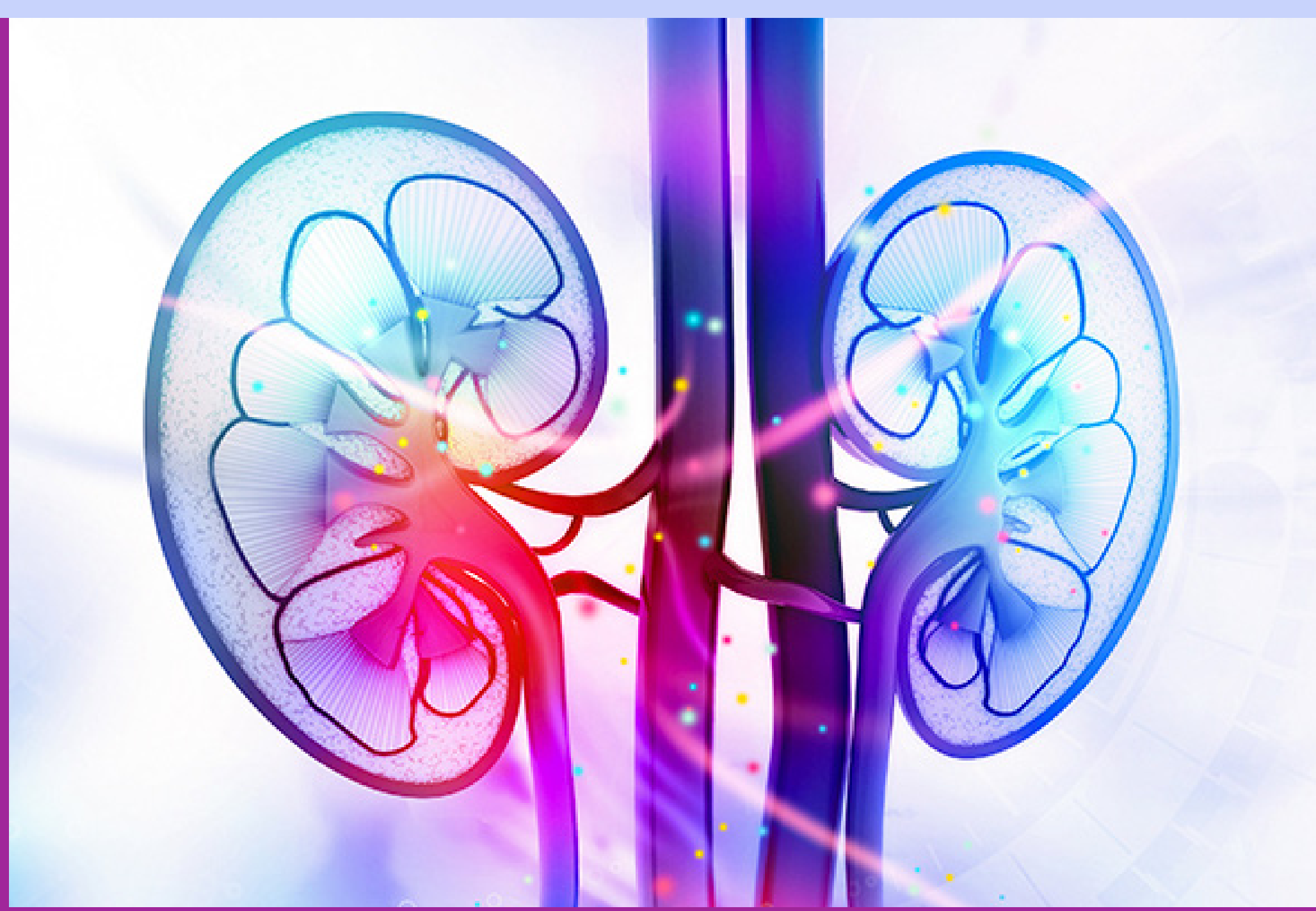

ISBN 978-607-8694-08-2
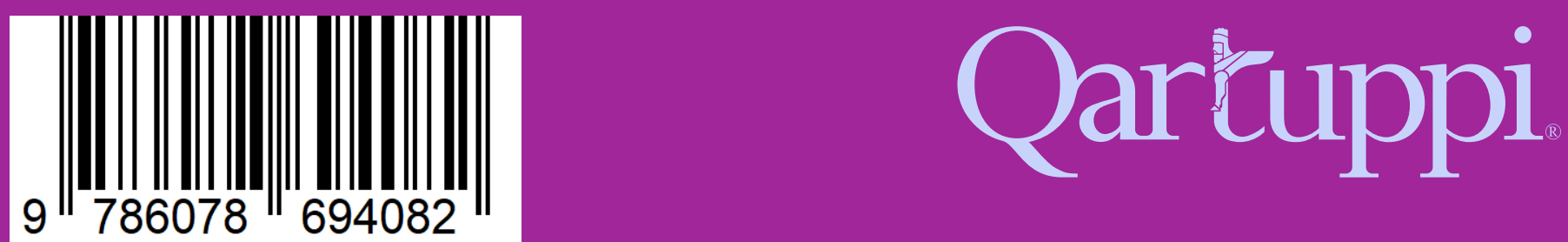